Daniel J. G. Lahr

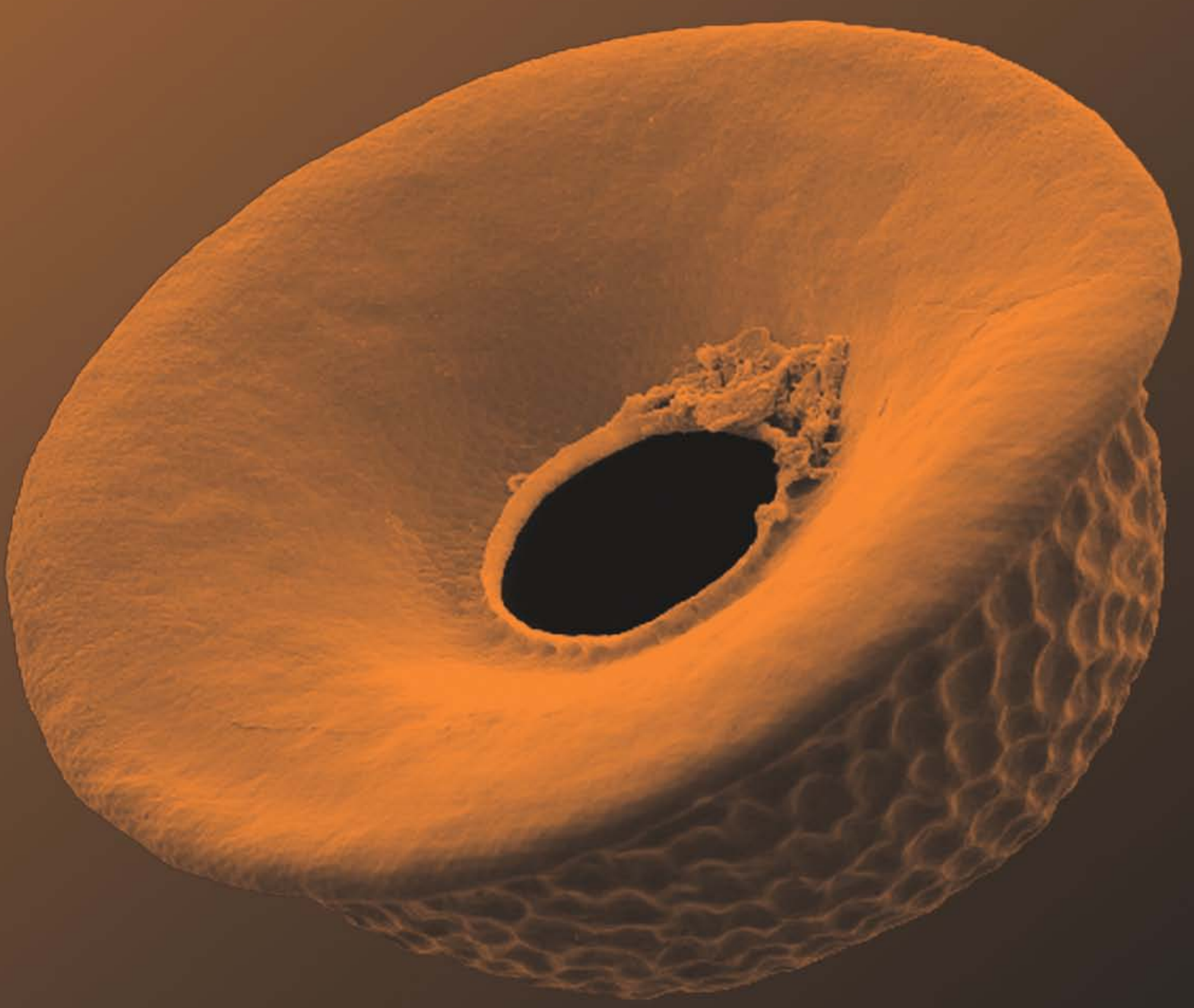

Taxonomia dos Arcellinida Kent, 1880 (Protista:Ramicristates) do Parque Ecológico do Rio Tietê

São Paulo 2006 
Daniel J. G. Lahr

\section{Taxonomia dos Arcellinida Kent, 1880 (Protista:Ramicristates) do Parque Ecológico do Rio Tietê}

Dissertação apresentada ao Instituto de

Biociências da Universidade de São Paulo, para a obtenção de Título de Mestre em Ciências, na Área de Zoologia.

Orientador(a): Profa. Dra. Sônia G. C. B. Lopes

São Paulo

2006 


\section{FICHA CATALOGRÁFICA}

Lahr, Daniel J. G.

Taxonomia dos Arcellinida Kent, 1880 (Protista:Ramicristates) do Parque Ecológico do Rio Tietê 169

Dissertação (Mestrado) - Instituto de Biociências da Universidade de São Paulo. Departamento de Zoologia.

1. Arcellinida 2. Tecameba Taxonomia 3. Tecameba - Rio Tietê 4. Tecameba - Ultraestrutura 5. Tecameba - Ecologia I. Universidade de São Paulo. Instituto de Biociências. Departamento de Zoologia.

Comissão Julgadora:

Prof(a). Dr(a). Prof(a). Dr(a).

Prof(a). Dr.(a). Sônia G. B. C. Lopes Orientadora 


\section{DEDICATÓRIA}

Aos meus avós, Ignez B. Lahr e Antonio P. Lahr (in memorian). 
"DiE KONTINUITÄT DES LEBENS WIRD IN GLEICHER FORM GEWAHRT." $<<$ A CONTINUIDADE DA VIDA É CONSERVADA DE FORMA IDÊNTICA. >>

Ueber die DAUer des Lebens (WeISMANn 1882) 


\section{AGRADECIMENTOS}

Em primeiro lugar, à minha família (Antonio Roberto Lahr, Maria de Lourdes Galafasse Lahr, Marcela Lahr e Ignez B. Lahr) pelo apoio que sempre me deram, foram fundamentais para que este trabalho fosse feito.

À Professora Sônia G. B. C. Lopes, que desde minha iniciação científica abraçou a causa dos Protistas e me ajudou sempre a superar o que viesse pela frente. Sua intocável ética e compromisso são modelos que sempre me inspirarão. Suas lições jamais serão esquecidas.

Ao Professor Osmar Domaneschi, também uma fonte de inspiração pela sua garra e determinação nesta fase difícil, e por sempre continuar a ver a maravilha na Zoologia. 0 pouco que pude absorver de seu conhecimento extremamente profundo e diligência para realizar o trabalho são ensinamentos que levarei comigo para sempre.

À Paulinha, pelo incentivo e ajuda durante a confecção deste trabalho. Seu apoio e carinho foram essenciais.

Aos colegas de Laboratório de Malacologia que acolheram o "estranho no ninho" como igual. Dr. Flávio Dias Passos, Dr. Maurício Leme da Fonseca, Dr. Maurício Moriya, MSc. Maria Júlia Chelini e J osé Eduardo Marian (ainda teremos o Laboratório de Estudos de Organismos que Ninguém Estuda!). Agradeço vocês por todas as discussões e ajudas logísticas.

Aos colegas de casa, Tropeço, Pererê, Maçarico e Gaúcho. Os momentos de diversão ajudaram a nunca estressar no trabalho.

À Prof. Dra. Edna Hardoim, pelo apoio e pela acolhida em seu laboratório em 2004.

Ao Prof. Dr. David J. Patterson (MBL-Massachusetts), que acompanhou e apoiou o projeto desde o início.

Ao Dr. Alan Warren (NHM-Londres) pelo fornecimento das Micrografias Eletrônicas de Difflugia.

Aos técnicos Enio Mattos e Eduardo Mattos, pela ajuda na coleta e imprescindível perícia ao Microscópio Eletrônico de Varredura. 
Ao Prof. Dr. Alberto de Freitas Ribeiro, responsável pelo Laboratório de Microscopia Eletrônica do IBUSP.

Ao PROAP, Programa de Apoio à Pós-Graduação da CAPES, pelo apoio financeiro ao Programa de Pós-Graduação do Departamento de Zoologia do IBUSP.

Ao Chefe do Departamento de Zoologia Prof. Dr. Miguel T. Rodrigues, e ao Coordenador e Vice-Coordenador da Pós-Graduação do DZ-USP Prof. Dr. Pedro Gnaspini e Prof. Dr. Fábio L. da Silveira.

À administração do Parque Ecológico do Rio Tietê, por ter permitido a coleta do material para o trabalho.

À CAPES por conceder a Bolsa de Mestrado. 


\section{ÍNDICE}

$\begin{array}{ll}\text { INTRODUÇÃO } & 1\end{array}$

A Prática Taxonômica em Protistas 1

RELAÇÕES FILOGENÉTICAS ENTRE AS "AMEBAS"

CONSIDERAÇÕES ECOLÓGICAS E BIOGEOGRÁFICAS 8

DistRIBUIÇÃO GEOGRÁFICA DE TECAMEBAS 12

$\begin{array}{ll}\text { OBJETIVOS } & 18\end{array}$

MATERIAIS E MÉTODOS 19

RESULTADOS E DISCUSSÃO

SeCÇÃo 1. Família DifflugiIdAe Wallich, 1864

Difflugia corona Wallich, $1864 \quad 29$

Difflugia gramen Pènard, 1902

Difflugia lanceolata Pènard, 189038

Difflugia claviformis Pènard, 1899

Difflugia gigantea Chardez, 1967

Discussão Secção 1

SecÇão 2. Família CentropyXIDAe Jung, 1942

Centropyxis aculeata (Ehrenberg, 1838) 50

Discussão Secção 2

SeCÇÃo 3. Família LeSQUeREUSIIdAE JUNG, 1942

Netzelia wailesi (Ogden, 1980) 61

Lesquereusia modesta Rhumbler, 1895

Discussão Secção 3 
SecÇÃo 4. Família ArCellidae Ehrenberg, 1843

Arcella hemisphaerica Perty, 1852

Arcella gibbosa Pènard, 1890

Arcella discoides Ehrenberg, 1871

Arcella brasiliensis Cunha, 1913

Discussão Secção 4

DISCUSSÃO 83

$\begin{array}{lr}\text { TABELAS } & 87\end{array}$

$\begin{array}{ll}\text { FIGURAS } & 112\end{array}$

$\begin{array}{ll}\text { RESUMO } & 150\end{array}$

$\begin{array}{ll}\text { ABSTRACT } & 151\end{array}$

REFERÊNCIAS BIBLIOGRÁFICAS 152 
Introdução 


\section{INTRODUÇÃO}

A Prática TAXonômica Em Protistas

A classificação de grandes grupos de eucariotos unicelulares tem sido uma das maiores preocupações da Protistologia Evolutiva nesta última década (SoGIN et al. 1993, Cavalier-Smith 1998, Patterson 1999, Baldauf et al. 2000, Baldauf 2003, Cavalier-Smith et al. 2004, Nikolaev et al. 2005, Richards \& Cavalier-Smith 2005, SMIRNOV et al. 2005), e os protistologistas avançaram em direção a esquemas de classificação mais objetivos e abrangentes. Entretanto, existe pouca discussão em relação à taxonomia e nomenclatura em grupos menos inclusivos, os blocos de construção para edifícios classificatórios - gêneros e espécies (PATTERSON 1999).

A área da Protistologia Evolutiva se desenvolveu fortemente nos últimos 30 anos, principalmente com o advento do Microscópio Eletrônico, que permitiu aos pesquisadores encontrar fortes evidências de uma "identidade ultra-estrutural" para diversos grupos de protistas (PATTERSON, 1999). Este foi um grande salto na prática taxonômica protistológica, pois até então, uma série de inconsistências na maneira como espécies foram descritas impediam que relações fossem inferidas entre os grupos de protistas. Os principais impedimentos são as descrições incompletas e o uso inconsistente das regras estabelecidas pelos códigos de nomenclatura zoológica, como será mostrado neste trabalho.

A prática taxonômica em protistologia é fundamentalmente diferente daquela aplicada a outros grupos de organismos, principalmente porque o estudo e preservação da maioria dos protistas não são tão simples e de costume quanto em 
plantas ou animais. Outro fator importante é a falta de uma prática padronizada para toda a protistologia. $\mathrm{Na}$ literatura tradicional, poucos táxons foram descritos objetivamente, isto é, utilizando afirmações que permitam distinguir claramente 0 que é observação direta e o que é dado interpretado. Poucos descritores costumavam designar tipos, ou mesmo localidades-tipo (PATTERSON \& LARSEN 1992).

Ao longo do tempo, no entanto, alguns aspectos sofreram modificações positivas. A aplicação da microscopia eletrônica na protistologia, datada do inicio dos anos 60, melhorou a descrição e clarificou a identidade de protistas (PATTERSON 1994, 1999; Patterson \& Brugerolle, 1988). Mais especificamente, nos estudos taxonômicos em Arcellinida Kent, 1880, o uso do Microscópio Eletrônico de Varredura (MEV) permitiu análises mais detalhadas de muitos caracteres em tecamebas e definições mais consistentes no nível específico (OGDEN \& ŽlvKović 1983, OGDEN 1983, MEISTERFELD 2000).

Difflugia Leclerc, 1815 foi o gênero que mais se beneficiou desta abordagem (Ogden 1979a, 1980a, 1980b, 1983, 1990; Ogden \& Fairman 1979, Ogden \& Hedley 1980; Ogden \& Meisterfeld 1989; Ogden \& Živković 1983; DekhtYar 1993). Finalmente, a análise estatística da biometria vem sendo usada cada vez mais na caracterização de espécies (SCHÖNBORN et al. 1983; BOBRov et al. 1999, BOBRov \& MAZEI 2004).

Surge então, um problema adicional quando realizamos estudos a partir do Microscópio Eletrônico: a incompatibilidade entre os dados obtidos e os dados previamente publicados a partir de observações em Microscópio Óptico (MO). Esta incompatibilidade nos impede de designar sinônimos de forma objetiva, com isso, a inovação taxonômica pode ajudar a manter a estabilidade dos nomes, desta 
maneira, permitimos inferências para pesquisadores em outras áreas (molecular, ecologia, filogenia).

Apesar de taxonomistas contemporâneos empregarem novas tecnologias na descrição das espécies, registrando novos caracteres, a identidade dos organismos estudados por pesquisadores pioneiros pode facilmente se tornar confusa, uma vez que, em muitos casos, é impossível a referência ou o estudo de material-tipo. Poucos foram os trabalhos que buscam resolver problemas deixados pelas contribuições tradicionais, ou resolver conflitos levantados por novas pesquisas. Além disso, 0 "conceito taxonômico" é uma questão raramente abordada pelos protistologistas. Uma vez que um dos objetivos da nomenclatura taxonômica é a estabilidade (CoRLISS 1972, PATterson \& LARSEN 1992, Ride et al. 1999), esta falha fundamental está fadada a criar confusão.

Um problema adicional deixado pelas contribuições passadas é a descrição de muitos táxons infrasubespecificos. De acordo com o ICZN (RIDE et al. 1999) táxons descritos como forma, variedade, entre outros, em período anterior a 1961 (artigo 45.6.4) estão destinados a ser subespecíficos a não ser que o autor cite expressamente 0 ranking infra-subespecífico, 0 que raramente ocorre. Adicionalmente, o Princípio da Coordenação (Artigo 46) afirma que um táxon estabelecido em qualquer ranking no grupo de espécie está destinado a ser estabelecido, simultaneamente para as outras categorias do grupo. Portanto, as variedades e formas descritas antes de 1961 podem (e devem) ser consideradas como espécies. Desta maneira será necessário analisá-las e estabelecer se são espécies distintas ou estão em sinonímia com a espécie dentro da qual foram descritas. 
Os problemas taxonômicos que surgem da existência de muitas variedades e formas, das práticas tradicionais de protistologia, e da falta de compatibilidade entre pesquisas prévias e contemporâneas são bastante evidenciados em vários grupos de protistas (PATTERSON \& LARSEN 1992), corroborando assim a necessidade de pesquisas que comparem explicitamente os "insights" obtidos por pesquisadores prévios com dados revelados a partir de tecnologia recente. Este estudo deve ser feito sempre levando em conta os regulamentos do Código Internacional de Nomenclatura Zoológica (RIDE et al. 1999) de maneira a estabilizar os conceitos taxonômicos de espécies de protistas, e futuramente, permitir inferências mais precisas para pesquisadores em áreas derivadas. Um dos objetivos deste trabalho é trazer subsídios para essa discussão com o estudo das Tecamebas encontradas no Parque Ecológico do Rio Tietê, em São Paulo.

Trabalho taxonômico consistente com redescrição e elucidação das sinonímias de espécies descritas de maneira incompleta são importantes no entendimento de outros aspectos da biologia destes organismos, como distribuição, dispersão, ecologia (BOBROV \& MAZEI, 2004), e ajudará a resolver questões como o conceito de espécie em organismos assexuados (SCHLEgel \& MeISTERfELD 2003, BOBROV \& MAZEI 2004). 
Em classificações tradicionais (ex:: DeflandRe 1953), as amebas estão compreendidas no Reino Protista, Filo Rhizopoda Schmarda, 1871, que engloba organismos capazes de formar pseudópodes dos tipos lobópode, filópode, actinópode ou reticulópode, sejam estes usados para locomoção ou alimentação. As primeiras classificações agrupavam, por conveniência, todas as amebas com lobópodes (inclusive os amebóides flagelados) na Classe Lobosea Carpenter, 1862 (LeVINE et al. 1980, BOVEe 1985).

Entretanto, devido a evidências ultra-estruturais e do ciclo de vida, os ameboflagelados foram excluídos dos Lobosea, por possuírem crista mitocondrial discóide e dictiossomos típicos (Complexo de Golgi), e colocados na classe Heterolobosea (PAge \& Blanton 1985; PAge 1987). A distinção de ambas as classes foi confirmada por evidências da análise de seqüências da pequena sub-unidade ribossomal - SSU rRNA (CLARK \& CROSS 1988; HINKLE \& SOGIN 1993).

A posição filogenética dos amebóides amitocondriados (pelobiontes) tem sido bastante questionada. MARGULIS (1974) e MARGULIS et al.(1990) consideram estes organismos em um Filo separado, Archaeprotista, ainda CAVALIER-SmitH $(1987,1993)$ e CoRLISS (1994) consideram-nos pertencentes ao Filo Archamoeba. Por outro lado, PAGE (1987) considera-os numa classe dentro de Rhizopoda, enquanto Bovee (1985) como uma ordem dentro de Lobosea. Os entamebídeos amitocondriados, vistos por alguns como o modelo do eucarioto primitivo (BAKKER-GRUNWALD \& WÖSTMANN 1993) 
também foram transferidos para os Archamoeba (CAVALIER-SMITH 1987) e mais tarde para um Filo separado os Entamoebia (CAVALIER-SMITH 1993).

As primeiras filogenias baseadas em SSU rRNA sustentavam uma origem independente para pelobiontes, entamebídeos e as outras amebas mitocondriadas com lobópodes (SOGIN 1991, HINKLE et al. 1994, SIMS et al. 1999) dando suporte para classificações que as separam em diferentes Classes e/ou Filos. As classificações recentes aceitam a polifilia das amebas com lobópodes, apoiando-se em dados ultra-estruturais e seguindo as filogenias baseadas em seqüências de RNA ribossomal, dividindo então as amebas com lobópodes em pelo menos três grupos (HAUSMANN \& HÜLSMANN 1996; LeE et al. 2000).

Uma visão mais recente e oposta sugere que todos os Lobosea, com exceção dos Heterolobosea sejam monofiléticos (CAVAlieR-Smith 1998, Clark \& Roger 1995), e neste caso, os pelobiontes e entamebídeos teriam perdido a mitocôndria secundariamente. Esta visão foi corroborada em análises de RNA ribossomal revisadas (Cavalier-Smith \& Chao 1996; Cavalier-Smith 2000, Bolivar et al. 2001, MILYUTINA et al. 2001) e mais tarde com a adição de seqüências de actina (FAHRNI et al. 2003).

Dentre os Lobosea, existem representantes popularmente chamados tecamebas (francês - "thecamoebiéns"; inglês - "testate amoebae"), termo que, segundo DeflandRe (1953) e Bovee (1985) pode ser aplicado para rizópodes pertencentes a dois grupos distintos: Subclasse Testaceafilosea De Saedeleer, 1934 na Classe Filosea Leidy, 1879, cujos representantes formam pseudópodes do tipo filópode e Subclasse Testacealobosea De Saedeleer, 1934, na Classe Lobosea Carpenter, 1862, caracterizada pela presença de pseudópodes do tipo lobópode. 
Trabalhos contemporâneos, seguindo o Princípio da Prioridade (ex.: Meisterfeld 2000) referem-se à Testacealobosea pelo sinônimo Arcellinida Kent, 1880, pois possuem a mesma composição. No entanto, o ranking dado à Arcellinida é Ordem.

Se pensarmos em termos de uma "identidade ultra-estrutural", a maior parte das amebas, inclusive os Testacelobosea e os Testaceafilosea, estariam no grande grupo Ramicristates, cuja sinapomorfia é a presença de cristas mitocondriais tubulares e ramificadas, de acordo com PATTERSON (1999).

Entretanto, estudos recentes (Nicolaev et al. 2005, SmiRnov et al. 2005) baseados principalmente em genes e seqüências do RNAr da pequena subunidade ribossomal (SSU rRNA) sugerem que a Subclasse Testacealobosea (= Ordem Arcellinida Kent 1880) é monofilética e um dos ramos do grande grupo Tubulina, que compreende a maior parte das amebas com lobópodes. 0 grupo Tubulina é bastante semelhante em composição com Rhizopoda, onde tradicionalmente se encaixavam as amebas com lobópodes, e o uso de um ou outro nome ainda é discutido.

Por outro lado, membros da Subclasse Testaceafilosea agrupam-se, de maneira polifilética, com os Cercozoa (Bolivar et al. 2001, SmiRnov et al. 2005) um grande grupo de eucariontes unicelulares que acomoda tanto os amebóides com filópodes e alguns grupos de flagelados pouco conhecidos. 
Discussão sobre a distribuição geográfica de protistas tem tomado grandes proporções, pois um maior conhecimento tem permitido levantar questões bastante abrangentes. Para Finlay (2002); Finlay \& Clarke (1999); Finlay \& Fenchel (1999); FINLAY et al. (1999, 2001), os protistas têm uma distribuição cosmopolita e mundial, então a diversidade global desses organismos deve ser baixa. Por outro lado, FOISSNER (1999a) afirma que existem protistas com distribuições geográficas restritas - ou até mesmo endemismo - não relacionadas com requerimentos ecológicos específicos, neste caso, a diversidade global deve ser grande.

No entanto, para inferir tais distribuições, nos deparamos com três vieses intrinsecamente conectados: metodológicos, ecológicos e taxonômicos.

0 viés metodológico está relacionado às questões de raridade e subamostragem. Para inferir a raridade de protistas, é comum o uso de raciocínios equivocados como "este organismo é tão distinto morfologicamente que se existisse em outro lugar já teria sido amostrado" (FINLAY 2002). Este tipo de raciocínio pode fazer sentido para grandes espécies de vertebrados, mas levando em conta 0 tamanho e inconspicuidade dos protistas, se torna um raciocínio falho.

FINLAY et al. (2004) utilizam um exemplo bastante interessante para ilustrar esta situação: em um lago com a área de um hectare, onde a faixa produtiva do hipolímnio é de 1,75 m, ou seja, o volume total do lago que um protista pode habitar é de 6300 toneladas de água. Supõe-se que exista uma população de uma dada espécie de ciliado composta por um milhão de indivíduos. Esta cifra pode não 
parecer consistente com a idéia de raridade. No entanto, levando em conta o volume médio de um ciliado, chega-se a conclusão de que cada indivíduo está cercado de 6,3 litros de água, tornando esta uma espécie que provavelmente nunca será amostrada utilizando métodos convencionais de coleta, mesmo em anos seguidos de amostragem.

Logo, espécies "raras" de protistas, ou seja, aquelas que ocorrem em ordens de magnitude onde a amostragem beira o impossível, podem ser encontradas em um único local, e devido a este problema intrínseco da metodologia em protistologia, vai ser considerada erroneamente endêmica.

O viés ecológico está relacionado com a capacidade de dispersão e ocupação de nichos. O lugar comum na microbiologia é a famosa frase atribuída aos bacteriologistas Martinus Willem Beijerinck e Sergey Winogradsky: "tudo (microbial) está em todo lugar" em relação à capacidade e facilidade de dispersão que estes organismos apresentam. A frase não está errada, mas sim incompleta.

A facilidade e natureza aleatória da dispersão de protistas levam a crer que estes organismos teriam a capacidade de chegar a todos os lugares do planeta, no entanto, somente podem se desenvolver e habitar aqueles lugares que oferecem nichos ecológicos que permitam que se desenvolvam. A frase, cunhada novamente por Finlay et al. (2004), fica: "um protista está onde seu habitat requerido ocorre". Portanto, pensar em barreiras geográficas é inadequado na opinião de FINLAY e colaboradores $(2002,2004)$.

WILKINSON (2001) corrobora esta opinião ao realizar uma meta-análise dos inventários de tecamebas considerando dois pontos o mais distantes possíveis no planeta Terra e que apresentam as mesmas características ecológicas: o continente 
Antártico e o Pólo Norte. Após comparar a composição das faunas, a conclusão é que aleatoriamente, todas as espécies menores de $150 \mu \mathrm{m}$ têm a capacidade de se dispersar para todos os lugares do globo.

O que determina a taxa de dispersão dos organismos nesta faixa será, então, apenas relativa à abundância local da espécie, como explicitado por FINLAY et al. (2004) e FINLAY (2002), pois uma vez que o seu diminuto tamanho permite que inúmeros fatores o carreguem para qualquer local do globo em pouco tempo, o que determina sua taxa de dispersão é a quantidade de organismos que existem em um dado local. A analogia feita para melhor compreensão deste fenômeno é com a loteria: quando existe um pequeno número de pessoas concorrendo, a chance de cada um ganhar é alta, porém, a chance de ninguém ganhar é também alta. No entanto, com muitas pessoas concorrendo, a chance individual é baixa, porém, a chance de alguém ganhar é alta.

O controverso argumento da taxonomia é o terceiro e mais delicado viés, pois na identificação e separação das espécies se baseiam todas as afirmações subseqüentes sejam elas biogeográficas ou ecológicas. FoISSNER (1997, 1998, 1999a) discorda da posição de que protistas possuem distribuições geográficas cosmopolitas pois há problemas de sub-amostragem e não há taxonomistas em número suficiente para se conhecer e descrever espécies, ou seja, ainda não conhecemos protistas o suficiente para estimar a diversidade global. Além disso as revisões taxonômicas são raras, e corre-se o risco de atribuir uma distribuição geográfica restrita a espécies cuja distribuição deveria ser mais ampla considerando as sinonímias e vice-versa. 
Certamente, o exemplo exponencial nesta discussão foi o Arcellinida Nebela vas Certes, 1889, assunto principal e polêmico em pelo menos dois congressos (4th European Congress of Protistology e 10th European Conference on Ciliate Biology) e uma série de artigos em diversas revistas (FoISSNER 1997, 1998, 1999a; FINLAY 2002; Finlay \& Clarke 1999; Finlay \& Fenchel 1999; Finlay et al. 1999, 2001; MitCHELL \& MEISTERFELD 2005).

N. vas é uma tecameba grande (cerca de $200 \mu \mathrm{m}$ ) e abundante registrada somente para o Hemisfério Sul, onde o esforço amostral para o conhecimento de potistas é muito pequeno. Não foi registrada para o Hemisfério Norte, onde o esforço amostral é maior. FINLAY et al. (2004) acreditam que a espécie exista na Europa, sob outro epíteto específico. Mitchell \& MeISTerfeld (2005) acreditam que realmente não foi reportada na Europa e que os sinônimos oferecidos por FINLAY et al. (2004) não são válidos. Nota-se neste ponto, a importância da taxonomia realizada de maneira objetiva e testável. 
A ocorrência de tecamebas nas águas continentais e oceânicas do mundo é relativamente pouco conhecida, no entanto, vários levantamentos destes organismos realizados em diferentes partes do globo (OGDEN \& HedLeY, 1980), enfatizando, até o momento espécies ocorrentes na Europa e África.

Existem poucos estudos sobre as tecamebas na América do Sul e a maioria destes estudos foi conduzida somente a partir de observações ao Microscópio Óptico (ex.: Boltovskoy 1956; Boltovskoy e LenA 1966, 1971; DeCloitre 1955; DionI 1967,1970; VUCETICH 1970, 1972, 1973, 1978).

DECLOITRE (1955) realizou levantamento de tecamebas que ocorrem na Venezuela, fornecendo listagem de espécies, com as respectivas caracterizações e distribuições geográficas, sendo uma referência importante nos trabalhos de identificação. Além disso, contém descrições de duas espécies novas.

DIONI (1967) apresentou listagem de espécies de tecamebas encontradas em Laguna Redonda, ao sul do Lago Don Felipe (Argentina). Já em seu trabalho de 1970, o autor ampliou seus estudos para as demais regiões do Lago Don Felipe e apresentou listagem das espécies encontradas, com as respectivas caracterizações, além das descrições de quatro espécies novas.

Boltovskoy \& LenA (1966) forneceram listas e desenhos das 17 espécies de tecamebas encontradas em Ushuaia (Argentina) e, em 1971, publicaram lista e desenhos das 14 espécies de tecamebas coletadas em Buenos Aires (Argentina). 
Os trabalhos de VUCETICH $(1970,1972,1973,1978)$ com tecamebas da Argentina são bastante completos, apresentando detalhadas listas de espécies com sinonímias e respectivas caracterizações, além da descrição de cinco espécies novas.

No Brasil, os primeiros estudos que citam tecamebas são do início do século passado, quando Prowazec (1910), CUnHA (1913) e Pinto (1925) publicaram artigos com listas de espécies de protozoários. Apesar de ótimas referências para conhecermos a ocorrência dos organismos, eles não entram profundamente no estudo taxonômico dos organismos, pois os objetivos desses trabalhos estavam voltados para a área médica, que era o interesse na época.

Depois destes trabalhos pioneiros, somente em 1962, CLosS \& MADEIRA publicaram um levantamento de tecamebas e foraminíferos do Arroio Chuí, em Santa Vitória do Palmar, (RS), no extremo sul do país, de clima sub-tropical. A região costeira do arroio é constituída de águas mixohalinas, onde somente algumas espécies de tecamebas sobrevivem, uma vez que, em geral, são organismos adaptados ao ambiente de água doce (OGDEN \& HEDLEY, 1980).

Closs \& MADEIRA (1962) ressaltaram a necessidade de estudos sobre tecamebas como indicadores de ambientes paleo-ecológicos dos sedimentos e comentaram a dificuldade de identificação e diferenciação das tecamebas aglutinantes de alguns foraminíferos. Neste levantamento foram registradas apenas 11 espécies de tecamebas com carapaça aglutinada coletadas no sedimento.

Posteriormente, em 1967, Closs \& MADEIRA fizeram levantamento de foraminíferos e tecamebas aglutinantes, desta vez na Lagoa do Tramandaí (RS). Esta é uma lagoa costeira, cuja maior dimensão é de aproximadamente $6 \mathrm{~km}$, e a área 
total é de $30 \mathrm{~km}^{2}$, que tem uma ligação com o mar. Isto faz com que boa parte da lagoa seja de águas mixohalinas, o que favorece a existência de foraminíferos e dificulta a ocorrência de tecamebas. Mais uma vez, foram feitas somente amostras de fundo, e encontradas praticamente as mesmas 11 espécies de tecamebas registradas no trabalho desses autores, publicado em 1962.

GREEN (1975) realizou levantamento e estudos de associações ecológicas de tecamebas em cinco lagos no vale do Rio Suia Missu, (MT). Os organismos foram coletados apenas utilizando rede de fitoplâncton de malha $180 \mu \mathrm{m}$, tendo sido registradas 43 espécies, uma delas nova, pertencente ao grupo das Testacealobosea, e outra nova ocorrência de Testaceafilosea para o Brasil.

Após um período sem nenhum registro de estudos específicos para tecamebas, TORRES \& J EBRAM publicaram em 1994 um levantamento das tecamebas ocorrentes na região de Porto Alegre (RS). Além dos ambientes já amostrados nos trabalhos citados anteriormente, como sedimento, água e raízes de plantas flutuantes, estes autores coletaram tecamebas em ambientes muscícolas, amostrando briófitas juntamente com $0,5 \mathrm{~cm}$ do sedimento e também tecamebas associadas a rochas e troncos situados junto e/ ou abaixo do nível de água, por meio de raspagem do substrato.

Embora a diversidade de ambientes tenha sido grande, esses autores registraram apenas sete espécies de tecamebas, pertencentes a dois gêneros, Arcella Ehrenberg, 1830 e Difflugia Leclerc, 1815, número este muito mais baixo quando comparado aos registrados em trabalhos onde apenas um tipo de ambiente foi amostrado. Esse baixo número talvez possa estar relacionado à metodologia que TORRES \& JEBRAM (1994) utilizaram. Estes autores separaram espécimes ainda vivos 
de tecamebas em diferentes meios de cultura e somente após sucessivas divisões dos organismos, é que eles foram identificados. Dessa maneira, nem todos os indivíduos das espécies coletadas podem ter sobrevivido nos meios de cultura.

Esta metodologia contrasta com a de outros autores, como DeCLOITRE (1955), Vucetich (1972, 1973, 1978), Green (1975), Hardolm \& Heckman (1996) e Velho et al. (1996), que simplesmente triam o material fixado a procura de tecamebas e Closs \& Madeira $(1962,1967)$, Closs \& Medeiros (1967) e Boltovskoy \& Lena (1966, 1971) que fixam a amostra em formalina neutralizada com bórax e depois coram o material com solução de Rosa de Bengala para diferenciar tecas vazias das que ainda abrigam protoplasma e, após secagem, separam as tecamebas com Tetracloreto de Carbono. .

DABÉS (1995) realizou estudo para descrever a composição de cinco lagoas marginais de inundação do Rio São Francisco. Seu trabalho é muito semelhante ao de GreEn (1975), coletando amostras com rede de plâncton, mas neste caso com malha de $35 \mu \mathrm{m}$. Ele identificou 32 espécies de tecamebas, das quais 22 coincidem com as citadas por Green (1975) para um ambiente bem distinto.

Os últimos trabalhos de levantamento de tecamebas no Brasil foram feitos por VelHo et al. (1996), VelHo \& LANSAC-TÔHA (1996) e HARdoIm \& HeCKMAN (1996) e DuLEBA \& DeBeney (2003).

VELHO et al. (1996), realizaram levantamento de zooplâncton em planícies de inundação do Rio Paraná (PR) em busca de tecamebas pertencentes apenas às famílias Arcellidae Ehrenberg, 1830 e Centropyxidae Deflandre. VELHO \& LANSAC-TÔHA (1996) listaram as espécies da família Difflugidae Awerintzew, 1906. Estes autores ressaltaram a necessidade de mais estudos sobre as tecamebas que ocorrem no 
Brasil, pois elas são ainda pouco conhecidas e o aumento no conhecimento destes organismos proporcionará uma base para que eles sejam incluídos mais vezes em estudos ecológicos.

HARDoIm \& HECKMAN (1996) publicaram artigo tratando dos Sarcodina Hertuig \& Lesser, 1875 de vida livre e dos ciliados da região do Pantanal. Neste caso, foram utilizadas técnicas mais abrangentes de coleta, visando encontrar os organismos em seus diferentes habitats e caracterizando esta relação. Estes autores fizeram coletas de sedimento, de plâncton, e ainda de tecamebas e ciliados associados à vegetação flutuante, alcançando quase todos os tipos de habitats destes organismos. Eles encontraram 36 espécies de tecamebas, um número mais baixo do que seria esperado, mas que é explicado, no artigo, pelas características de sazonalidade do clima seco-úmido que ocorre nas planícies de inundação do Pantanal, permitindo, grosso modo, que somente espécies muito resistentes sobrevivam.

Duleba \& Debenay (2003) utilizaram as tecamebas, juntamente com foraminíferos como indicadores de poluição na Estação Ecológica de Juréia-Itatins, e ressaltaram as dificuldades e a necessidade de uma melhor compreensão das complexas relações entre o microorganismos e os parâmetros abióticos.

No caso dos trabalhos de Green (1975), Dabés (1995) e Hardolm \& HeCKMAN (1996) que são estudos ecológicos, estes autores consideram como tecamebas tanto os representantes da subclasse Testacealobosea como os da Testaceafilosea, pois esses organismos são altamente convergentes e ocupam praticamente os mesmos nichos ecológicos.

BoltovsKoy \& LeNA $(1966,1971)$, DiONI $(1967,1970)$ e VUCETICH $(1972,1973$, 1978), também consideram as duas subclasses ao fazer um levantamento destes 
organismos, enquanto que Closs \& MADeIRA $(1962,1967)$, Closs \& Medeiros (1967) e Duleba \& Debenay (2003) consideraram apenas as tecamebas aglutinantes, pois estas eram coletadas juntamente com os foraminíferos bentônicos. TORRES \& J EBRAM, 1994, devido à metodologia utilizada, estudaram apenas dois gêneros de Testacealobosea. VeLHO et al. (1996) e VELHO \& LANSAC-TÔHA (1996), são os primeiros a considerar apenas os Testacealobosea.

Logo, pode-se perceber que os trabalhos realizados com tecamebas na América do Sul e Brasil, foram feitos com objetivos distintos e os aspectos abordados nas publicações diferem e dificultam a comparação. Torna-se necessário então, a padronização de um método e novos estudos taxonômicos e ecológicos destes organismos, pois segundo FoISSNER (1999b), omitir as tecamebas dos estudos ecológicos recentes é um infeliz erro, pois esses organismos têm grande potencial como bioindicadores devido à alta biomassa, abundância considerável, grande diversidade, distinta distribuição e facilidade de contagem e identificação quando comparados com outros protistas. 
OBJETIVOS

0 presente trabalho tem por objetivos descrever espécies de Arcellinida encontradas no Rio Tietê, São Paulo e trazer sugestões no sentido de contribuir para uma prática taxonômica mais objetiva, padronizada e consistente não somente no âmbito dos Arcellinida, mas em qualquer outro grupo de protistas. Pretende-se trazer subsídios que permitam inferências mais explícitas, ou pelo menos suposições bem fundadas para pesquisadores em áreas que dependem da taxonomia. 
Materiais e Métodos 


\section{MATERIAIS E MÉTODOS}

Foram feitas duas coletas no Parque Ecológico do Rio Tietê, localizado na Rodovia Ayrton Senna, São Paulo-SP, km 17 (Fig.1).

Dois tipos de ambientes de interesse foram amostrados: o Rio Tietê e uma Lagoa marginal. Em cada um dos ambientes foram feitas coletas de tecamebas associadas a dois micro-habitats distintos: as raízes de plantas aquáticas e 0 sedimento. As coletas referentes à Lagoa marginal, tanto de fundo quanto de raízes de plantas aquáticas foram feitas na localidade 2329'055"S e 4630'939"W, e

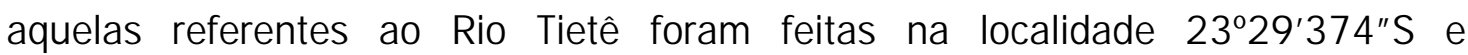
$46031^{\prime} 500$ "W. Portanto, foram amostradas tecamebas associadas:

- às raízes de plantas aquáticas do Rio Tietê,

- às raízes de plantas aquáticas da Lagoa marginal,

- ao sedimento do Rio Tietê,

- ao sedimento da Lagoa marginal

As duas coletas foram feitas em estações climáticas distintas, sendo a primeira na estação chuvosa e quente (fevereiro 2004) e a segunda na estação seca e fria (agosto 2004) para evitar que espécies que encistam fossem sub-amostradas, ou até mesmo não coletadas.

Para amostrar os ambientes de interesse habitados por tecamebas, foram empregados dois métodos de coleta:

- Para a coleta de tecamebas associadas a raízes de plantas flutuantes, adaptou-se o método descrito por Dıonı (1967, 1970), onde uma bandeja de $500 \mathrm{~cm}^{2}$ de superfície é colocada embaixo das plantas flutuantes e 
levantada, sendo o material coletado acondicionado em recipientes plásticos fechados com volume padronizado em $2 \mathrm{~L}$ e transportado para o laboratório, onde foi fixado em formol $5 \%$ neutralizado.

- Para a coleta de sedimento, usamos uma caneca plástica com $10 \mathrm{~cm}$ de altura e 7,5 cm de diâmetro acoplada a um longo bastão de madeira, sendo o material coletado acondicionado em recipientes plásticos de $2 \mathrm{~L}$, fechados e levados para o laboratório, onde foi fixado em formol $5 \%$, neutralizado.

Os materiais coletados e fixados foram filtrados em uma série de tamises (Fig. 2), com o objetivo de obter somente o componente da amostra cuja granulação correspondesse ao tamanho das tecamebas. 0 primeiro tamis, com malha de $1 \mathrm{~mm}$, foi utilizado para retirar componentes mais grosseiros, como folhas e gravetos; 0 segundo, com malha de $500 \mu \mathrm{m}$ e 0 terceiro de $38 \mu \mathrm{m}$, foram usados para selecionar o material a ser analisado que correspondeu ao sedimento retido entre estes dois últimos tamises. 0 volume final da amostra foi $200 \mathrm{ml}$ para cada um dos 2 litros iniciais. Ao final deste procedimento, obteve-se, portanto quatro frascos de $200 \mathrm{ml}$ para cada coleta, totalizando 8 amostras peneiradas para análise.

Este material foi então conservado em álcool $70 \%$ e corado com Rosa de Bengala para confirmação de que a teca abrigava citoplasma no momento da fixação. Desta maneira, temos o dado de quais espécies de organismos vivem em cada habitat, evitando, por exemplo, computar em uma amostra de sedimento uma tecameba que vive associada a raízes ou na coluna d'água que tenha morrido e a teca depositada sobre o fundo. Tecas vazias, no entanto, foram igualmente identificadas, medidas e registradas. 
Apesar da peneiração, a quantidade de material resultante foi muito grande e as amostras não foram triadas na íntegra, tendo sido estabelecidas alíquotas. Cada alíquota consistiu de cerca de $2 \mathrm{ml}$ do componente tâmisado retirado com uma pipeta Pasteur após homogeneização da amostrae colocado em uma placa de Petri para triagem sob microscópio estereoscópico.

Para estabelecer a quantidade de alíquotas a serem analisadas em cada amostra, foi realizado um estudo de estimativa de biodiversidade para atingir um ponto ótimo entre esforço amostral e riqueza registrada. Isto foi feito por meio de um estudo piloto com material aleatoriamente retirado de amostras da Coleta 1. Foram extraídas 18 alíquotas de $2 \mathrm{ml}$ integralmente triadas e as espécies identificadas. Utilizando o software EstimateS (COLWELL 2004) um gráfico do tipo "curva do coletor" (Fig. 3) foi obtido plotando vários estimadores estatísticos de riqueza.

Este gráfico evidencia que a curva de espécies atinge uma assíntota em torno de 4 à 7 alíquotas, ou seja, qualquer esforço amostral superior a 7 alíquotas trará pouco incremento no número de espécies obtido. Levando em conta que cada alíquota neste estudo teve, em média, cerca de 200 indivíduos misturados ao sedimento, o tempo dispendido para analisar cada alíquota foi um fator limitante. Ficou estabelecido que a análise de quatro alíquotas por amostra seria suficiente para registrar uma porcentagem significativa da biodiversidade. Os dados dessa triagem experimental serviram apenas para padronização de uma metodologia de triagem e não foram incluídos no presente trabalho.

Sumarizando, foram analisadas quatro alíquotas de $2 \mathrm{ml}$ retiradas do conteúdo peneirado de $200 \mathrm{ml}$ provindos de cada um dos 8 recipientes originais de 
2 litros, num total de 32 alíquotas analisadas. Isto corresponde a $800 \mathrm{ml}$ do total de 16 litros coletados em campo, o que corresponde a apenas $5 \%$ da coleta inicial.

Conforme recomenda FinLAY et. al (2001), todo esse trabalho foi realizado por apenas uma pessoa (o autor deste trabalho) para que o erro seja padronizado.

Cada indivíduo encontrado foi identificado, observado quanto a condição de seu citoplasma (presente ou ausente) e, usando gratícula, foi medido segundo os parâmetros morfométricos estabelecidos (comprimento da teca, largura da teca, altura da teca, diâmetro da abertura, número e comprimento de espinhos).

Desde que possível, um mínimo de 50 indivíduos por espécie foram armazenados para posterior descrição detalhada. A escolha dos indivíduos foi feita buscando obter uma maior representatividade possível de formas e tamanhos para cada espécie.

Para retirar os indíviduos das sub-amostras e armazená-los em Eppendorfs, foi necessário desenvolver um aparato (Fig. 4) utilizando um micromanipulador comum e adaptando em sua extremidade uma pipeta Pasteur. Esta foi conectada por meio de cânulas à uma seringa, o que permitiu a remoção das tecamebas sem causar grande distúrbio na alíquota e evitou a mistura entre o sedimento já triado com 0 não triado presentes na placa de Petri. Além disso, esse procedimento minimizou a quantidade de álcool aspirado pela pipeta juntamente com as tecamebas, evitando assim excesso desse líquido quando transportado para o Eppendorf, e que a reposição de álcool na placa de Petri causasse turbulência na sub-amostra, misturando o sedimento. 
Após a triagem, os organismos separados tiveram destinos distintos. Alguns foram reservados para observação em microscopia óptica e outros para Microscopia Eletrônica de Varredura (MEV).

Para a observação em microscopia óptica, foram feitas lâminas semipermanentes usando glicerina que permite, por suas características viscosas, que 0 material seja colocado em posição propicia para o exame de detalhes imprescindíveis de sua estrutura (DıONI, 1970). Cada uma das espécies, desta maneira, pode ser observada em maior detalhe, permitindo assim que sejam feitos desenhos, fotos, medidas e a própria descrição dos espécimes observados.

As preparações para observação em Microscópio Eletrônico de Varredura seguem Ogden \& Hedley 1980 e Yang e colaboradores (YANG et al. 2004, YANG \& SHen 2005), com algumas modificações.

Tecas de indivíduos das espécies a serem analisadas foram limpas por meio de sucessivas passagens em água destilada, através de um pequeno recipiente com uma malha de $20 \mu \mathrm{m}$ para reter os espécimes. Após esse procedimento, as tecas de representantes dos gêneros Difflugia, Lesquereusia, Netzelia e Centropyxis, que possuem dimensões relativamente maiores e maior robustez na teca devido à natureza aglutinada, foram colocadas em lâminas sem lamínula para secar a temperatura ambiente. Após a secagem, foram transferidas usando a eletricidade estática de um fio de cabelo para o stub previamente coberto com substância adesiva, obtida a partir da diluição de fita adesiva comercial em clorofórmio.

Esta técnica permitiu posicionar as tecas na posição desejada. Tecas dos indivíduos pertencentes ao gênero Arcella, que são relativamente pequenas e mais frágeis, sofreram desidratação em série de álcool e foram secas diretamente no 
stub. Após a preparação, os stubs foram cobertos por uma fina camada de ouro, e observados sob Microscópio Eletrônico de Varredura da marca Zeiss, modelo DSM940 operando de 10 a 25 kV no Laboratório de Microscopia Eletrônica - IBUSP.

A terminologia utilizada em trabalhos que envolvem tecamebas é pouco estabelecida, sendo que diferentes denominações são usadas por diferentes ou até mesmo pelo mesmo autor (Folssner \& Korganova, 2000). Portanto, no presente estudo as descrições seguem o seguinte padrão:

- Forma da teca: compreende a forma geral da teca, e se o contorno é bem definido ou irregular.

- Composição da teca: compreende a forma, natureza e distribuição das partículas que compõe a teca; organização da matriz orgânica cimentante; cor da teca; textura da superfície da teca.

- Complexo apertural: compreende o conjunto de estruturas que delimitam e circundam a abertura, cujo diâmetro foi medido.

- Polaridade: os termos região apertural e abapertural foram propostos em substituição aos inapropriados termos oral e aboral.

Para cada espécie foram feitas medidas de estruturas e eixos diferentes, apropriados para cada caso, estas informações estão esquematizados nas secções pertinentes (Figs. 5, 19, 25, 35, 43, 54, 76, 86, 99, 108, 119, 130, 149).

As análises estatísticas foram realizadas utilizando os programas Systat 10 (SPSS INC., 2000) e Statistica 6.0 (STATSOFT INC. 1995).

Na descrição de cada espécie, seguindo o nome, foi compilada uma lista de sinônimos, quando existentes, e logo em seguida, uma lista de Dados Previamente Reportados, na tentativa de melhor delimitar o conceito taxonômico de cada espécie. 
Esta iniciativa segue o conceito de Cresônímia, introduzido por LERENARD (2003), que busca o "uso" do nome. Desta maneira, como poucos autores em protistologia compilaram listas sinonímicas, pode-se delimitar ao menos como o nome específico tem sido usado.

Na lista de Cresônimos, entre parênteses está discriminada com uma abreviatura o tipo de informação que o trabalho traz: desc - descrição, dim dimensões, eco - ecologia, geo - distribuição geográfica, syn - lista sinonímica, SEM - imagens ao Microscópio Eletrônico de Varredura. 
Resultados e Discussão 


\section{RESULTADOS E DISCUSSÃO}

Foram registradas espécies pertencentes a quatro famílias e cinco gêneros:

Família Difflugiidae Wallich, 1864

Gênero Difflugia Leclerc, 1815

Difflugia corona Wallich, 1864;

Difflugia gramen Pènard, 1902;

Difflugia lanceolata Pènard, 1890;

Difflugia claviformis Pènard, 1899;

Difflugia gigantea Chardez, 1967

Família Centropyxidae Jung, 1942

Gênero Centropyxis Stein, 1857

Centropyxis aculeata (Ehrenberg, 1838)

Família Lesquereusiidae Jung, 1942

Gênero Netzelia Ogden, 1979

Netzelia wailesi (Ogden, 1980)

Gênero Lesquereusia Schlumberger, 1845

Lesquereusia modesta Rhumbler, 1895; 
Família Arcellidae Ehrenberg, 1843

Gênero Arcella Ehrenberg, 1832

Arcella hemisphaerica Perty, 1852;

Arcella gibbosa Pènard, 1890;

Arcella discoides Ehrenberg, 1871;

Arcella brasiliensis Cunha, 1913

Cada Família será apresentada em uma Secção distinta, onde as espécies serão descritas e discutidas. Optou-se por esta forma de apresentação devido a uma necessidade de detalhar melhor as diagnoses e discutir as características de identificação de cada espécie comparativamente às suas semelhantes. Ao final da Secção de cada família, existe uma discussão das questões levantadas e pertinentes somente àqueles organismos. Após a apresentação e a discussão por famílias, será feita uma discussão geral com o objetivo de levantar e comparar os aspectos pertinentes a todas as famílias e que podem ser compreendidos de forma mais abrangente dentro da Protistologia. 


\section{Secção 1.}

\section{Família Difflugiidae Leclerc,1815}


A família Difflugiidae Wallich, 1864, formada por organismos com a teca composta apenas de grãos minerais e diatomáceas aglutinados por uma matriz orgânica cimentante, com a abertura terminal, consta de 11 gêneros (MEISTERfELD 2000) dos quais apenas Difflugia Leclerc, 1815 foi registrado na presente pesquisa.

Apesar de Difflugia ser um gênero bem definido de tecamebas, há considerável incerteza na delimitação das espécies. Existem descrições de cerca de 300 espécies e 200 táxons sub e infrasubespecificos (OGDEN 1983, MeISTERfELD 2000). Tais descrições foram, em sua maioria, feitas a partir de observações ao microscópio óptico, o que dificulta comparações detalhadas quanto à estrutura, a forma e a composição da teca (OGDEN \& ŽIVKović 1983).

Além disso, apenas em poucos casos os tipos foram designados. Por exemplo, GAUTHIER-LIÈVRE \& THOMAS (1958), na mais completa revisão do gênero realizado em solo africano (OGDEN 1983) descreveram 129 táxons, dos quais 45 novos para a ciência, mas os tipos não foram designados.

No presente trabalho foram encontradas cinco espécies do gênero Difflugia ocorrentes nas águas poluídas do Parque Ecológico do Rio Tietê. Estas observações estendem a circunscrição das espécies, e trazem nova luz nos âmbitos da morfologia, biometria, ecologia e distribuição de Difflugia. 
Gênero Difflugia Leclerc, 1815

Difflugia corona Wallich, 1864 
Difflugia corona Wallich, 1864

Pranchas Ila, Ilb; Figs. 5 a 18

Sinônimos

Difflugia proteiformis Ehrenberg subespécie globularis Dujardin variedade corona. Wallich, 1864

Difflugia corona ecornis Gauthier-Lièvre et Thomas, 1958 (publicado como Difflugia corona var. ecornis) syn. nov.

Dados Previamente Reportados (Cresônimos)

Difflugia proteiformis Ehrenberg globularis Dujardin var. corona. Wallich, 1864:240-241 pl. 15, figs. 4b, c (desc)

Difflugia corona - Daday, 1905:13-14 (desc, dim, geo); Deflandre, 1926:523525 (desc, dim, geo, syn); Štepánek, 1952:16-17 (desc, dim); Boltovskoy, 1956:307-308 fig. 5 (desc, geo, syn); Gauthier-Lièvre et Thomas, 1958:254-256, fig. 2a (desc, dim, eco, geo); Closs et Madeira, 1962:8-9 (desc, dim, geo, syn); Closs et Madeira, 1967:14 (desc, dim, geo); Vucetich, 1972:277-278 (desc, dim, eco, geo, syn); Vucetich, 1973:301 (desc, dim, eco, geo, syn); Ogden et Hedley, 1980:128-129, figs. A-D (desc, dim, geo, SEM); Ogden et Živkovic, 1983:346348, fig. 4a-d (desc, dim, eco, geo, SEM); Medioli et Scott, 1985:27 fig. 2a, b (desc, syn); Dekhtyar, 1993:11-13, figs 4a-f (não Protocucurbitella coroniformis Gauthier-Lièvre et Thomas, 1960; desc, dim, eco, geo, syn, SEM); Torres et Jebram, 1994:72 (desc, dim, eco); Velho et Lansac-Tôha, 1996:179-181 figs. 1, 1a (desc, dim, geo); Blanco, 2001 (desc, dim); Zapata et al., 2002:24 (desc, dim, geo); Bobrov et Mazei, 2004:136 (dim) 
Difflugia corona ecornis - Gauthier-Lièvre et Thomas, 1958:256-258, fig. 3 (publicado como Difflugia corona var. ecornis)

Material examinado: 683 espécimes sob M0, 26 sob MEV; 42 micrografias feitas por Colin G. Ogden depositadas no Natural History Museum, Londres (NHM)

\section{Morfologia}

Teca sub-esférica a esférica (Fig. 5a, 6 ), circular em vista apertural (Fig. 5b, 6 e 7). Espinhos cônicos (Fig. 8) e ocos inseridos em número variável na linha média até a região abapertural (Figs. 6 e 7). Superfície da teca lisa (Fig. 9), partículas agregadas achatadas raramente interrompendo 0 aspecto circular do contorno. Toda a teca composta de pequenos grãos de areia, partículas de quartzo arredondadas e estruturas cilíndricas de natureza exógena, ambas sempre achatadas (Figs. 9, 10) todas aglutinadas por uma matriz orgânica cimentante lisa (Fig. 10). Região interna da teca coberta por matriz orgânica. Paredes da teca homogêneas em espessura (Fig. 11), exceto pela abertura mais espessa.

Abertura terminal, circular, com 9 a 15 lobos denticulados (Fig. 12). Complexo apertural delimitado por um contorno particulado da teca e um colar de cimento orgânico. As partículas delimitam uma borda circular e uma matriz orgânica cobre 0 bordo livre formando lobos (Fig. 13). Cobertura apertural espessa, cada lobo uma estrutura oca na parte mais exterior. Cada lobo se estende a curta distância para o interior da teca como uma sólida coluna, observadas em MO como estruturas cilíndricas perpendiculares ao contorno da abertura; ao MEV, é possível notar que cada lobo apresenta, no bordo de cada coluna, uma ou duas fileiras de protuberâncias aculeiformes (Fig. 14) que variam em número, forma e comprimento 
(de 3 a $4 \mu \mathrm{m}$ ). As protuberâncias podem ser distribuídas aleatoriamente, não necessariamente em fileiras.

\section{Biometria}

A caracterização biométrica dos espécimes de Difflugia corona encontrados no presente trabalho está sumarizada na Tabela I. As medidas analisadas mostraram-se altamente variáveis $(\mathrm{CV}=25,2$ - 67,0), sendo que 0 menor erro padrão (0.11) foi verificado para o número de espinhos cônicos.

A análise da distribuição de freqüências de medida indica que D. corona apresenta uma classe principal de tamanho e uma grande amplitude de medidas para todos os caracteres. As menores tecas têm um terço do tamanho das maiores. A altura da teca varia de 80 a $330 \mu$ m, mas $58 \%$ estão dentro dos limites de 160 a $240 \mu \mathrm{m}$. A análise de frequêencia do diâmetro da teca apresenta resultados semelhantes. Quanto ao diâmetro da abertura, a principal classe de tamanho é ainda menor, onde $67 \%$ das medidas estão entre 70-120 $\mu \mathrm{m}$. 0 tamanho dos espinhos cônicos variou de 20 a 40 um em $70 \%$ das tecas analisadas. 0 número de espinhos variou de 0 a 10, mas em $86,4 \%$ dos casos, está restrito a 3-5.

Todas as medidas em D. corona são positivamente correlacionadas umas as outras (Tabela II), exceto o número e espinhos que não é significativamente correlacionado com o diâmetro da teca e comprimento dos espinhos. A Tabela III mostra razões entre os valores morfométricos.

\section{Ecologia e Distribuição Geográfica}

Difflugia corona é registrada para África, Ásia, Europa, América do Sul e do Norte (OGDeN \& HEDLEY 1980, OGDEN \& ŽIVKOVIC 1983). Registros foram feitos a partir de amostras de plâncton, sedimento e perifíton. No presente estudo, a maioria dos 
organismos (46.76\%) foi encontrada em ambientes de perifíton, como as raízes de plantas aquáticas no Rio propriamente dito (Tabela IV), confirmando observações prévias (Tabela V).

Observações: a forma e a composição da teca de D. corona registradas neste trabalho estão de acordo com estudos recentes realizados sob MEV (OGDEN \& HedLEY 1980, OGDeN \& ŽIVKOVIC 1983, DeKHTYAR 1993), mas a complexa arquitetura apertural dessa espécie é descrita aqui pela primeira vez. Com base na análise de micrografias do material identificado por Colin G. Ogden e depositado na coleção de protistas do Natural History Museum (NHM), cedidos pelo Dr. Alan Warren, pode-se verificar que o complexo apertural coincide com a presente descrição. Alguns dos espécimes registrados por Ogden possuem um bordo apertural construído em sua maior parte por partículas aglutinadas, enquanto os encontrados no Rio Tietê sempre o fazem exclusivamente com material orgânico.

Em comparação a estudos prévios (Tabela VI), D. corona apresenta, em todo o mundo, uma grande amplitude de medidas. 0 presente estudo encontrou uma maior variação dentro de uma mesma população, e isso é atribuído ao tamanho da amostra $(n=683)$.

Observações taxonômico - nomenclaturais quanto a Difflugia corona var. ecornis Gauthier-Lièvre et Thomas, 1958

De acordo com o ICZN (RIDE et al. 1999), Difflugia corona var. ecornis deve ser considerada como Difflugia corona subespécie ecornis, porque foi descrita antes de 1961 como uma variedade e está destinada portanto a ser tratada como subespécie (artigo 45.6.4). 
Não é possível distinguir Difflugia corona ecornis dos indivíduos observados aqui e em outros trabalhos identificados como Difflugia corona. 0 presente estudo encontrou 76 espécimes sem espinhos, dos quais 15 foram examinados ao MEV. Todas as características morfológicas desses exemplares, como: forma da teca (Fig. 15); lobos da abertura (Fig. 16); composição da teca (Fig. 17); protuberâncias aculeiformes nos lobos (Fig. 18) - e valores biométricos (Tabela I) são como em D. corona. Esses dados sugerem que os espécimes sem espinhos fazem parte de um contínuo dentro de Difflugia corona e que os nomes Difflugia corona var. ecornis, Difflugia corona ecornis e Difflugia ecornis devem ser sinonimizados com D. corona corona (criada a partir do Princípio da Coordenação, artigo 43.1).

O que se observou para $D$. corona pode ser indicativo de uma tendência mais geral entre os protistas unicelulares assexuados. Muitas descrições antigas são inadequadas para distinguir táxons de acordo com princípios atuais (MEISTERFELD 2000). Pequenas amostragens subestimam as variações biométricas nas populações e à medida que um maior número de indivíduos é analisado, as amplitudes de medidas e de outros atributos dentro de uma espécie tendem a aumentar. Desta maneira, o conceito taxonômico da espécie em questão vai expandir, e, táxons previamente designados como variedades e/ou subespécies tenderão a perder suas identidades. 
Gênero Difflugia Leclerc, 1815

\section{Difflugia gramen Pènard, 1902}


Difflugia gramen Pènard, 1902

Prancha III; Figs. 19 a 24

\section{Dados Previamente Reportados (Cresônimos)}

Difflugia gramen - Pènard, 1902:281; Deflandre, 1926:518 (eco, syn); Štěpánek, 1952:17 (desc, dim, eco); Gauthier-Lièvre et Thomas, 1958:257 PI I figs a-e (desc, dim, eco, geo, syn); Štěpánek et Jiří, 1958:139, fig. 1 (desc, dim, eco, syn); Green, 1975:550 (eco, geo); Vucetich, 1970:45 (syn), 1972:275, fig. 4 (desc, dim, eco, geo, syn), 1973:302, fig. 25 (desc, dim, eco, geo, syn), 1978:81 (eco); Velho et Lansac-Tôha, 1996:182 PI I figs 6, 6a (desc, dim, eco, syn); Ogden, 1980b:125 figs 1-6 (desc, eco, dim, SEM), 1983:50 (desc, eco, dim); Ogden et Meisterfeld, 1989:121 figs 5, 6, 23, 24 (desc, dim, eco, geo, syn, SEM) Material examinado: 192 espécimes sob MO, 16 espécimes sob MEV

\section{Morfologia}

Teca esférica a ovóide (Figs. 19a, 20), levemente afilada na região apertural, circular em vista apertural (Fig. 19b). Contorno regular, por vezes interrompido por uma partícula maior (Fig. 21). Toda a teca composta de alguns grãos minerais grandes e muitos pequenos, em sua maioria grandes partículas de quartzo e entre estas estão as pequenas, em geral esféricas, cimentadas por uma matriz orgânica (Fig. 22). Superfície da teca levemente rugosa. Matriz cimentante lisa, entre as partículas (Fig. 22), às vezes apresentam pequenas perfurações.

Abertura terminal, com 3 a 4 lobos (Figs. 19a, 20 e 23), delimitados por um colar irregular levemente em relevo, construído com pequenas partículas aglutinadas 
- pequenos grãos de areia e estruturas cilíndricas - e matriz orgânica cimentante lisa, evidenciada por protuberâncias aculeiformes (Fig. 24). Um anel de poros na matriz orgânica envolve a abertura imediatamente exterior ao colar (Fig. 23).

\section{Biometria}

Todos os caracteres analisados apresentam alta variabilidade (CV entre 18,7 e 31,5$)$ e baixo erro padrão da média $(0,79)$ é observado apenas para o diâmetro da abertura (Tabela I). A análise da freqüência de medidas revela que todos os caracteres possuem uma grande amplitude, mas todas apresentam uma classe principal de medidas: para comprimento da teca, $54,6 \%$ das medidas estão entre os limites de 90 a $110 \mu \mathrm{m}$; para o diâmetro da teca, 52,58\% estão entre 60-100 $\mu \mathrm{m}$; para diâmetro da abertura 77,04\% estão entre $20-40 \mu \mathrm{m}$. A Tabela II mostra que todos os caracteres são positivamente correlacionados. A Tabela III mostra razões entre os valores morfométricos.

\section{Ecologia e Distribuição Geográfica}

Difflugia gramen é registrada em todos os continentes (OGDEN \& HeDLeY, 1980). Espécimes podem ser encontrados em plâncton, perifíton e no sedimento. Na América do Sul, registros foram feitos por Deflandre (1926), Decloitre (1955), VUCETICH $(1972,1973,1978)$. Para o Brasil, registros foram feitos no Rio de Janeiro (Walles 1913, Cunha 1913), Mato Grosso (Green 1975), Minas Gerais (Dabés 1995), e Mato Grosso do Sul (VelHo \& LANSAC-TôHA 1996) onde a espécie foi encontrada associada às raízes de plantas aquáticas.

A maioria dos organismos $(62.58 \%$ do total) foi encontrada em hábitats lênticos (Tabela IV), preferivelmente associadas ao sedimento (40.53\%). Trabalhos 
prévios não observaram isto (Tabela VII). Uma associação com o perifiton foi indicada por Vucetich (1973), OGDen (1980b) e OGDen \& MeISTERFELD (1989).

Observações: a redescrição feita por OGDEN (1980b) da espécie Difflugia gramen coincide com os dados do presente e de outros trabalhos (PĖNARD 1902; GauthieR-LièVRe \& Thomas 1958; Ště́pÁnek \& JIŘi 1958; VUCETICH 1972, 1973; VelHo \& Lansac-TôHa 1996; Ogden \& Hedley 1980; Ogden 1983; Ogden \& Meisterfeld 1989; ver Tabela VI).

Apesar da semelhança entre os dados morfológicos no material do presente trabalho, pode-se registrar maior amplitude de variação nos caracteres da teca, isto se deve ao fato do presente trabalho incluir mais indivíduos do que estudos prévios (Tabela VI). A maioria das observações prévias fornece medidas que caem dentro da abrangência observada para todos os caracteres, exceto para os mencionados por GaUtHIER-LièVRe \& THOMAS (1958) e OGDEN (1983), que observaram indivíduos menores. 0 presente estudo estende o tamanho máximo para esta espécie. OGDEN (1983) observou que uma característica comum para duas populações britânicas em Norfolk (OGDEN 1980b, 1983) é a razão diâmetro da abertura/comprimento da teca $(0,32 \pm 0,04$ e $0,34 \pm 0,04)$, e no presente estudo esta razão foi confirmada $(0,35 \pm$ 0,09 , Tabela III).

Ogden (1980b) e Ogden \& Meisterfeld (1989) observaram que a textura e composição da teca varia de um contorno liso composto de finos grãos de areia até um contorno rugoso, composto de grãos de areia de médio tamanho, por vezes, interrompendo o contorno da teca, enquanto o presente estudo observou uma situação intermediária onde a teca é produzida com os dois tipos de grãos, e quando 
a teca apresenta uma textura rugosa, o aspecto circular do contorno é raramente interrompido.

Os colares aperturais observados aqui são mais claramente delineados que os previamente descritos (Ogden \& Hedley, 1980; Ogden 1980b, 1983; Ogden \& Meisterfeld 1989), e compostos de grãos de areia juntamente com material orgânico. Os poros ao redor da abertura são menores e mais esparsos do que os observados por OGDEN (1980b).

A mais conspícua variação observada se refere ao material cimentante. OGDEN (1980b) e OGDEN \& MeISTERFELD (1989) mostram um matriz cimentante arranjada em forma de rede, enquanto o presente trabalho revela uma textura lisa. 
Gênero Difflugia Leclerc, 1815

\section{Difflugia lanceolata Pènard, 1890}


Difflugia lanceolata Pènard, 1890

Prancha IV; Figs. 25 a 34

Dados Previamente Reportados (Cresônimos)

Difflugia lanceolata: Pènard, 1890:145-146, pl. IV, figs 59,60; Decloitre, 1954:107-108, fig. 25 (dim); Vucetich, 1973: 311, pl. V, fig. 43 (desc, dim, geo); Ogden et Hedley, 1980:140, pl 59, figs A-D (desc, dim, geo, SEM); Ogden, 1983:11, figs 6a-6f (desc, dim, geo, syn, SEM)

Material Examinado: 149 espécimes sob MO, 10 sob MEV

\section{Morfologia}

Teca piriforme, alongada (Figs. 25 a 29), sendo algumas mais cilíndricas (Figs. 26 a 28) e outras em forma de gota (Figs. 28 e 29), circular em vista apertural. Extremidade abapertural varia de uma semi-circunferência (Fig. 27) a acuminada (Figs. 26 e 28 a 30). Teca de contorno regular, com partículas achatadas de quartzo (Fig. 31) e frústulas achatadas de diatomáceas, arranjadas como um quebra-cabeça, cujas peças não se sobrepõe (Fig. 32), portanto; paredes da teca finas e superfície lisa e com aspecto polido. Particulas são aglutinadas por unidades circulares de cimento orgânico (Fig. 31).

Abertura terminal, circular (Fig. 25), complexo apertural construído com particulas achatadas ou arredondadas, cobertos por várias camadas de cimento orgânico (Fig. 33), cujo padrão da matriz é similar ao encontrado no resto da teca, o que evidencia que seja construído com o mesmo material (Fig. 34).

Biometria 
Todos os caracteres são variáveis (CV entre 15,1 e 18,4), apresentando alto erro padrão da média (SE $=0,56-2,16)$, como está sumarizado na Tabela I. A análise da freqüência de tamanhos evidencia que todos os caracteres apresentam uma grande amplitude de medidas, mas sempre é possível distinguir uma classe principal: para diâmetro da teca, $63,75 \%$ das medidas estão dentro dos limites de 80 a $90 \mu \mathrm{m}$; para comprimento da teca, $70,46 \%$ estão entre $180-200 \mu \mathrm{m}$; para diâmetro da abertura, $73,82 \%$ esta entre $30-40 \mu \mathrm{m}$. A Tabela II mostra que todas as características estão mutuamente correlacionadas. A Tabela III mostra razões entre os valores morfométricos.

\section{Ecologia e Distribuição Geográfica}

D. lanceolata é registrada para África, Ásia, Europa, América do Sul e do Norte (Tabela II). Na América do Sul, os registros são da Argentina (Vucetich 1973), Venezuela (Grospietsch 1975) e, Brasil, em Mato Grosso (Hardoim et Heckman 1996) e Goiás (Lansac-Tôha et al. 2000). No presente estudo 87,2\% dos indivíduos foram encontrados associados às raízes de plantas aquáticas do rio propriamente dito (Tabela IV).

Observações: as características da teca estão em completo acordo com a diagnose de D. lanceolata descrita em Ogden (1983) e Ogden \& Hedley (1980). Variações observadas na população do Rio Tiete dizem respeito à forma geral da teca e região abapertural. Apesar de essas variações serem reportadas na literatura, nunca havia ocorrido na mesma população. Os menores e maiores indivíduos conhecidos desta espécie foram encontrados neste estudo, estendendo a abrangência morfométrica conhecida (Tabela VI). 
Gênero Difflugia Leclerc, 1815

\section{Difflugia claviformis Pènard, 1899}


Difflugia claviformis Pènard, 1899

Prancha V; Figs. 35 a 42

\section{Sinônimos}

Difflugia pyriformis var. claviformis Pènard, 1899

Difflugia oblonga var. claviformis Cash, 1909

Difflugia (oblonga) claviformis Štepánek, 1952

Dados Previamente Reportados (Crêsonimos)

Difflugia pyriformis var. claviformis - Pènard, 1899 figs. 12-14; 1902: 218 fig. 3, 4

Difflugia oblonga var. claviformis - Cash et Hopkinson, 1909; Chardez, 1967:594

PI II fig 18 (desc, dim, syn)

Difflugia (oblonga) claviformis - Štepánek, 1952: 25 (desc, syn); 1967: 39 fig. 8. 6,8 (syn)

Difflugia claviformis - Ogden, 1979a:145, 146, 148 fig. 4 (desc, SEM); Ogden et Hedley, 1980:126 PI. 52 figs A-D (desc, dim, geo, SEM)

Material Examinado: 113 espécimes sob MO, 12 espécimes sob MEV

\section{Morfologia}

Teca piriforme, alongada (Fig. 35a), circular em vista apertural (Fig. 35b). Região abapertural com um espinho cônico que varia em forma e tamanho (Figs. 36, 37, 38), afilando de maneira homogênea desde a região abapertural até a apertural. Contorno da teca regular, raramente interrompido por uma partícula maior. Região apertural com superfície levemente rugosa, composta por particulas arredondadas 
de quartzo e estruturas cilíndricas de natureza exógena, região abapertural com superfície mais lisa composta por partículas mais achatadas de quartzo (Figs. 39, 40); m ambos os casos as partículas estão embebidas em uma matriz orgânica cimentante com padrão de rede (Figs.39 e 40).

Abertura terminal, circular (Fig. 35b). Complexo apertural construído de particulas cilíndricas e esféricas, menores que as encontradas em outras regiões da teca (Fig. 41), aglutinadas e cobertas por várias camadas de matriz orgânica depositadas no bordo livre, de aspecto liso (Fig. 42).

\section{Biometria}

Todos os caracteres são altamente variáveis ( $C V=24,0-28,7)$, com alto erro padrão da média $(1,11$ - 6,12), sumarizados na Tabela I. Análises da distribuição de freqüências de medidas evidenciam que todos os caracteres têm uma grande amplitude, entretanto, todos possuem uma classe principal de medidas: $67,24 \%$ das

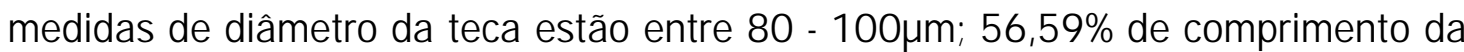
teca estão entre 180 - $240 \mu \mathrm{m} ; 91,13 \%$ de diâmetro da abertura estão entre 40 - 60 um. A Tabela II mostra que todos os caracteres são positivamente correlacionados entre si. A Tabela III mostra razões entre os valores morfométricos.

\section{Ecologia e Distribuição Geográfica}

Difflugia claviformis tem registros para Europa e América do Norte (OGDEN \& HedLey 1980), Venezuela (GROSPIETSCH 1975), e de amostras bentônicas em lagoas costais do Rio Grande do Sul (MADEIRA-FALCETTA 1974). O presente estudo encontrou $88 \%$ dos indivíduos no rio propriamente dito, sendo $64 \%$ deles associados com as raízes de plantas aquáticas e $24 \%$ associados com o sedimento (Tabela IV). 
Observações: A morfologia das tecas observadas no presente trabalho está de acordo com a descrição de D. claviformis feita por OgDen \& HedLEY (1980) e OGDEN (1979a), exceto pela observação adicional da cobertura orgânica apertural, e maior variação na forma e tamanho do espinho cônico. Mudanças na circunscrição desta espécie foram principalmente devido à variação na forma do espinho. CASH \& HOPKINSON (1909) restringiram D. claviformis apenas para indivíduos cujas tecas apresentam um espinho abapertural mamiliforme. OGDEN (1979a) e OGDEN \& HEDLEY (1980), entretanto, juntaram diferentes morfologias de espinhos sob este taxon e admitem até que o espinho possa ser reduzido ou mesmo ausente. Estes autores afirmam que a identidade ultra-estrutural do cimento é o fator mais importante na diagnose destas espécies. 0 presente trabalho reforça estas observações, pois os espécimes do Rio Tietê, ao contrário das populações européias, são em sua maioria, providos de um espinho tubular, mas existem o que não possuem espinho. Diagnoses diferenciais para espécies similares, a saber, D. acuminata Ehremberg, 1838, D. elegans Pènard, 1890 e D. curvicaulis Pènard, 1899, são dadas em outro trabalho (OGDEN 1979a). A população do Rio Tietê apresenta maiores variações em tamanho do que os registrados em estudos prévios (Tabela VI). 
Gênero Difflugia Leclerc, 1815

\section{Difflugia gigantea Chardez, 1967}


Difflugia gigantea Chardez, 1967

Prancha Vl; Figs. 43 a 51

\begin{abstract}
Sinônimos
Difflugia oblonga v. gigantea Chardez, 1967

Dados Previamente Reportados (Cresônimos)

Difflugia oblonga v. gigantea - Chardez, 1967:593 fig. 2 (dim, syn)

Difflugia gigantea - Ogden et Fairman, 1979:375 figs 12-15 (desc, dim, SEM)

Material Examinado: 9 espécimes sob MO, 5 espécimes sob MEV
\end{abstract}

\title{
Morfologia
}

Teca piriforme, mais globosa na região abapertural e mais alongada desde a linha média do comprimento da teca até a abertura (Figs. 43a, 44, 45, 46), circular em vista apertural (Fig. 43b). Região abapertural esférica. Superfície da teca lisa, por vezes interrompida por partículas maiores. Teca de contorno irregular composta de partículas aglutinadas de quartzo e frústulas de diatomáceas (Figs. 44, 45, 46). Particulas embebidas em um cimento orgânico em forma de malha de rede (Figs. 47, 48), cujas perfurações não atravessam a espessura toda da teca, pois existe uma camada subjacente onde menores perfurações podem ser vistas.

Abertura terminal, circular (Fig. 43b). Complexo apertural formado por partículas cilíndricas e esféricas, aglutinadas e cobertas por cimento orgânico (Figs. $49,50)$. Numerosas camadas de cimento são depositadas no bordo livre, mas vestígios da organização em malha de rede evidenciam que é formado pela mesma matriz cimentante (Figs. 51). 


\section{Biometria}

Todos os caracteres são altamente variáveis (CV entre 16.1 e 20.6) e apresentam alto erro padrão da média (4.71 - 26.03), como sumarizado na Tabela I. A Tabela III mostra razões entre os valores morfométricos.

\section{Ecologia e Distribuição Geográfica}

Registrada para a Inglaterra e América do Norte, Difflugia gigantea é um organismo raro (Tabela VI). 0 presente trabalho encontrou apenas nove espécimes. OgDen \& Fairman (1979) também reportam números baixos associados com Sphagnum. A Tabela IV mostra que apenas não foram encontrados espécimes associados com as raízes de plantas aquáticas do Rio propriamente dito.

Observações: Difflugia gigantea foi originalmente proposta por CHARDEZ (1967) como Difflugia oblonga v. gigantea, e elevada ao ranking de espécie por OGDEN \& FAIRMAN (1979). D. oblonga difere de D. gigantea por possuir o contorno da teca mais irregular, rugoso, devido a grandes partículas aglutinadas. Em D. oblonga observa-se um pescoço bem definido, característico da espécie, e matriz orgânica formada por tiras ligando as partículas (OGDen \& Fairman 1979, Ogden \& Hedley 1980), ambas as características não ocorrem em D. gigantea. Os espécimes estudados no presente estudo são geralmente mais alongados, especialmente na região apertural, as outras características estão de acordo com OGDEN \& FAIRMAN (1979). A população do Rio Tietê apresenta maior variação do que previamente reportado na literatura (Tabela VI). 
DISCUSSÃO

A maioria dos estudos sobre Difflugia não designa material-tipo e está baseada em um pequeno número de exemplares; desta maneira, a identidade e circunscrição das espécies não é clara. 0 gênero mais próximo a Difflugia é Netzelia Ogden, 1979, caracterizado por tecas compostas por material endógeno (idiossomos), ou por estruturas de sílica encontradas na natureza (OGDEN 1979a, ANDERSON 1987, MeISTERfELd 2000). As tecas de Netzelia possuem contorno regular, e superfície lisa. As partículas que formam a teca de Difflugia, no entanto são coletadas do ambiente.

Neste estudo, as espécies que possuem tecas esféricas podem ser diferenciadas pela forma, tamanho e arquitetura do complexo apertural: D. corona pode ser identificada pela presença de espinhos e D. gramen pelo formato do complexo apertural. No entanto D. gramen pode ser confundida com outros Arcellinida não encontrados no presente estudo, como Difflugia lobostoma, mas a organização nuclear distingue as espécies. D. gramen é um dos poucos Arcellinida que possui o núcleo vesicular, enquanto $D$. lobostoma possui um núcleo ovular com muitos nucléolos.

Distinções entre as espécies piriformes de Difflugia são menos claras (Chardez \& Decloitre 1973; Ogden 1979a, 1980a, 1980b, 1983; Ogden \& Fairman 1979), como é o caso de D. lanceolata e D. claviformis, que possuem aparências similares ao MO, e que são indistinguíveis pelas dimensões da teca (Tabela I) e pelas razões entre as medidas (Tabela III). Nesses casos, a diferença mais importante parece ser o padrão da matriz orgânica cimentante considerada uma confiável 
característica específica (OGDEN 1983, 1990; OGdeN \& ŽIVKović 1983; MeISTERfeLD 2000). Em D. lanceolata o cimento é composto por unidades circulares, aneliformes, que conectam as partículas achatadas em alguns pontos, e em D. claviformis, o cimento possui uma organização semelhante a malha de uma rede, onde as partículas estão embebidas.

Difflugia gigantea pode ser reconhecida por suas grandes dimensões, mas novamente, a matriz orgânica cimentante é singular. Na região externa da teca existe uma camada perfurada, e subjacente a esta, localiza-se uma segunda camada com poros menores. Quaisquer incertezas sobre estas características irão minar as distinções entre estas espécies piriformes. 


\section{Secção 2.}

Família Centropyxidae Jung, 1942 
A Família Centropyxidae Jung, 1942 composta por organismos cuja teca é formada de grãos minerais e diatomáceas aglutinados por uma matriz orgânica cimentante ou somente de quitina; possui abertura excêntrica, em geral invaginada. A família é composta de quatro gêneros (MeISTERfELD 2000) dos quais apenas Centropyxis Stein, 1857 foi registrado na presente pesquisa.

O gênero Centropyxis apresenta como condição exclusiva a presença no citoplasma de núcleo ovular, desta maneira, as espécies são diferenciadas apenas através da morfologia da teca. Mais de 130 espécies e muitas variedades foram descritas até hoje e muitas destas descrições são incompletas (MEISTERFELD 2002).

A espécie-tipo Centropyxis aculeata (Ehrenberg, 1838) não possui espécimetipo designado e as espécies têm sido estabelecidas com base em caracteres subjetivos. É o caso, por exemplo, da diagnose da espécie Centropyxis discoides Pènard, 1890 feita com base em um único caráter, "teca mais comprimida anteriormente" (Deflandre 1929), e da diagnose da espécie Centropyxis ecornis (Leidy, 1879) feita com base apenas na ausência de espinhos na teca.

A alta variabilidade presente nas espécies atribuídas ao gênero Centropyxis em relação a todas as características da teca (forma e tamanho da teca; forma e tamanho da abertura; forma, tamanho e número dos espinhos) já vem sendo apontada em vários estudos (Wallich 1864; Leidy 1879; PènARd 1902; CASH \& HoPkinson 1905; RoOt 1918; Deflandre 1929; Chardez 1956, 1966a; NetZel 1972, 1975; Ogden 1988; Medioli \& Scott 1983, 1985; Wanner 1999). Mesmo assim, variedades e formas continuaram e continuam a ser descritas com base em número 
reduzido de indivíduos, desconsiderando-se que essas variações podem estar dentro das variações naturais de uma espécie em particular.

Nessas descrições, não há preocupação em analisar a possibilidade de variação contínua. Um exemplo é a diferenciação entre Centropyxis aculeata e C. ecornis. Em 1918, Root descreveu a herança da forma da carapaça em indivíduos de Centropyxis aculeata cultivados em laboratório, sem perturbações ambientais. Neste trabalho, Root fez o primeiro registro de que Centropyxis aculeata é capaz de produzir indivíduos sem espinhos na carapaça, única característica considerada por outros autores como diagnóstica de C. ecornis. Apesar disso, essas duas espécies nunca foram sinonimizadas.

Essas questões puderam ser verificadas no presente trabalho quando se tentou agrupar os indivíduos nas diferentes espécies, subespécies, variedades e formas de Centropyxis com base nas descrições tradicionais. Ao se fazer isso, verificou-se que essa separação é subjetiva. Passou-se, então, a tratar os dados de forma mais ampla, considerando grande número de indivíduos, analisando a biometria da teca, o hábitat dos espécimes e a descrição detalhada da teca sob MEV.

As análises indicam que os espécimes coletados poderiam ser classificados em Centropyxis aculeata, Centropyxis discoides e Centropyxis ecornis e algumas de suas variedades, totalizando 11 táxons. No entanto, todas as análises morfométricas e morfológicas revelaram a ausência de características morfológicas distintas e únicas necessárias para separar estes 11 táxons, e, no presente trabalho, considerase todas pertencentes a uma única entidade taxonômica. 
Os dados biométricos obtidos (Fig. 52), o teste para normalidade (teste de Kolgomorov-Smirnov) e a análise combinada para cada táxon nominal e cada caráter, encaixam-se em uma curva normal de distribuição $(p<0,01)$. Para descrever e analisar o espaço morfológico, as características foram comparadas duas a duas em gráficos de dispersão (Fig. 53) para táxons em nível de espécie. As análises conjuntas indicam um contínuo entre as espécies. Isso mostra que variedades descritas a partir de características discriminatórias apenas para um pequeno número de indivíduos não são válidas. Os espécimes encontrados nesta pesquisa podem ser acomodados nestas variedades, mas uma análise crítica de toda a amostra revela que as distinções entre elas não são válidas.

As diferenças entre as formas mais tradicionais e as mais atuais de lidar com descrições taxonômicas em protistas devem ser muito bem especificadas para que trabalhos futuros possam trazer análises cada vez mais aprimoradas. Esse procedimento foi adotado no presente trabalho. Inicialmente, descreve-se a mais abrangente unidade encontrada como um complexo de táxons nominais não distintos, em seguida, os mesmos táxons são listados e a razão pela qual não é possível fazer distinção é discutida. O nome adotado para todo o complexo foi o mais antigo disponível. 
Gênero Centropyxis Stein, 1857

\section{Centropyxis aculeata (Ehrenberg, 1838)}


Centropyxis aculeata (Ehrenberg, 1838)

Prancha VIl; Figs. 55 a 75

Sinônimos

Arcella aculeata - Ehrenberg, 1838: 133, pl IX, fig. VI

Centropyxis aculeata - Pènard, 1902: 303, fig. 1

Táxons não-distintos previamente descritos

Centropyxis aculeata var. tropica - Deflandre, 1929: 348, figs. 94, 95

Centropyxis aculeata var. grandis - Deflandre, 1929: 349, fig. 93

Centropyxis aculeata var. oblonga - Deflandre, 1929: 349, fig. 96-103

Centropyxis aculeata var. minima - Van Oye, 1956: 97-98, pl. I, fig. 8

Centropyxis aculeata var. intermedia - Van Oye, 1949: 338, fig. 12

Centropyxis aculeata var. gigantea - Decloitre, 1978: 64

Centropyxis discoides - Deflandre, 1929: 351-353, fig. 104-107

Centropyxis aculeata var. discoides - Pènard, 1890; Pènard, 1902: 306, fig.

$1-7$

Centropyxis discoides var. grandistoma - Chardez, 1966b

Centropyxis ecornis - Leidy 1879, pl. XXX, fig. 20-34

Centropyxis ecornis var. deflandrei - Thomas, 1957

Centropyxis ecornis var. leidyi - Thomas, 1957

Material Examinado: 2120 espécimes ao MO; 30 espécimes ao MEV 


\section{Morfologia}

Teca circular irregular em vista apertural (Figs. 54a, 55), achatada em vista lateral (Figs. 54b, 60, 61), variando de um disco homogeneamente achatado à levemente arqueado, arredondado na região posterior e comprimido anteriormente, em maior ou menor grau. Teca provida de 0-10 espinhos cônicos, ocos, inseridos lateral e/ou posteriormente em uma linha longitudinal simples (Figs. 59-61). Espinhos variáveis em forma (Figs. 62-67), às vezes providos de uma pequena partícula de quartzo terminal (Fig. 62).

Região apertural composta unicamente de material aglutinante na maioria dos espécimes (Figs. 68-70); região abapertural composta de grãos aglutinados de quartzo e/ ou frústulas de diatomáceas (Figs. 71, 72, 73). Exceções a esta condição: teca completamente composta por partículas aglutinadas cimentadas (neste caso, a região apertural é coberta por uma camada de cimento orgânico) ou completamente sem partículas. Matriz orgânica cimentante completamente organizada em varias camadas entrelaçadas que criam um padrão de pequenas depressões observáveis tanto na face interna (Fig. 74) como na externa (Fig. 75).

Abertura em geral excêntrica, em alguns casos central ou sub-central, de contorno circular a irregular (Fig. 55-59). Varia de circular a irregular ou em forma de polígono. Contorno da abertura é um lábio (Fig. 68), Espécimes >150 $\mu \mathrm{m}$ apresentam quatro pilares ocos que se projetam do contorno da abertura (lábio) até a região abapertural da teca, onde deixam depressões (Fig. 71) sugestivas de sua existência. Em geral, os dois pilares posteriores (Fig. 69) são mais delgados que os anteriores (Fig. 70). 


\section{Biometria}

A Tabela VIII mostra os detalhes da biometria. Todas as medidas são altamente variáveis (CV entre 26,17 e 56,00). 0 número de espinhos apresenta 0 menor erro padrão da média. A análise da freqüência de distribuição das medidas evidencia que o complexo Centropyxis aculeata possui uma classe principal de medidas e uma amplitude grande para todos os caracteres: para diâmetro da teca, 56,63\% das medidas estão entre 140-180 $\mu \mathrm{m}$; para comprimento da teca, 54,6\% das medidas estão entre $140-180 \mu \mathrm{m}$, para a altura da teca, $88,51 \%$ das medidas

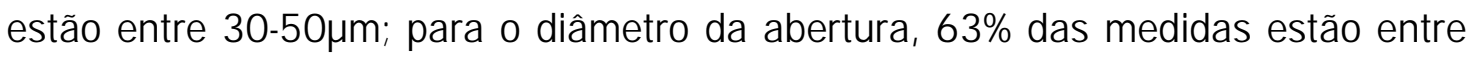

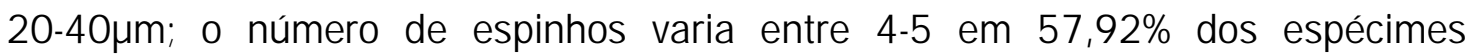
medidos. As razões entre medidas morfométricas estão apresentadas na Tabela IX. Todas as medidas estudadas no presente trabalho são positivamente correlacionadas mutuamente (Tabela X), exceto número de espinhos - altura da teca e comprimento de espinhos - diâmetro da abertura.

\section{Ecologia}

A exploração de habitat pelos indivíduos amostrados está sumarizada na Tabela XI. Este organismo parece preferir a associação com raízes em um ambiente de águas correntes, porém também foi encontrado em outros micro-habitat. Exceção a esta regra é a forma sem espinhos, tradicionalmente referida como Centropyxis ecornis ecornis (Ehrenberg, 1841), que vive preferencialmente no fundo do Rio (na Tabela XI, note a inversão de valores para raízes e sedimento quando comparada com as outras formas). O número de espinhos é uma característica fortemente herdada (Root 1918), portanto esta relação pode ser atribuída a uma adaptação a condições ambientais específicas, o que também pode explicar o pico no histograma 
para número de espinhos para todos os táxons (Fig. 52), demonstrando que 0 polimorfismo na espécie pode responder a seleção, como sugerido por outros autores (BOBRov \& MAZEI 2004, LAHR \& LOPES 2006).

Observações: a morfologia das tecas observadas no presente estudo está em completo acordo com estudos ultra-estruturais (Netzel 1972, 1975; HedLeY et al. 1976; OGDEN \& HEDLEY 1980; OGDEN 1988) e não apresenta contradições quando comparadas a estudos morfológicos realizados sob MO (DADAY 1905; DefLANDRE 1926, 1929; Decloitre 1978, Van Oye 1949, 1956, 1958, 1959; Chardez 1966a; ŠtepáneK 1952, 1963, 1965; VUCetich 1972, 1973; Bovee 1985; Velho et al. 1996; ZAPATA 2002). Comparado aos estudos prévios, o complexo C. aculeata em todo o mundo apresenta uma grande amplitude de medidas, e o presente estudo apresenta a maior variação já reportada (Tabela VIII) para a mesma população, provavelmente devido ao tamanho da amostra.

Visando não perder as informações de outros autores de forma a propiciar análises futuras, serão apresentadas as principais características dos diferentes táxons que estão sendo incluídas nos intervalos de variações definidos no presente estudo, cada um desses táxons é considerado indistinguível de qualquer outro na lista. Cada táxon será brevemente abordado, somente descrevendo as características diagnósticas, e como estas mesmas características não podem ser usadas como distintivas de cada táxon.

Centropyxis aculeata var. tropica Deflandre, 1929

Definida na descrição original como distinta de C. aculeata aculeata (Ehrenberg, 1838) pela presença de espinhos longos, nunca presentes na espécie- 
tipo; designa espécimes com comprimento da teca 123 - $136 \mu \mathrm{m}$ e comprimento dos espinhos 42 - $60 \mu \mathrm{m}$ para esta variedade; autores subseqüentes expandiram 0 comprimento da teca para 70-150; comprimento dos espinhos 20-60. 0 presente estudo encontrou 557 indivíduos que se encaixam nesta descrição. Entretanto, um gráfico de dispersão (Fig. 53m) comprimento da teca vs. comprimento dos espinhos de 1092 espécimes designados ao complexo C. aculeata mostra que não há elementos suficientes para separar espécimes com espinhos relativamente curtos daqueles com espinhos relativamente longos.

Centropyxis aculeata var. grandis Deflandre, 1929

Definida pela descrição original como distinta de C. aculeata aculeata (Ehrenberg, 1838) pelas grandes dimensões (comprimento da teca $180 \mu \mathrm{m}$ ); autores subseqüentes expandiram o comprimento para 150-200 $\mu \mathrm{m}$. 0 presente trabalho analisou 355 indivíduos que se encaixam nesta descrição. Os histogramas (Fig. 52d, $h, l, p, s, x)$ contendo toda a amostra do complexo $C$. aculeata mostra que não há diferenças de tamanho que permitam separar estes dois táxons.

Centropyxis aculeata var. oblonga Deflandre, 1929

Definida pela descrição original como distinta de C. aculeata aculeata (Ehrenberg, 1838) pelo formato oblongo da teca em vista apertural, nunca circular. Isto pode ser testado pela relação comprimento da teca vs. largura da teca. A descrição original designa comprimento da teca 106-140 $\mu \mathrm{m}$ e largura da teca 95$111 \mu \mathrm{m}$; autores subseqüentes expandiram o comprimento da teca para 61-140 $\mu \mathrm{m}$ e largura da teca para 65-120 $\mu \mathrm{m}$. 0 presente trabalho encontrou 173 espécimes 
que se encaixam nesta descrição. Entretanto, um gráfico de dispersão (Fig. 53a) usando toda a amostra de C. aculeata mostra que não há distinção entre esta e outras formas.

Centropyxis aculeata var. discoides Pènard, 1890

Estabelecida posteriormente para nível de espécie por Deflandre (1929), difere de C. aculeata aculeata (Ehrenberg, 1838) pelo maior comprimento da teca (150 - $450 \mu \mathrm{m})$ e um perfil lateral mais discóide; trabalhos subseqüentes expandiram a amplitude do comprimento da teca para 70-450 $\mu \mathrm{m}$. 0 presente estudo encontrou 895 espécimes que se encaixam nesta descrição. A compressão da região anterior é um caráter que mostra grande variação e muitas formas de transição podem ser encontradas. Nos histogramas relativos a toda a amostra (Fig. $52 d, h, l, p, s, x)$ verifica-se que não há distinção aparente em nenhum dos atributos analisados entre C. aculeata e C. discoides.

Centropyxis aculeata var. minima Van Oye, 1956

Definida pela descrição original como distinta de C. aculeata aculeata (Ehrenberg, 1838) a partir de indivíduos que possuem comprimento da teca de 65$78 \mu \mathrm{m}$ e largura da teca de $70 \mu \mathrm{m}$. 0 presente trabalho encontrou quatro indivíduos que se encaixam nesta descrição, mas em um histograma de toda a amostra (Fig. 52d) não se encontram limites definidos para separar estes táxons.

Centropyxis aculeata var. intermedia Van Oye, 1956 
Estabelecida a partir de indivíduos que estão "entre C. aculeata aculeata e C. discoides discoides", principalmente baseando-se em dimensões (comprimento da teca $161 \mu \mathrm{m}$, largura da teca $153 \mu \mathrm{m}$ ) e posição da abertura. 0 presente estudo analisou 210 indivíduos que se encaixam nesta descrição, porém, os histogramas (Figs. 52d, h) não evidenciam distinção aparente.

Centropyxis aculeata var. gigantea Decloitre, 1978

Estabelecida a partir de indivíduos com dimensões maiores que C. aculeata var. grandis Deflandre, 1929. Os histogramas (Figs. 52d, h) não evidenciam distinção aparente.

Centropyxis ecornis ecornis (Ehrenberg, 1841)

Descrita originalmente como Arcella ecornis e mais tarde transferida para 0 gênero Centropyxis Leidy 1879, difere de C. aculeata aculeata (Ehrenberg, 1838) pela ausência completa de espinhos látero-posteriores. 0 presente estudo encontrou 126 espécimes que se encaixam nesta descrição, mas o histograma do número de espinhos (Fig. 52x) apresenta uma distribuição normal para este caráter quando analisado com toda a amostra. Além disso, sabe-se desde Root (1918) que indivíduos de C. aculeata aculeata (Ehrenberg, 1838) sem espinhos são comuns em cultura.

Centropyxis ecornis var. deflandrei Thomas, 1957

Definida pela descrição original como distinta de C. ecornis ecornis (Ehrenberg, 1841) devido ao maior comprimento da teca (239-276 $\mu \mathrm{m})$. O presente 
estudo analisou cinco indivíduos que se encaixam nesta descrição, mas o histograma de toda a amostra (Fig. 52d) não demonstra possibilidade de separação destes dois táxons baseado em tamanho.

Centropyxis ecornis var. leidyi Thomas, 1957

Definida pela descrição original como distinta de C. ecornis ecornis (Ehrenberg, 1841) pela razão diâmetro da abertura/comprimento da teca. 0 presente trabalho encontrou 75 indivíduos que se encaixam nesta descrição, mas o gráfico de dispersão comprimento da teca vs. diâmetro da abertura (Fig. 53n) não mostra possibilidade de separação destes dois táxons baseado nestas características.

Centropyxis discoides var. grandistoma Chardez, 1966

Definida pela descrição original como distinta de C. discoides discoides Pènard, 1890 por possuir uma abertura relativamente maior (diâmetro da abertura 115-118 $\mu \mathrm{m})$, comprimento da teca entre 147-155 $\mu \mathrm{m}$ e altura da teca entre 21-25 $\mu \mathrm{m} .0$ presente trabalho encontrou 15 indivíduos que se encaixam nesta descrição, mas o gráfico de dispersão comprimento da teca vs. diâmetro da abertura (Fig. 53n) mostra que não existe separação entre estes dois táxons baseado nestas características.

DISCUSSÃO

Os dados obtidos no presente trabalho podem ser comparados com aqueles obtidos em levantamentos de autores prévios, a conclusão que segue é de que estes 
11 táxons nominais se referem à mesma entidade na natureza. Ainda assim, um intrínseco impedimento de qualquer trabalho taxonômico é explorar um número de aspectos que podem não refletir a variabilidade destes organismos. Caracteres citoplasmáticos e moleculares ainda não foram feitos, e existe uma possibilidade que futuros estudos desta natureza ainda dividam mais espécies crípticas, como visto em outros grupos de eucariotos. Em suma, medidas taxonômicas distintas devem ser tomadas quando se trata de protistas assexuados, de maneira a garantir estabilidade.

Portanto, apesar da evidência corrente nos levar à sinonimizar todos os táxons, é desejável que informações levantadas por autores prévios não seja perdida, por isso todos os táxons nominais foram agrupados em um único complexo não distinto morfolgicamente. Adicionalmente, variabilidade morfológica tradicionalmente descrita com táxons sub ou infra-subespecíficos nos informa sobre dados adicionais, como ecologia (Bobrov \& M Azel 2004). 


\section{Secção 3.}

Família Lesquereusiidae Jung, 1942 
A família Lesquereusiidae Jung, 1942 - originalmente proposta para acomodar somente o gênero Lesquereusia Schlumberger, 1845 - foi redefinida por OGDEN (1979) de maneira a acomodar todos os membros da subclasse Lobosia Carpenter, 1862 capazes de secretar elementos feitos de sílica e adicioná-los à teca. Atualmente, suspeita-se que a ordem Arcellinida (tecamebas com pseudópodes do tipo lobópode) esteja dentro do super-grupo Amoebozoa (Nicolaev et al. 2005) e a composição mais recente (Meisterfeld 2002) da família inclui os gêneros: Lesquereusia Schlumberger, 1895; Netzelia Ogden, 1979; Quadrulella Cockerell, 1909; Microquadrula Golemansky, 1968 e Pomoriella Golemansky, 1970.

A instituição desta família se compromete a um contexto de estabelecer critérios válidos para os táxons de tecamebas, de maneira a criar um sistema taxonômico abrangente, há muito necessário (OGDEN 1979). Entretanto, a definição dada aos Lesquereusiidade é circunscritiva, isto é, procura descrever a aparência de todos os táxons incluídos. Os aspectos negativos deste tipo de definição foram abordados em PATTERSON (1999) e não é recomendável usar este tipo de definição, pois permite que diferentes conceitos de inclusão existam ao mesmo tempo. Ainda, em concordância com o paradigma corrente na classificação de organismos - a sistemática filogenética - os esforços devem levar a criação de grupos holo ou monofiléticos.

A monofilia de Lesquereusiidae é questionável, uma vez que os membros inclusos compartilham afinidades com membros de outras famílias (MEISTERFELD, 
2000), principalmente em relação à morfologia da teca. Portanto, o caráter "elementos feitos de sílica de origem endógena" pode ser homoplástico.

Para construir um sistema taxonômico abrangente, ou um edifício de classificação, a discussão deve primeiramente ser baseada em seus blocos de construção - espécies e gêneros (LAHR \& LOPES, 2006) - estabelecendo critérios válidos para estes táxons.

No presente estudo foram registradas duas espécies de Lesquereusiidae: Netzelia wailesi (Ogden, 1980) e Lesquereusia modesta Rhumbler, 1895.

Os resultados aqui apresentados fornecem subsídios para uma discussão sobre o monofiletismo da família e apontam a necessidade de uma revisão no grupo. 
Gênero Netzelia Ogden, 1979

Netzelia wailesi (Ogden, 1980) 
Netzelia wailesi (Ogden, 1980)

Prancha VIII; Figs. 76 a 85

\author{
Sinônimos \\ Difflugia tuberculata - Pènard, 1902 (em parte) \\ D. tuberculata var. minor - Wailes, 1912:124 \\ D. tuberculata var. minor - Cash et Hopkinson, 1919:41 PI. 61, fig. 12, 13 \\ Difflugia wailesi - Ogden, 1980:130, figs. 23, 24, 25 \\ Netzelia wailesi - Meisterfeld, 1984:62 \\ Material Examinado: 463 espécimes sob MO, 10 espécimes sob MEV
}

\title{
Morfologia
}

Teca sub-esférica a ovóide, levemente afilada na região apertural (Figs. 76a, 77). Circular em secção transversal (Fig. 76b). Superfície da teca lisa, aspecto circular do contorno nunca é interrompido por partículas (Fig. 77) embora pequenas protuberâncias com aparência de tubérculos possam ser observadas em alguns espécimes; estas protuberâncias, no entanto, não são evidentes o suficiente para alterar o contorno e dar à teca um aspecto de amora (Fig. 78). Teca construída com partículas achatadas, grande quantidade de frústulas de diatomáceas e pequenos idiossomos em forma de prego, de natureza silicosa, todos embebidos em matriz orgânica (Figs. 78, Fig. 79, Fig. 80). Esta matriz cobre as superfícies interna e externa da teca (Fig. 81). Longos pilares estruturais cilíndricos estão localizados no interior da teca (Fig. 82). A malha perfurada do cimento em forma de rede pode ser 
vista entre as partículas aglutinadas (Figs. 79, 83). As perfurações comunicam 0 meio interno com o meio externo da teca.

Abertura terminal (Figs. 76a, 77), com 4-6 lobos em forma de pétala, delimitados por um colar levemente em alto-relevo composto de pequenas partículas - grãos de areia ou frústulas de diatomáceas - cimentados e cobertos por matriz orgânica (Figs. 84, 85). Um anel de 8-12 pequenos poros, imediatamente exterior ao colar, circunda a abertura (Fig. 85).

\section{Biometria}

A caracterização morfométrica em detalhes está na Tabela XII. Todos os caracteres apresentam alta variabilidade (CV = 19,12-19,62) e baixo erro padrão da média somente em diâmetro da abertura $(0,52)$. A análise de freqüência de medidas evidencia que todos os caracteres morfométricos têm distribuição normal e são caracterizados por uma larga amplitude. Entretanto, todos apresentam uma classe principal de medidas: para diâmetro da teca, $57,43 \%$ de todas as medidas estão entre 170-200 $\mu$ m; para altura da teca, 58,51\% das medidas estão entre 170-200 $\mu \mathrm{m}$; e para o diâmetro da abertura, 83,57\% estão entre 50-70 $\mu \mathrm{m}$. A Tabela XIII apresenta as razões entre os caracteres medidos. A Tabela XIV evidencia que todos os caracteres estão relacionados mutuamente.

\section{Ecologia e Distribuição Geográfica}

N. wailesi é encontrada em todo o mundo. Localidades registradas são sumarizadas por OGDEN \& MeISTERFELD (1989) a partir de amostras de algas, plantas aquáticas e Sphagnum. Para o Brasil, o sinônimo Difflugia tuberculata var. minor é registrado para o Rio de Janeiro (WAlLES 1912) e em associação com plantas aquáticas em Minas Gerais (DABÉs \& VeLHo 2001). 0 presente estudo encontrou 463 
indivíduos e os detalhes da exploração de habitat são sumarizados na Tabela XV. A maioria dos organismos $(58,42 \%)$ foi encontrada associada às raízes de plantas aquáticas no ambiente de água corrente. No entanto, muitos espécimes foram encontrados em outros habitats, comprovando que esta é uma espécie com amplo nicho ecológico.

Observações: Difflugia wailesi foi elevada ao status de espécie por OGDEN, (1980) a partir de indivíduos com a teca lisa descritos como uma forma pequena de Difflugia tuberculata Wallich 1864 por PÈnARD (1902), e D. tuberculata var. minor descrita por WAILES (1912), porém a descrição formal para este táxon, apesar de realizada em 1912, foi publicada somente em CASH et al. (1919). OGDEN (1980) considera que os espécimes de teca lisa observados por Pènard provavelmente pertencentes à Netzelia. A confirmação de que D. wailesi era capaz de produzir partículas de sílica foi dada por MeISTERFELD (1984) e a espécie foi então transferida para o gênero Netzelia. Mais tarde a espécie ganhou uma redescrição sob o mesmo nome, Netzelia wailesi (Ogden \& MeISTERfELd 1989). As observações do presente estudo estão de acordo com aquelas feitas por OGDEN (1980) e OGDEN \& MEISTERFELD (1989): a teca é lisa, podendo apresentar pequenos tubérculos e é recoberta por fina camada de matriz orgânica; a arquitetura da abertura, a forma e a composição da teca e o padrão da matriz orgânica cimentante são fundamentais na diagnose da espécie.

A abertura é como observada nas duas outras espécies do gênero ( $N$. tuberculata e N. oviformis) que compreende um colar elevado construído com pequenos idiossomos e/ou matriz orgânica (MeISTERfELd 2000). Uma vez que os organismos analisados no presente trabalho foram extraídos da natureza, onde 
existe disponibilidade de partículas de sílica, as tecas são principalmente compostas de material exógeno aglutinado, como observado em OGDEN \& MEISTERFELD (1989), e cobertos por uma camada de cimento, similar a N. oviformis, porém sensivelmente mais fina. Um pequeno número de partículas de sílica autógenas foi identificado nos espécimes estudados.

Comparados aos indivíduos de outras populações (OGDEN 1980, OGDEN \& Meisterfeld 1989), os observados no Rio Tietê possuem estrutura da superfície interna da teca suportada por longos pilares cilíndricos e são consideravelmente maiores. Ainda assim, a razão diâmetro da abertura/altura da teca é a mesma que a previamente observada para a população de Norfolk (OGDEN 1980). 
Gênero Lesquereusia Schlumberger, 1845

\section{Lesquereusia modesta Rhumbler, 1895}


Lesquereusia modesta Rhumbler, 1895

Prancha IX - Figs. 86 a 98

Sinônimos

Lecquereusia modesta Rhumbler, 1895:101, PI. IV fig. 2

Lesquereusia modesta Cash et Hopkinson, 1909:70, PI. XXII fig. 15, PI. XXIII

fig. 9

Material Examinado: 50 espécimes sob MO, 8 espécimes sob MEV

\section{Morfologia}

Teca ovóide (Figs. 86, 87, 88, 89), achatada lateralmente (Figs. 90, 91). Pescoço assimétrico, dobrado sobre o corpo. Superfície da teca lisa, contorno não interrompido por partículas aglutinadas. Um septo divide a teca internamente, ao longo da linha onde o pescoço encontra o corpo, até um ponto onde as duas cavidades se conectam. Teca construída por partículas de quartzo arredondadas e achatadas, frústulas de diatomáceas (Fig. 92) e partículas autógenas de sílica idiossomos - de morfologias variáveis (cilíndricos - Figs. 93, 94 em forma de prego Fig. 95). As partículas são aglutinadas por uma matriz orgânica cimentante estruturada em padrão de malha de rede (Figs. 92, 93, 94, 95). A matriz orgânica cobre o lado externo e interno da teca (Fig. 96, 97, 98).

Abertura terminal (Figs. 86a, 87), circular, rodeada de pequenas partículas cilindros de sílica, grânulos de quartzo e frústulas de diatomáceas - cimentados e cobertos pela matriz orgânica (Figs. 90, 97, 98). 


\section{Biometria}

Os detalhes da caracterização biométrica são apresentados na tabela XII. Todos os caracteres apresentam alta variabilidade (CV $=25,33-28,92$ ). 0 diâmetro da abertura apresenta o menor erro padrão da média. A análise de distribuição de freqüências das medidas evidencia que todos os caracteres possuem uma distribuição normal. Os caracteres apresentam uma grande amplitude de medidas. Entretanto, sempre existe uma classe principal de medidas: para largura da teca, 62\% das medidas estão entre 60-80 $\mu \mathrm{m}$; para altura da teca, $84 \%$ estão entre 100 $120 \mu \mathrm{m}$; para o diâmetro da abertura, 64\% estão entre 20-30 $\mu \mathrm{m}$. A Tabela XIII apresenta as razões de tamanho entre os caracteres medidos. A Tabela XIV evidencia que todas as medidas estão correlacionadas mutuamente, exceto largura da teca - altura da teca.

\section{Ecologia e Distribuição Geográfica}

Distribuição cosmopolita conforme sumarizado por THOMAS \& GAUTHIER-LIÈVRE (1959). Para a América do Sul os registros são: DefLANDRE (1926), BoLTOVsKoY \& LENA (1966, 1971), VUCETICH (1972). Registros prévios para o Brasil são de amostras de plâncton e/ou plantas aquáticas no Mato Grosso (GREen 1975, HARDoIM \& HECKMAN 1996), Mato Grosso do Sul (BonECKER et al. 1998), Paraná (LANSAC-TÔHA et al. 1997, VelHo et al. 1999), São Paulo (OLIVEIRA et al. 1992, DuRIGAN et al. 1992, Rolla et al. 1992), Goiás (LANSAC-TôHA et al. 1999, 2000) e Rio Grande do Sul (TORRES 1998). 0 presente estudo registrou L. modesta preferencialmente associada a raízes de plantas aquáticas (Tabela XV). Não há registro dessa espécie para os outros habitats 
amostrados, sugerindo que ela seja bastante seletiva em relação à exploração de habitat.

Observações: os resultados obtidos no presente trabalho concordam com observações feitas em outros trabalhos ultra-estruturais (OGDEN \& HedLEY 1980) e com microscopia óptica (Rhumbler 1895, Deflandre 1926, Thomas \& GaUTHIER-LiÈVRe 1959), no que se refere à forma e composição da teca. Novos dados para registro são: a possibilidade de aglutinação de frústulas de diatomáceas, idiossomos de morfologias diferentes e a maior amplitude de medidas. A espécie mais próxima é $L$. spiralis, que não aglutina partículas de quartzo ou frústulas de diatomáceas, e produz típicos idiossomos vermiformes, ausentes em L. modesta.

\section{DISCUSSÃO}

Os dados encontrados no presente trabalho aumentam o envelope das espécies estudadas, tanto para atributos morfológicos como para características morfométricas.

Além disso, o presente trabalho corrobora que as características para os níveis de gênero e espécie nesta família estão bem estabelecidas, sendo assim, pouca confusão pode surgir do estudo de organismos tão característicos. No entanto, a definição da família a partir de um método circunscritivo é preocupante, pois grandes são as chances de polifiletismo desta família, cujos integrantes são muito distintos e compartilham características com outras famílias, como Difflugiidae (Meisterfeld 2000). 


\section{Secção 4.}

\section{Família Arcellidae Ehrenberg, 1843}


A família Arcellidae Ehrenberg, 1843 formada por organismos com a teca rígida composta por unidades areolares orgânicas de construção, em geral de quitina, com a abertura arredondada, central, consta de três gêneros (MEISTERfELD 2000) dos quais apenas Arcella Ehrenberg, 1832 foi registrado na presente pesquisa.

O gênero Arcella compreende as tecamebas com pseudópodes do tipo lobópode capazes de construir toda a teca a partir de unidades de quitina em forma de caixote, geralmente hexagonais, o que resulta em uma superfície areolar. Existem mais de 50 espécies descritas, e muitas variedades e formas (MEISTERFELD 2000). As variedades foram, em sua maioria, descritas na primeira metade do século passado. Entretanto, muitas das descrições são incompletas e baseadas em poucos espécimes, como visto em outros grupos de tecamebas (LAHR \& LOPES 2006).

No presente trabalho os indivíduos coletados poderiam ser identificados em trinta táxons dentro do gênero, porém uma análise morfológica e biométrica comparativa entre os espécimes encontrados e a revisão da variabilidade reportada na literatura, sugere uma falta de caracteres diagnósticos para alguns dos táxons nominais. Com isso, dos 2433 indivíduos analisados, apenas quatro espécies foram consideradas, sendo o nome adotado o mais antigo disponível: Arcella discoides Ehrenberg, 1871; A. megastoma Pènard, 1902; A. polypora Pènard, 1890; A. hemisphaerica Perty, 1852; A. rotundata Playfair, 1918; A. gibbosa Pènard, 1890 e Arcella brasiliensis Cunha, 1913. 
As Tabelas XVI, XVII e XVIII apresentam todos os táxons nominais aos quais as espécies foram atribuídas, e compara-os com pesquisas prévias em relação a caracteres diagnósticos, amplitude morfométrica e localidades. Os táxons foram agrupados em grupos de entidades nominais não-distintas de acordo com os resultados do presente trabalho, o nome adotado para o grupo é o mais antigo disponível, de acordo com o Princípio da Prioridade. 
Gênero Arcella Ehrenberg, 1843

Arcella hemisphaerica Perty, 1852 
Arcella hemisphaerica Perty, 1852

Prancha X; Figs. 108 a 118

Táxons não-distintos previamente descritos

Arcella hemisphaerica Perty, 1852 Pl. 9 Fig. 5

Arcella vulgaris var. hemisphaerica, Wailes, 1913 PI. 59, Fig. 5

Arcella hemisphaerica fma undulata Deflandre, 1928: 214, Figs 122-124

Arcella hemisphaerica var depressa Playfair, 1918 PI. 34, Fig. 7

Arcella hemisphaerica var intermedia Deflandre, 1928: 215, figs 128-137

Arcella hemisphaerica var intermedia fma undulata Deflandre, 1928: 216, figs $138-140$

Arcella hemisphaerica var gibba Deflandre, 1928: 216, figs 141-148

Arcella hemisphaerica var playfairiana Deflandre, 1928: 217 figs 126, 127

Arcella hemisphaerica var tuberculata Stepanek, 1963: 56, figs 7, 54

Arcella rotundata Playfair, 1918, PI 34 fig 1

Arcella rotundata var stenostoma Deflandre, 1928: 233, figs 226-232

Arcella rotundata var stenostoma fma undulata Deflandre, 1928: 235, figs 233-234

Arcella rotundata var aplanata Deflandre, 1928: 235, figs 235-239

Arcella rotundata var alta Playfair, 1918 PI 34, fig 2

Arcella rotundata var alta fma undulata Stepanek, 1963: 58 figs 38, 40

Material Examinado: 1126 espécimes sob MO, 11 espécimes sob MEV 


\section{Morfologia}

Teca circular em vista apertural (Figs. 99, 100, 101), hemisférica em vista lateral (Figs. 102, 103, 104). Região abapertural pode ser provida de depressões de modo que a teca apresente uma aparência ondulada (Figs. 103, 104). Toda a teca é feita de material quitinoso construída a partir de unidades hexagonais ocas em forma de caixa (Figs. 105, 106, 107). Um pequeno poro (1-2 $\mu \mathrm{m})$ está presente em cada vértice de cada hexágono. Os hexágonos têm aparência inflada em ambas as regiões da teca (apertural e abapertural). Abertura central (Fig. 108), invaginada, circundada por um pequeno lábio recurvado (Fig. 109). Teca amarelo claro a marrom escuro. Provida de dois núcleos.

\section{Biometria}

Os detalhes da caracterização biométrica são apresentados na Tabela XIX. Todas as medidas são altamente variáveis (CV entre 11-16), porém dentro dos limites esperados para populações naturais de tecamebas (BoBrov \& MAZEI 2004). 0

diâmetro da abertura apresenta o mais baixo erro padrão da média $(0,098)$. A análise da freqüência de medidas mostra que o complexo Arcella hemisphaerica possui uma classe principal de tamanho e uma grande amplitude de medidas. Para diâmetro da teca, 77,7\% das medidas estão entre 55-65 $\mu$ m; para altura da teca, 96,1\% das medidas estão entre 25-35 $\mu \mathrm{m}$ e para diâmetro da abertura, $91,7 \%$ das medidas estão entre 15-25 $\mu \mathrm{m}$. As razões entre as características morfométricas são apresentadas na Tabela XX. Todas as características morfométricas estão positivamente correlacionadas entre si (Tabela XXI). 


\section{Ecologia e Distribuição Geográfica}

Esta espécie é conhecida para todos os continentes (OGdEN \& HedLEY 1980). Para o Brasil, os registros são para amostras de plâncton em Mato Grosso (GREen, 1975), Minas Gerais (DABÉS 1995, BONECKER et al. 1996); também foi registrada para amostras de macrófitas aquáticas em Mato Grosso (HARDolm \& HeCKMAN 1996). 0 presente trabalho encontrou a maioria dos indivíduos $(81,4 \%)$ associados às raízes de plantas aquáticas no ambiente de água corrente (o rio propriamente dito). Em um menor grau, indivíduos foram amostrados em outros micro-habitats, exceto no sedimento do rio (Tabela XXII).

Observações: A morfologia das tecas encontradas no presente estudo está de acordo com estudos ultra-estruturais (OGDEN \& HEDLEY 1980) e não apresenta contradições quando comparado a estudos morfológicos realizados sob MO (Tabela $\mathrm{XVI}$ ). Comparado aos estudos prévios, o complexo A. hemisphaerica em todo 0 mundo apresenta uma grande amplitude de medidas, e o presente estudo mostra a maior variação (Tabela XIX) dentro da mesma população, provavelmente devido ao tamanho da amostra. 
Gênero Arcella Ehrenberg, 1832

Arcella gibbosa Pènard, 1890 
Arcella gibbosa Pènard, 1890

Prancha Xl; Figs. 119 a 129

Táxons não-distintos previamente descritos

Arcella gibbosa - Pènard, 1890: 155, PI 5 figs 96-98, PI 6 fig 1

Arcella gibbosa var. levis - Deflandre, 1928: 229, fig 207

Arcella gibbosa var. mitriforms - Deflandre, 1928: 230, figs 208-218

Arcella gibbosa var. aplanata - Van Oye, 1956: 334 fig 4

Material Examinado: 106 espécimes sob MO, 14 espécimes sob MEV

\section{Morfologia}

Teca circular em vista apertural (Figs. 110, 111), perfil alto em vista lateral com um domo bem evidente (Figs. 112, 113, 114). Região abapertural provida de depressões bem demarcadas, variáveis em profundidade. Toda teca feita com material quitinoso construída a partir de unidades hexagonais ocas em forma de caixa (Figs. 115). Geralmente, na região abapertural, mais de um pequeno poro (1-2 $\mu m)$ está presente em cada vértice de cada hexágono (Figs. 116, 117), enquanto na região apertural, a maioria dos vértices é provida de um único poro (Figs. 118, 119). Hexágonos tem aparência inflada na região abapertural (Figs. 116, 117) e parecem colapsados na região apertural (Figs. 118, 119). Abertura central, invaginada e circundada por um lábio recurvado (Fig. 120). Teca amarelo claro a marrom escuro. Provida de dois núcleos. 


\section{Biometria}

Detalhes da caracterização morfométrica são apresentados na Tabela XIX. Todas as medidas são altamente variáveis (CV entre 17,7-27,6). Diâmetro da abertura apresenta 0 mais baixo erro padrão da média $(0,654)$. A análise de freqüência de medidas evidencia que o complexo Arcella gibbosa possui uma principal classe de medidas e uma grande amplitude de medidas para todos os caracteres analisados: para o diâmetro da teca, $75,47 \%$ das medidas estão entre 70-90 $\mu \mathrm{m}$; para altura da teca, 63,2\% das medidas estão entre $70-80 \mu \mathrm{m}$ e para 0 diâmetro da abertura, 94,3\% das medidas estão entre 10-20 $\mu \mathrm{m}$. As razões entre as características morfométricas são apresentadas na Tabela XX. Todas as características estudadas estão correlacionadas entre si (Tabela XXI).

\section{Ecologia e Distribuição Geográfica}

Registros desta espécie são para Europa, Américas do Sul e do Norte e África (OGDEN \& HedLey 1980). No Brasil, existem registros para amostras de plâncton em Mato Grosso (Green 1975), Minas Gerais (BonECKER et al. 1996, 1997), Goiás (LANSAC-TÔHA et al. 1999, 2000), Mato Grosso do Sul e Paraná (VelHo et al. 1996, 1999; LANSAC-TÔHA et al. 1997), para musgos no Rio de Janeiro (WAILES 1913) e macrófitas no Rio Grande do Sul (TORRES \& Jebram 1994). 0 presente trabalho registrou a maioria dos indivíduos $(68,1 \%)$ associados a raízes de plantas aquáticas no ambiente de água parada. Organismos foram encontrados nos outros microhabitats, exceto o sedimento do Rio (Tabela XXII).

Observações: A morfologia das tecas encontradas no presente estudo está de acordo com estudos ultra-estruturais (OGden \& Hedley 1980, Meisterfeld 2000) e não apresenta contradições quando comparado a estudos morfológicos realizados 
sob MO (Tabela XVII). Comparativamente, o complexo A. gibbosa ao redor do mundo possui uma grande amplitude de medidas, e o presente estudo apresenta a maior variação dentro de uma mesma população (Tabela XIX) provavelmente devido ao grande tamanho da amostra. 
Gênero Arcella Ehrenberg, 1832

Arcella discoides Ehrenberg, 1871 
Arcella discoides Ehrenberg, 1871

Pranchas XIla, Xllb; Figs. 130 a 141

Táxons não-distintos previamente descritos

Arcella discoides - Ehrenberg, 1871: 259, PL 3 fig 1

Arcella discoides var. difficilis - Deflandre, 1929: 257, figs 327,328

Arcella discoides var. scutelliformis - Playfair, 1918, PI 34, fig 8

Arcella discoides var. foveosa - Playfair, 1918, PI 34, fig 9

Arcella discoides var. pseudovulgaris - Deflandre, 1928: 261, fig 340-344

Arcella discoides var. pseudovulgaris fma. undulata - Deflandre, 1928: 261, fig 345

Arcella discoides var. pseudovulgaris fma. arcuata - Deflandre, 1928: 261, fig 346-348

Arcella polypora - Pènard, 1890: 156 Pl 8, figs 2, 9

Arcella polypora var. curvata - Deflandre, 1928: 265 figs 357-362;

Arcella megastoma - Pènard, 1902: 409

Arcella megastoma fma. arcuata - Deflandre, 1928: 268, figs 373-374

Material Examinado: 1198 espécimes sob MO, 19 espécimes sob MEV.

\section{Morfologia}

Teca circular a elíptica em vista abapertural (Figs. 121, 122, 123), achatada em forma de disco em vista lateral (Figs. 121, 125, por vezes arqueada (Figs. 126, 127) - tecas arqueadas tem aparência elíptica em vista apertural. Toda a teca é construída por material quitinoso a partir de unidades ocas em forma de caixa, 
grosseiramente hexagonais (Fig. 128, 129, 130). 0 padrão conspícuo criado pelas unidades de construção não é visível na região abapertural, devido a uma camada de cobertura adicional (Fig. 131, 132, 133), que pode cobrir toda a região abapertural de maneira homogênea (Fig. 134). Na região apertural não há camada de cobertura, portanto, o padrão areolar é visível, e as unidades de construção são colapsadas (Fig. 135). Abertura central, circular na maioria dos casos, elíptica nos organismos que apresentam a teca arqueada, o eixo longo da abertura é perpendicular ao eixo longo da teca (Fig. 135, 136, 137, 138), delimitada por um pequeno lábio curvado (Fig. 139). Um anel de poros, em geral de 3 um de diâmetro cada, localiza-se circundando a abertura. Este anel não está presente em todos os organismos. Teca amarelo claro a marrom escuro, tecas grandes $(>300 \mu \mathrm{m})$ em geral apresentam um tom verde escuro no topo da região abapertural. Provida de um número variável de núcleos (dois ou mais).

\section{Biometria}

Os detalhes da caracterização morfométrica são apresentados na Tabela XIX. Todas as medidas são altamente variáveis (CV entre 29,2-40,7), altura da teca apresenta 0 menor erro padrão da média $(0,255)$. A análise de freqüência de medidas mostra que o complexo Arcella discoides possui uma classe principal de medidas e uma grande amplitude de medidas para todos os caracteres: para diâmetro da teca, $72,78 \%$ das medidas estão entre 100-150 $\mu \mathrm{m}$; para altura da teca, $69,86 \%$ das medidas estão entre $20-30 \mu \mathrm{m}$ e para diâmetro da abertura, $65,18 \%$ das medidas estão entre $50-100 \mu \mathrm{m}$. As razões entre as características morfométricas são apresentadas na Tabela XX. Todas as características estudadas estão correlacionadas mutuamente (Tabela XXI). 


\section{Ecologia e distribuição geográfica}

Há registros desta espécie para as Américas, Europa, África, Ásia e Austrália (OGDEN \& Hedley 1980). No Brasil, registros são para amostras de musgos no Rio de Janeiro (CUnHA 1913, Walles 1913), amostras de plâncton para o Ceará (CunHA 1913), Mato Grosso (Green 1975, Hardolm \& HeCKMAn 1996), Goiás (LansaC-TôHa et al. 2000), São Paulo (Durigan et al. 1992, OlivelRA et al. 1992, SipaúBA-TAVARES et al. 1995), Minas Gerais (Dabés 1995), Mato Grosso do Sul (DAdAY 1905; VelHo et al. 1996, 1999; LANSAC-TÔHA et al. 1997; BONECKER et al. 1998) e Paraná (LOPES 1993; NUNES et al. 1996; VelHo et al. 1996, 1999; LANSAC-TÔHA et al. 1997). O presente estudo encontrou a maioria dos indivíduos associados às raízes de plantas aquáticas tanto no Rio $(57,7 \%)$ quanto no lago (33\%). De um total de 2433 indivíduos pertencentes ao gênero Arcella, esta foi a única espécie amostrada no sedimento do Rio (Tabela XXII).

Observações: A morfologia das tecas encontradas no presente estudo está de acordo com estudos ultra-estruturais (OGDEN \& HEDLEY 1980) e não apresenta nenhuma contradição quando comparada com estudos realizados sob MO (Tabela XVIII). Comparativamente, o complexo A. discoides ao redor do mundo apresenta uma grande amplitude de medidas, e o presente trabalho mostra maior variação encontrada para uma mesma população, provavelmente devido ao tamanho da amostra. A principal característica que separaria A. megastoma seria o número de núcleos, mas este é um caráter extremamente variável e parece aumentar com 0 tamanho da teca. A. polypora seria distinta pelo anel de poros ao redor da abertura, mas este anel é visto em outros táxons nominais comprovando ser ambíguo demais para uma característica diagnóstica. 
Gênero Arcella Ehrenberg, 1841

\section{Arcella brasiliensis Cunha, 1913}


Arcella brasiliensis Cunha, 1913

Prancha XIII; Figs. 150 a 155

Material Examinado: 5 espécimes sob MO, 1 espécime sob MEV

\section{Morfologia}

Teca circular em vista apertural (Figs. 140, 141), hemisférica em vista lateral, com uma carena marginal distinta (Fig. 152). Superfície abapertural provida de depressões, que dão a teca um aspecto ondulado. Região apertural lisa. Teca construída a partir de unidades em forma de caixa hexagonais e ocas (Fig. 143), por vezes um poro está presente em um vértice (Fig. 144). Abertura circular, central, invaginada (Fig. 145), circundada por um lábio soerguido (Fig. 146). Teca amarelo claro a marrom.

\section{Biometria}

Detalhes da caracterização morfométrica são apresentados na Tabela XIX. Todas as medidas são altamente variáveis (CV entre 10,6 - 26,1), diâmetro da abertura apresenta o menor erro padrão da média $(3,74)$. As razões entre as características morfométricas são apresentadas na Tabela XX.

\section{Ecologia e Distribuição Geográfica}

Esta espécie está registrada apenas para o Brasil, no Rio de Janeiro (CUNHA 1913), Minas Gerais (DABÉs 1995), Goiás (LANSAC-TÔHA et al. 2000), Mato Grosso do Sul e Paraná (VelHo et al. 1996, LANSAC-TôHA et al. 1997). O presente estudo amostrou somente cinco indivíduos, portanto, esta é uma espécie rara no Rio Tietê (Tabela XXIII). 
Observações: descrições prévias (CunHA 1913, Deflandre 1928, Velho et al. 1996) retratam esta espécie com um domo abapertural liso, mas os indivíduos analisados no presente estudo eram todos providos de pequenas depressões, dando a impressão de uma teca ondulada. 0 desenho da descrição original apresenta a carena marginal provida de um padrão alternado de areolações, mas DefLANDRE (1928) atribui este padrão a uma ilusão de óptica. 0 estudo ultra-estrutural mostra a ausência de tal padrão alternado de areolações. 0 presente estudo encontrou uma maior amplitude de medidas que previamente reportado (DeflandRE 1928, VelHo et al. 1996).

DISCUSSÃo

0 presente trabalho encontrou quatro entidades bastante distintas morfologicamente. Os complexos Arcella hemisphaerica, A. gibbosa, A. discoides e A. brasiliensis apresentam caracteres de distinção únicos, e também, podem ser diferenciadas a partir das razões entre suas medidas.

A. hemisphaerica possui um característico contorno de semicírculo em vista lateral; A. gibbosa apresenta depressões e costelas; A. discoides possui um perfil bastante achatado em forma de calota e A. brasiliensis possui uma carena ao longo da ondulação marginal. Estas características permitem identificar com facilidade estes organismos.

As razões entre as medidas morfométricas também trazem interessantes caracteres de distinção, em especial, a razão altura da teca/diâmetro da teca. DeflandRe (1928) dividiu o gênero em quatro grupos, não filogenéticos: as "altas", 
com razão at/ dt próxima de 1; as "hemisféricas", com razão at/ dt próxima de 0,5; as "baixas" com razão at/dt próxima de 0,3; e as "carenadas" que apresentam uma carena ao longo da ondulação marginal. Curiosamente, cada uma das quatro espécies encontradas no presente estudo se encaixa em cada uma das quatro categorias estabelecidas por Deflandre, no entanto, o presente estudo conta com um número de observações biométricas sem precedentes na literatura (Tabela XX).

No âmbito da nomenclatura, o presente trabalho corrobora mais uma vez a necessidade de revisões abrangentes nos grupos menos inclusivos de tecamebas. A quantidade de táxons nominais não distintos encontrada evidencia que pesquisadores realizaram poucos estudos comparativos entre as espécies do gênero Arcella.

Se as determinações do ICZN (RIDE et al. 1999) forem seguidas, mais explicitamente as determinações para o grupo de espécie e o Princípio da Coordenação explicitados na Introdução deste trabalho, um problema mais imediato surge: os táxons descritos como infrasubespecificos, em geral, utilizam a mesma denominação como por exemplo, Arcella megastoma fma. arcuata e Arcella discoides fma. arcuata, ambas descritas por DefLANDRE (1928). Seguindo o artigo 45 e o Princípio da Coordenação, ambos os táxons seriam Arcella arcuata Deflandre, 1928, estão, a princípio, se referindo a organismos diferentes. Este é somente um exemplo de um fato bastante comum que somente uma revisão que levante todos os nomes existentes pode resolver.

A solução proposta no presente trabalho, quando não é o caso de uma revisão completa, é tratar todos os nomes sob uma única entidade operacionalmente distinta, e listar todos os nomes indistinguíveis sob o nome mais 
antigo. Desta maneira, a informação taxonômica contida na literatura tradicional não se perde, evitando o aparecimento de nomes antigos com autoridades novas; ainda, o conceito taxonômico que 0 autor mais recente utilizou fica explícito, e pode ser contestado. 
Discussão Final 


\section{DISCUSSÃO}

A variação morfométrica das tecamebas encontradas no Rio Tietê é a mais extensa já reportada. A Tabela VI mostra pesquisas com grande amostragem, assim como os dados biométricos obtidos para o gênero Difflugia, para todos os outros gêneros, resultados similares foram encontrados.

Altas variações também foram obtidas para algumas espécies em BoBRov \& MAZE (2004), onde se observou que o caráter mais variável é o diâmetro da abertura. 0 presente estudo difere e apresenta este caráter com os menores valores relativos de coeficiente de variação, para a maioria das espécies. BoBrov \& MAZEI (2004) usaram uma série de dados de numerosas localidades e a variação por eles observada pode refletir pressões seletivas de vários fatores ecológicos. Uma única população, como a encontrada no Rio Tietê, deve, portanto, apresentar pouca variação em características altamente selecionadas.

A alta variação observada é, em parte, conseqüência do grande número de indivíduos investigados. Pode ser também atribuída a fatores ecológicos como microhabitats e abrangências ambientais grandes, uma vez que o Rio Tietê é altamente poluído. Consequentemente, mais adaptação específica a nichos ocorreria.

Atributos de cada espécie apresentam distribuições normais. Uma classe principal de medidas está sempre presente, e estudos que confiam em um número reduzido de indivíduos estão inclinados a registrar dados com uma abrangência de medidas limitada. Este tipo de trabalho traz boas estimativas da média, decorrência da presença de uma classe principal, mas subestima a amplitude. 
O aumento na amplitude de atributos leva a maior sobreposição entre espécies nominais descritas anteriormente, e deveria nos levar a questionar a validade de alguns daqueles táxons.

Apesar de não haver consenso sobre o conceito de espécie para protistas assexuados, tanto como categoria ou como táxon (SONNEBORN 1957, MeISTERfeld 1979, Wanner 1999, Mayr 2001, Schlegel \& Meisterfeld 2003), o fato de que somos capazes de separar entidades distintas não é ponto de disputa. As entidades podem ser determinadas, e se são espécies ou não, em qualquer instância, é uma questão distinta. Estas entidades são o objetivo de nosso estudo. Colocar nomes em sinonímia não resolve o problema por inteiro - não sabemos se são realmente sinônimos, devido à incompatibilidade entre estudos prévios e contemporâneos - e não deixa explicito se é interpretação ou ação objetiva.

As análises realizadas no presente estudo corroboram a necessidade de estudos como delineados por BOBRov \& MAZEI (2004): revelar a variabilidade morfológica de populações em várias localidades; fazer análise biométrica detalhada dentro de complexos de espécies proximamente relacionadas; realizar trabalho taxonômico cauteloso e levar as limitações ecológicas em conta ao estudar tecamebas, pois isso é essencial para um melhor entendimento das populações naturais. Adicionalmente, estressamos que análises detalhadas da taxonomia e inovação são necessárias para resolução de problemas relacionados à incompatibilidade entre pesquisas recentes e antigas.

Ao lidar com protistas assexuados, onde nenhum consenso de espécie foi estabelecido, é fundamental tomar medidas cautelosas quando os dados levam a juntar ou separar táxons. Medidas radicais como observado em MEDIOLI \& SCOTT 
(1983) podem provocar muita confusão. 0 estudo de C. aculeata e táxons similares delineado no presente trabalho poderiam levar um taxonomista a sinonimizar todos os táxons.

Outros pesquisadores já encontraram evidências de que os limites das espécies podem estar superestimados para outros grupos de eucariotos unicelulares, principalmente devido a melhores procedimentos de amostragem (PATterson \& Lee 2000, com flagelados heterotróficos). Entretanto, levando todas as variáveis em conta, como falta de tipos, localidades distantes, diferentes métodos de estudo e impedimentos intrínsecos do trabalho morfológico, as sinonímias resultantes não seriam objetivas. Nestes casos, a informação sobre táxons levantada por autores prévios deve ser preservada.

Logo, separar informação objetiva de dados interpretados, e claridade em relação a dados não interpretados é requerida. Pesquisas assim vão avançar em direção a discussões mais frutíferas sobre o conceito taxonômico para protistas assexuados. Adicionalmente, preservar os conceitos de autores prévios irá ajudar em identificar importantes formas ecológicas, como demonstrado aqui para Difflugia ecornis e Centropyxis ecornis.

As amplitudes de atributos morfológicos e morfométricos observados para todas as famílias sustentam que o conhecimento da variabilidade em populações naturais de tecamebas é no mínimo subestimado. Também, a paucidade de registros para uma espécie tão conspícua como A. brasiliensis indica considerável sub-amostragem em populações naturais, um problema fundamental em práticas protozoológicas (FINLAY 2002, FINLAY et al. 2004, FOISSNER 1999a). 
Amostragem e trabalho taxonômico em regiões menos estudadas do globo contribuirão para o conhecimento de populações naturais de tecamebas. 
Tabelas 
Tabela I. Caracterização biométrica dos espécimes de Difflugia investigadas no Rio Tietê. Os caracteres são como designados nas Figs. 5, 19, 25, 35, 43. Medidas em $\mu m$. x - média aritmética; M - mediana; SD - desvio padrão; SE - erro padrão da média; CV - coeficiente de variação em \%; Min - mínimo; Max - máximo; $n$ - número de espécimes investigados.

\begin{tabular}{|c|c|c|c|c|c|c|c|c|}
\hline Caracteres & $\overline{\mathrm{X}}$ & $M$ & SD & $\mathrm{SE}$ & $\mathrm{CV}$ & Min & $\operatorname{Max}$ & $\mathrm{n}$ \\
\hline \multicolumn{9}{|l|}{ Difflugia corona } \\
\hline comprimento da teca & 192.1 & 200.0 & 48.36 & 1.85 & 25.2 & 80.0 & 380.0 & 683 \\
\hline diâmetro da teca & 189.8 & 200.0 & 48.76 & 1.87 & 25.7 & 80.0 & 360.0 & 683 \\
\hline diâmetro da abertura & 91.6 & 100.0 & 26.22 & 1.00 & 28.6 & 30.0 & 200.0 & 683 \\
\hline comp. de espinhos & 37.5 & 40.0 & 12.07 & 0.49 & 32.2 & 10.0 & 100.0 & 607 \\
\hline número de espinhos & 3.0 & 4.0 & 2.03 & 0.11 & 67.0 & 0.0 & 10.0 & 337 \\
\hline \multicolumn{9}{|l|}{ Difflugia gramen } \\
\hline comprimento da teca & 108.0 & 100.0 & 20.21 & 1.46 & 18.7 & 80.0 & 160.0 & 192 \\
\hline diâmetro da teca & 92.3 & 80.0 & 29.07 & 2.10 & 31.5 & 50.0 & 160.0 & 192 \\
\hline diâmetro da abertura & 38.0 & 40.0 & 10.94 & 0.79 & 28.7 & 20.0 & 80.0 & 192 \\
\hline \multicolumn{9}{|l|}{ Difflugia lanceolata } \\
\hline comprimento da teca & 174.8 & 180.0 & 26.37 & 2.16 & 15.1 & 80.0 & 240.0 & 149 \\
\hline diâmetro da teca & 75.1 & 80.0 & 13.83 & 1.13 & 18.4 & 40.0 & 120.0 & 149 \\
\hline diâmetro da abertura & 39.6 & 40.0 & 6.84 & 0.56 & 17.3 & 20.0 & 80.0 & 149 \\
\hline \multicolumn{9}{|l|}{ Difflugia claviformis } \\
\hline comprimento da teca & 226.5 & 220.0 & 65.05 & 6.12 & 28.7 & 110.0 & 380.0 & 113 \\
\hline diâmetro da teca & 88.0 & 80.0 & 24.27 & 2.28 & 27.6 & 60.0 & 200.0 & 113 \\
\hline diâmetro da abertura & 49.3 & 40.0 & 11.83 & 1.11 & 24.0 & 40.0 & 90.0 & 113 \\
\hline \multicolumn{9}{|l|}{ Difflugia gigantea } \\
\hline comprimento da teca & 380.0 & 420.0 & 78.10 & 26.03 & 20.6 & 280.0 & 460.0 & 9 \\
\hline diâmetro da teca & 204.4 & 200.0 & 32.83 & 10.94 & 16.1 & 180.0 & 280.0 & 9 \\
\hline diâmetro da abertura & 86.7 & 80.0 & 14.14 & 4.71 & 16.3 & 80.0 & 120.0 & 9 \\
\hline
\end{tabular}


Tabela II. Coeficiente de correlação entre as caracterísicas morfométricas nas espécies de Difflugia estudadas no Rio Tietê. Caracteres como designados nas Figs 5, 19, 25, 35, 43. n - número de espécimes estudados; NAnão aplicável.

\begin{tabular}{|c|c|c|c|c|c|c|c|c|c|c|}
\hline Espécie (n) & ct-dt & ct-da & dt-da & ce-ct & ce-dt & ce-da & ne-ct & ne-dt & ne-da & ne-ce \\
\hline Difflugia corona $(n=t)$ & $0.93 *$ & $0.84 *$ & $0.85^{*}$ & $0.41 *$ & $0.44^{*}$ & $0.42 *$ & $0.16 * *$ & $0.12^{\mathrm{NS}}$ & $0.17^{* *} *$ & $0.18^{\mathrm{NS}}$ \\
\hline Difflugia gramen $(n=192)$ & $0.72 *$ & $0.50 *$ & $0.58 *$ & NA & NA & NA & NA & NA & NA & NA \\
\hline Difflugia lanceolata $(n=149)$ & $0.66 *$ & $0.45^{*}$ & $0.75^{*}$ & NA & NA & NA & NA & NA & NA & NA \\
\hline Difflugia claviformis ( $n=113$ ) & $0.70 *$ & $0.72 *$ & $0.58 *$ & NA & NA & NA & NA & NA & NA & NA \\
\hline
\end{tabular}

†- para as relações ct-dt, ct-da e dt-da $n=683$; para ce-ctl, ce-dt e ce-da $n=608$; para ne-ct, ne-dt, ne-da e ne-ce $\mathrm{n}=261$. * $\mathrm{p}<0.001 ; * * \mathrm{p}<0.01$. NS - não significativo 
Tabela III. Razões morfométricas entre os caracteres estudados para a população de Difflugia do Rio Tietê. Caracteres como designados nas Figs 5, 19, 25, 35, 43. SD desvio padrão; $n$ - número de espécimes estudados.

\begin{tabular}{llll}
\hline Espécie $(n)$ & $\mathrm{dt} / \mathrm{ct}(\mathrm{SD})$ & $\mathrm{da} / \mathrm{ct}(\mathrm{SD})$ & $\mathrm{da} / \mathrm{dt}(\mathrm{SD})$ \\
\hline Difflugia corona $(\mathrm{n}=683)$ & $0.99(0.11)$ & $0.48(0.08)$ & $0.49(0.08)$ \\
Difflugia gramen $(\mathrm{n}=192)$ & $0.85(0.20)$ & $0.35(0.09)$ & $0.43(0.11)$ \\
Difflugia lanceolata $(\mathrm{n}=149)$ & $0.43(0.07)$ & $0.23(0.04)$ & $0.53(0.08)$ \\
Difflugia claviformis $(\mathrm{n}=113)$ & $0.40(0.10)$ & $0.23(0.06)$ & $0.58(0.13)$ \\
Difflugia gigantea $(\mathrm{n}=9)$ & $0.55(0.11)$ & $0.24(0.05)$ & $0.43(0.08)$ \\
\hline
\end{tabular}


Tabela IV. Exploração de habitat das espécies de Difflugia estudadas do Rio Tietê. Números em \%.

\begin{tabular}{lcccc}
\hline Espécie (n) & \multicolumn{2}{c}{ Lago } & \multicolumn{2}{c}{ Rio } \\
& Sedimento & Raízes & Sedimento & Raízes \\
\hline & & & & \\
Difflugia corona (683) & 26.06 & 46.76 & 9.15 & 18.03 \\
Difflugia gramen (192) & 40.51 & 22.05 & 3.08 & 34.36 \\
Difflugia lanceolata (149) & 0.00 & 3.57 & 9.29 & 87.14 \\
Difflugia claviformis (113) & 5.60 & 6.40 & 64.00 & 24.00 \\
Difflugia gigantea (9) & 33.33 & 33.33 & 33.33 & 0.00 \\
\hline
\end{tabular}


Tabela V. Localidades e exploração do habitat de Difflugia corona . P - presente no micro-habitat. N - não presente ou não amostrada no micro-habitat. ? - amostragem não específicada pelo autor.

\begin{tabular}{|c|c|c|c|c|c|}
\hline \multirow[b]{2}{*}{ Localidades } & \multirow{2}{*}{\multicolumn{2}{|c|}{$\begin{array}{l}\text { Sedimento } \\
\text { Ôn }\end{array}$}} & \multicolumn{2}{|c|}{ Perifíton } & Plâncton \\
\hline & & & Lên & Lót & Lên Lót \\
\hline
\end{tabular}

Difflugia corona

Europa e Ásia

Kunratice, Praga, República Tcheca (Stepanek 1952)

Lunz, Áustria (Laminger, 1972)

Ardennes, Bélgica (Chardez, 1961)

Penza, Rússia (Bobrov et Mazei, 2004)

Hampshire, Inglaterra (Ogden et Hedley, 1980)

Vlasina lake, Sérvia e Montenegro (Ogden et Zivkovic, 1983)

$\begin{array}{cccccc}\mathrm{P} & \mathrm{N} & \mathrm{P} & \mathrm{N} & \mathrm{N} & \mathrm{N} \\ \mathrm{N} & \mathrm{P} & \mathrm{N} & \mathrm{N} & \mathrm{N} & \mathrm{N} \\ \mathrm{P} & \mathrm{N} & \mathrm{P} & \mathrm{N} & \mathrm{N} & \mathrm{N} \\ \mathrm{N} & \mathrm{P} & \mathrm{N} & \mathrm{N} & \mathrm{N} & \mathrm{N} \\ ? & ? & ? & ? & ? & ? \\ \mathrm{~N} & \mathrm{~N} & \mathrm{~N} & \mathrm{~N} & \mathrm{P} & \mathrm{N}\end{array}$

África

Sanhadja e La Calle, Algéria (Gauthier-Lièvre et Thomas, 1958)

Sangalkam, Senegal (Gauthier-Lièvre et Thomas, 1958)

Gao, República de Mali (Gauthier-Lièvre et Thomas, 1958)

Banfora e Tiogo, Burkina-Faso (Gauthier-Lièvre et Thomas, 1958)

Abéché e Oum Hadjer, Chade (Gauthier-Lièvre et Thomas, 1958)

N'Djolé, Gabão (Gauthier-Lièvre et Thomas, 1958)

$\begin{array}{llllll}\mathrm{N} & \mathrm{P} & \mathrm{N} & \mathrm{N} & \mathrm{N} & \mathrm{N} \\ \mathrm{N} & \mathrm{P} & \mathrm{N} & \mathrm{N} & \mathrm{N} & \mathrm{N} \\ \mathrm{N} & \mathrm{P} & \mathrm{N} & \mathrm{N} & \mathrm{N} & \mathrm{N} \\ \mathrm{P} & \mathrm{P} & \mathrm{N} & \mathrm{N} & \mathrm{N} & \mathrm{N} \\ \mathrm{N} & \mathrm{P} & \mathrm{N} & \mathrm{N} & \mathrm{N} & \mathrm{N} \\ \mathrm{N} & \mathrm{P} & \mathrm{N} & \mathrm{N} & \mathrm{N} & \mathrm{N}\end{array}$

América do Sul

San Fernando de Apure e Guarico, Venezuela (Deflandre 1926)

Puerto Nuevo, Buenos Aires, Argentina (Boltovskoy, 1956)

Rio San Felipe, Buenos Aires, Argentina (Vucetich, 1972)

Ushuaia, SF, Formosa e Eurioica, Argentina (Vucetich, 1973)

Buenos Aires, Argentina (Boltovskoy et Lena, 1971)

Contaco River, Osorno, Chile (Zapata et al. , 2002)

$\begin{array}{llllll}\mathrm{N} & \mathrm{N} & \mathrm{N} & \mathrm{N} & \mathrm{P} & \mathrm{P} \\ \mathrm{N} & \mathrm{P} & \mathrm{N} & \mathrm{N} & \mathrm{N} & \mathrm{N} \\ \mathrm{N} & \mathrm{N} & \mathrm{P} & \mathrm{N} & \mathrm{N} & \mathrm{N} \\ \mathrm{N} & \mathrm{N} & \mathrm{P} & \mathrm{N} & \mathrm{N} & \mathrm{N} \\ \mathrm{N} & \mathrm{N} & \mathrm{P} & \mathrm{N} & \mathrm{N} & \mathrm{N} \\ \mathrm{N} & \mathrm{P} & \mathrm{N} & \mathrm{N} & \mathrm{N} & \mathrm{N}\end{array}$

Brasil

Rio de Janeiro (Cunha, 1913)

Santa Vitória do Palmar, RS (Closs et Madeira, 1962)

Tramandaí Lagoon, RS (Closs et Madeira, 1967)

Northern Pantanal, MT (Hardoim et Heckman, 1996)

Vale do Rio Suia Missu, Mato Grosso (Green, 1975)

Rio São Francisco, Três Marias, Minas Gerais (Dabés, 1995)

Lagoa Mirim, Rio Grande do Sul (Closs et Medeiros, 1967)

Alto Paraná, MS (Velho et Lansac-Tôha, 1996)

Rio Tietê, São Paulo (presente estudo)

\begin{tabular}{llllll}
$?$ & $?$ & $?$ & $?$ & $?$ & $?$ \\
$\mathrm{~N}$ & $\mathrm{P}$ & $\mathrm{N}$ & $\mathrm{N}$ & $\mathrm{N}$ & $\mathrm{N}$ \\
$\mathrm{P}$ & $\mathrm{N}$ & $\mathrm{N}$ & $\mathrm{N}$ & $\mathrm{N}$ & $\mathrm{N}$ \\
$\mathrm{N}$ & $\mathrm{P}$ & $\mathrm{N}$ & $\mathrm{P}$ & $\mathrm{N}$ & $\mathrm{N}$ \\
$\mathrm{N}$ & $\mathrm{N}$ & $\mathrm{N}$ & $\mathrm{N}$ & $\mathrm{P}$ & $\mathrm{N}$ \\
$\mathrm{N}$ & $\mathrm{N}$ & $\mathrm{N}$ & $\mathrm{N}$ & $\mathrm{P}$ & $\mathrm{N}$ \\
$\mathrm{P}$ & $\mathrm{N}$ & $\mathrm{N}$ & $\mathrm{N}$ & $\mathrm{N}$ & $\mathrm{N}$ \\
$\mathrm{N}$ & $\mathrm{N}$ & $\mathrm{N}$ & $\mathrm{N}$ & $\mathrm{P}$ & $\mathrm{P}$ \\
$\mathrm{P}$ & $\mathrm{P}$ & $\mathrm{P}$ & $\mathrm{P}$ & $\mathrm{N}$ & $\mathrm{N}$ \\
\hline
\end{tabular}


Tabela И. Comparações morfométricas entre diferentes populações das espécies de Difflugia investigadas. Caracteres como designados nas Figs 5, 19, 25, 35, 43. Eixos.Medidas em $\mu \mathrm{m}$. ? - não informado.

\begin{tabular}{|c|c|c|c|c|c|c|c|}
\hline Referências & $\mathrm{dt}$ & ct & da & la & ce & ne & $\mathrm{n}$ \\
\hline \multicolumn{8}{|l|}{ Difflugia corona } \\
\hline Daday (1905) & $?$ & 230 & $?$ & $6-12$ & $?$ & $5-7$ & $?$ \\
\hline Deflandre (1926) & $240-260$ & $216-225$ & $?$ & $?$ & $?$ & $4-6$ & $?$ \\
\hline Stepanek (1952) & $105-175$ & $?$ & $35-70$ & $?$ & $5-35$ & 1 & $?$ \\
\hline Boltovskoy (1956) & $100-240$ & $?$ & $?$ & $6-14$ & $?$ & $0-10$ & $?$ \\
\hline Gauthier-Lièvre et Thomas (1958) & $120-190$ & $110-200$ & $50-80$ & $>12$ & $?$ & $6-10$ & $?$ \\
\hline Closs et Madeira (1962) & $120-330$ & $?$ & $?$ & $5-20$ & $?$ & $<7$ & $?$ \\
\hline Closs et Madeira (1967) & $100-270$ & $?$ & $?$ & $?$ & $?$ & 0 & $?$ \\
\hline Vucetich (1972) & $130-180$ & $135-200$ & $?$ & $8-10$ & $?$ & $4-6$ & $?$ \\
\hline Vucetich (1973) & $130-180$ & $135-200$ & $50-80$ & $?$ & $?$ & $?$ & $?$ \\
\hline Ogden et Hedley (1980) & $141-176$ & $137-189$ & $51-83$ & $12-20$ & $?$ & $?$ & 10 \\
\hline Ogden et Zvkovic (1983) & $126-177$ & $126-190$ & $53-86$ & $10-16$ & $?$ & $2-8$ & 14 \\
\hline Dekhtyar (1993) & $112.0-120.0$ & $112.3-128.2$ & $59.4-66.7$ & & $24-32$ & & 10 \\
\hline Torres et Jebram (1994) & $130-180$ & $135-200$ & $50-80$ & $?$ & $?$ & $?$ & $?$ \\
\hline Velho et Lansac-Tôha(1996) & 119-189 & $121-196$ & $56-75$ & $?$ & $?$ & $?$ & 10 \\
\hline Blanco (2001) & $50-230$ & $50-220$ & $20-90$ & $?$ & $?$ & $0-7$ & 200 \\
\hline Zapata et al. (2002) & $?$ & 110-195 & $?$ & 8-12 & $?$ & $>2$ & $?$ \\
\hline Bobrov et Mazei (2004) & $132.5-184.5$ & $141-210$ & $8.5-86.1$ & $?$ & $?$ & $?$ & 65 \\
\hline presente estudo & $80-330$ & $80-380$ & $30-200$ & $9-15$ & $10-100$ & $0-10$ & 683 \\
\hline \multicolumn{8}{|l|}{ Difflugia gramen } \\
\hline Stepanek (1952) & 105 & 112 & 42 & 3 & CA & CA & $?$ \\
\hline Gauthier-Lièvre et Thomas (1958) & $43-70$ & $60-80$ & $?$ & 3 & CA & CA & $?$ \\
\hline Stepanek et J iri (1958) & $53.4-64.7$ & 70.8-92.4 & $17.5-28$ & 3 & CA & CA & 100 \\
\hline Vucetich (1972) & $56-64$ & $75-90$ & $19-27$ & 3 & CA & CA & $?$ \\
\hline Velho et Lansac-Tôha (1996) & $64-75$ & $78-97$ & $23-29$ & 3 & CA & CA & 10 \\
\hline Ogden (1980) & $70-112$ & 89-117 & 23-39 & 3 & CA & CA & 35 \\
\hline Ogden (1983) & $42-75$ & $61-97$ & $18-33$ & $3-4$ & CA & CA & 44 \\
\hline
\end{tabular}




\begin{tabular}{|c|c|c|c|c|c|c|c|}
\hline Referências & $\mathrm{dt}$ & $\mathrm{ct}$ & da & la & ce & ne & $\mathrm{n}$ \\
\hline Ogden et Hedley (1980) & $80-98$ & $68-95$ & $28-36$ & 3 & CA & CA & 4 \\
\hline Yugoslavia (Ogden et Meisterfeld 1989) & $50.5-81.1$ & $69.3-90$ & $24.3-32.4$ & $3-4$ & CA & CA & 25 \\
\hline Suffolk (Ogden et Meisterfeld 1989) & $50.4-88.0$ & 68.9-97.4 & 19.6-33.3 & $3-4$ & CA & CA & 36 \\
\hline Norfolk (Ogden et Meisterfeld 1989) & $69.8-112.2$ & 89-121.9 & 23.2-39.1 & $3-4$ & CA & CA & 35 \\
\hline Bobrov and Mazei (2004) & $39.5-77.5$ & $57.0-85.5$ & $15.9-36.0$ & 3 & CA & CA & 40 \\
\hline presente estudo & $50-160$ & $80-160$ & $20-80$ & $3-4$ & CA & CA & 192 \\
\hline \multicolumn{8}{|l|}{ Difflugia lanceolata } \\
\hline Decloitre (1954) & $66-68$ & 110-130 & $20-36$ & CA & CA & CA & 2 \\
\hline Gauthier-Liévre et Thomas (1958) & $48-60$ & $120-190$ & $20-25$ & CA & CA & CA & ? \\
\hline Ogden (1983) & $56-92$ & $108-155$ & $22-32$ & CA & CA & CA & 38 \\
\hline Ogden et Hedley (1980) & $46-72$ & $116-159$ & $23-28$ & CA & CA & CA & 4 \\
\hline Bobrov and Mazei (2004) & $40.5-84.5$ & $87.5-189.5$ & $21-54$ & CA & CA & CA & 82 \\
\hline presente estudo & $40-120$ & $80-240$ & $20-80$ & $\mathrm{CA}$ & CA & CA & 149 \\
\hline \multicolumn{8}{|l|}{ Difflugia claviformis } \\
\hline Penard (1899) & $130-200$ & $390-435$ & $?$ & CA & CA & CA & $?$ \\
\hline Ogden (1979) & $105-123$ & $288-316$ & $34-40$ & CA & CA & CA & 2 \\
\hline Ogden et Hedley (1980) & 97-196 & 247-393 & $33-62$ & CA & CA & CA & 12 \\
\hline presente estudo & $60-200$ & $110-380$ & $40-90$ & $C A$ & CA & CA & 113 \\
\hline \multicolumn{8}{|l|}{ Difflugia gigantea } \\
\hline Chardez (1967) & $?$ & $450-580$ & $?$ & CA & CA & CA & $?$ \\
\hline Ogden et Fairman (1979) & $168-231$ & $341-480$ & $55-84$ & $C A$ & CA & CA & 7 \\
\hline presente estudo & $180-280$ & $280-460$ & $80-120$ & CA & CA & CA & 9 \\
\hline
\end{tabular}


Tabela VII. Localidades e exploração de habitat de Difflugia gramen . P - presente no microhabitat. $\mathrm{N}$ - não presente ou não amostrada nohabitat. ? - amostragem não especificada pelo autor.

\begin{tabular}{ll}
\hline & Sedimento Períiton Plâncton \\
Localidades & Lên Lót Lên Lót Lên Lót \\
\hline
\end{tabular}

Difflugia gramen

Europa

Norfolk, Inglaterra (Ogden 1980, Ogden et Meisterfeld 1989)

Suffolk, Inglaterra (Ogden 1983, Ogden et Meisterfeld 1989)

Vlasina, Sérvia e Montenegro (Ogden et Meisterfeld 1989)

Praga, República Tcheca (Štěpánek 1952)

Bohemia, República Tcheca (Štěpánek et Jiř́ 1958)

$\begin{array}{llllll}\mathrm{N} & \mathrm{N} & \mathrm{P} & \mathrm{N} & \mathrm{N} & \mathrm{N} \\ \mathrm{N} & \mathrm{N} & \mathrm{N} & \mathrm{P} & \mathrm{N} & \mathrm{N} \\ \mathrm{N} & \mathrm{N} & \mathrm{N} & \mathrm{N} & \mathrm{P} & \mathrm{N} \\ \mathrm{N} & \mathrm{N} & \mathrm{N} & \mathrm{N} & \mathrm{N} & \mathrm{P} \\ \mathrm{N} & \mathrm{N} & \mathrm{N} & \mathrm{N} & \mathrm{N} & \mathrm{P}\end{array}$

África

Rabat e Settat, Marrocos (Gauthier-Lièvre et Thomas 1958)

Sanhadja, La Calle, Algéria (Gauthier-Lièvre et Thomas 1958)

Sangalkam, Senegal (Gauthier-Lièvre et Thomas 1958)

Tabarka, Tunísia (Gauthier-Lièvre et Thomas 1958)

$\begin{array}{llllll}N & P & N & N & N & N \\ N & P & N & N & N & N \\ N & P & N & N & N & N \\ N & P & N & N & N & N\end{array}$

América do Sul

San Fernando de Apure e Guarico, Venezuela (Deflandre 1926)

Formosa, Argentina (Vucetich 1970, 1973)

Buenos Aires, Argentina (Vucetich 1972, 1973)

Corrientes, Argentina (Vucetich 1973, 1978)

$\begin{array}{llllll}\mathrm{N} & \mathrm{N} & \mathrm{N} & \mathrm{N} & \mathrm{P} & \mathrm{P} \\ \mathrm{N} & \mathrm{N} & \mathrm{N} & \mathrm{P} & \mathrm{N} & \mathrm{N} \\ \mathrm{N} & \mathrm{N} & \mathrm{P} & \mathrm{N} & \mathrm{N} & \mathrm{N} \\ \mathrm{N} & \mathrm{N} & \mathrm{P} & \mathrm{N} & \mathrm{N} & \mathrm{P}\end{array}$

Brasil

Rio de Janeiro, RJ (Wailes 1911, Cunha 1913)

Vale do Rio Suia Missu, MT (Green, 1975)

Rio São Francisco, Três Marias, MG (Dabés, 1995)

Alto Paraná, MS (Velho et Lansac-Tôha, 1996)

Represa Lomba do Sabão, RS (Torres et Schwarzbold 2002)

Rio Tietê, SP (presente estudo)

\begin{tabular}{llllll}
$?$ & $?$ & $?$ & $?$ & $?$ & $?$ \\
$\mathrm{~N}$ & $\mathrm{~N}$ & $\mathrm{~N}$ & $\mathrm{~N}$ & $\mathrm{P}$ & $\mathrm{N}$ \\
$\mathrm{N}$ & $\mathrm{N}$ & $\mathrm{N}$ & $\mathrm{N}$ & $\mathrm{P}$ & $\mathrm{N}$ \\
$\mathrm{N}$ & $\mathrm{N}$ & $\mathrm{N}$ & $\mathrm{N}$ & $\mathrm{P}$ & $\mathrm{P}$ \\
$\mathrm{N}$ & $\mathrm{N}$ & $\mathrm{P}$ & $\mathrm{N}$ & $\mathrm{N}$ & $\mathrm{N}$ \\
$\mathrm{P}$ & $\mathrm{P}$ & $\mathrm{P}$ & $\mathrm{P}$ & $\mathrm{N}$ & $\mathrm{N}$ \\
\hline
\end{tabular}


Tabela VIII. Caracterização biométrica dos espécimes de Centropyxis do Rio Tietê. Caracteres como designados na Fig 54. Medidas em $\mu \mathrm{m}$. $\mathrm{x}$ - média aritimética; $M$ mediana; SD - desvio padrão; SE - erro padrão da média; CV - coeficiente de variação em \%; Min - mínimo; Max - máximo; n - número de espécimes investigados.

\begin{tabular}{|c|c|c|c|c|c|c|c|c|}
\hline Caracteres & $x$ & $M$ & Min & $\operatorname{Max}$ & SD & SE & $\mathrm{CV}$ & $n$ \\
\hline \multicolumn{9}{|l|}{ Todos táxons } \\
\hline diâmetro da teca & 159.4 & 160.0 & 60.0 & 400.0 & 41.72 & 0.91 & 26.2 & 2120 \\
\hline comprimento da teca & 157.3 & 160.0 & 80.0 & 400.0 & 41.92 & 0.91 & 26.7 & 2109 \\
\hline altura da teca & 41.5 & 40.0 & 20.0 & 150.0 & 11.85 & 0.26 & 28.6 & 2120 \\
\hline diâmetro da abertura & 71.2 & 70.0 & 30.0 & 200.0 & 20.42 & 0.44 & 28.7 & 2120 \\
\hline comp. de espinhos & 30.7 & 30.0 & 10.0 & 100.0 & 10.36 & 0.23 & 33.8 & 1957 \\
\hline número de espinhos & 3.8 & 4.0 & 0.0 & 10.0 & 1.99 & 0.07 & 53.0 & 882 \\
\hline \multicolumn{9}{|l|}{ C. aculeata } \\
\hline diâmetro da teca & 149.4 & 150.0 & 80.0 & 320.0 & 33.32 & 1.01 & 22.3 & 1086 \\
\hline comprimento da teca & 146.7 & 140.0 & 80.0 & 400.0 & 33.42 & 1.02 & 22.8 & 1076 \\
\hline altura da teca & 41.7 & 40.0 & 20.0 & 120.0 & 10.33 & 0.31 & 24.8 & 1086 \\
\hline diâmetro da abertura & 66.0 & 60.0 & 30.0 & 160.0 & 17.24 & 0.52 & 26.1 & 1086 \\
\hline comp. de espinhos & 33.2 & 35.0 & 10.0 & 100.0 & 10.16 & 0.31 & 30.6 & 1084 \\
\hline número de espinhos & 4.4 & 4.0 & 1.0 & 8.0 & 1.27 & 0.07 & 28.6 & 320 \\
\hline \multicolumn{9}{|l|}{ C. discoides } \\
\hline diâmetro da teca & 166.1 & 160.0 & 80.0 & 400.0 & 45.87 & 1.53 & 27.6 & 901 \\
\hline comprimento da teca & 164.5 & 160.0 & 80.0 & 400.0 & 46.17 & 1.54 & 28.1 & 901 \\
\hline altura da teca & 40.0 & 40.0 & 20.0 & 150.0 & 12.20 & 0.41 & 30.5 & 901 \\
\hline diâmetro da abertura & 75.6 & 75.0 & 30.0 & 200.0 & 21.96 & 0.73 & 29.0 & 901 \\
\hline comp. de espinhos & 27.4 & 30.0 & 10.0 & 90.0 & 9.66 & 0.33 & 35.2 & 868 \\
\hline número de espinhos & 4.3 & 4.0 & 1.0 & 10.0 & 1.40 & 0.07 & 32.6 & 431 \\
\hline \multicolumn{9}{|l|}{ C. ecornis } \\
\hline diâmetro da teca & 192.4 & 200.0 & 100.0 & 380.0 & 37.04 & 3.30 & 19.3 & 126 \\
\hline comprimento da teca & 189.5 & 200.0 & 100.0 & 380.0 & 36.79 & 3.28 & 19.4 & 126 \\
\hline altura da teca & 47.8 & 50.0 & 20.0 & 80.0 & 12.89 & 1.15 & 27.0 & 126 \\
\hline diâmetro da abertura & 83.4 & 80.0 & 40.0 & 180.0 & 19.77 & 1.76 & 23.7 & 126 \\
\hline
\end{tabular}


Tabela IX. Razões morfométricas para as populações estudadas de Centropyxis no Rio Tietê. Caracteres como designados na Fig. 54. SD - desvio padrão; $n$ - número de espécimes estudados; NA - não aplicável.

\begin{tabular}{ccccc}
\hline Razão & Todos (2120) & C. aculeata (1086) & C. ecornis (901) & C. discoides (126) \\
\hline ct/dt (SD) & $0.99(0.05)$ & $0.98(0.06)$ & $0.99(0.05)$ & $0.99(0.04)$ \\
at/dt (SD) & $0.27(0.07)$ & $0.29(0.07)$ & $0.25(0.06)$ & $0.25(0.06)$ \\
$\mathrm{da} / \mathrm{dt}$ (SD) & $0.45(0.07)$ & $0.44(0.07)$ & $0.46(0.06)$ & $0.43(0.06)$ \\
$\mathrm{da} / \mathrm{at}(\mathrm{SD})$ & $1.78(0.52)$ & $1.63(0.46)$ & $1.96(0.52)$ & $1.85(0.64)$ \\
$\mathrm{ce} / \mathrm{da}(\mathrm{SD})$ & $0.43(0.24)$ & $0.53(0.22)$ & $0.37(0.19)$ & $\mathrm{NA}$ \\
$\mathrm{ce} / \mathrm{at}$ (SD) & $0.72(0.35)$ & $0.83(0.32)$ & $0.69(0.29)$ & $\mathrm{NA}$ \\
$\mathrm{ce} / \mathrm{dt}(\mathrm{SD})$ & $0.19(0.09)$ & $0.23(0.08)$ & $0.16(0.07)$ & $\mathrm{NA}$ \\
\hline
\end{tabular}


Tabela X. Coeficiente de correlação entre as espécies de Centropyxis estudadas no Rio Tietê. Caracteres como designados na Fig 54. n - número de espécimes; NA - não aplicável.

\begin{tabular}{|c|c|c|c|c|}
\hline Correlação & Todos táxons $(1947 \dagger)$ & C. aculeata $(1089 \dagger)$ & C. discoides (868†) & C. ecomis (126) \\
\hline dt-ct & $0.98 *$ & $0.97 *$ & $0.99 *$ & $0.97 *$ \\
\hline dt-at & $0.55^{*}$ & $0.48 *$ & $0.67 *$ & $0.47 *$ \\
\hline$d t-d a$ & $0.84 *$ & $0.78^{*}$ & $0.87 *$ & $0.75^{*}$ \\
\hline dt-ce & $0.24 *$ & $0.21 *$ & $0.43 *$ & NA \\
\hline dt-ne & $0.11 * *$ & $0.23 *$ & $0.04 \mathrm{NS}$ & NA \\
\hline ct-at & $0.54 *$ & $0.48 *$ & $0.67 *$ & $0.44 *$ \\
\hline ct-da & $0.84 *$ & $0.78 *$ & $0.88 *$ & $0.76^{*}$ \\
\hline ct-ce & $0.25 *$ & $0.22 *$ & $0.44^{*}$ & NA \\
\hline ct-ne & $0.11 * *$ & $0.21 *$ & $0.05 \mathrm{NS}$ & NA \\
\hline at-da & $0.44^{*}$ & $0.41 *$ & $0.54 *$ & $0.46 *$ \\
\hline at-ce & $0.30 *$ & $0.19 *$ & $0.41 *$ & NA \\
\hline at-ne & $0.05 \mathrm{NS}$ & $0.12 *$ & $0.22 *$ & NA \\
\hline da-ce & $0.18^{*}$ & $0.18 *$ & $0.35 *$ & NA \\
\hline da-ne & $0.15^{*}$ & $0.19 *$ & $0.13 * *$ & NA \\
\hline ce-ne & $0.10 * *$ & $0.18 *$ & $0.08 \mathrm{NS}$ & NA \\
\hline
\end{tabular}

$* \mathrm{p}=0.001 ; * * 0.01>\mathrm{p}>0.001$; NS não significaivo; $\dagger$ quando 0 caráter ne é analisado, o número de espécimes é: Todos táxons $=755, C$. aculeata $=325, C$. discoides $=431$ 
Tabela XI. Exploração de habitat dos espécimes de Centropyxis estudadas no Rio Tietê. Números em \%. n - número de espécimes

\begin{tabular}{lcccc}
\hline \multicolumn{1}{c}{ Espécie $(\mathrm{n})$} & \multicolumn{2}{c}{ Rio } & \multicolumn{2}{c}{ Lago } \\
& Raízes & Sedimento & Raízes & Sedimento \\
\hline Todos táxons $(\mathrm{n}=2120)$ & 52.64 & 26.65 & 18.92 & 1.79 \\
C. aculeata $(\mathrm{n}=1093)$ & 56.27 & 24.52 & 16.93 & 2.29 \\
C. discoides $(\mathrm{n}=901)$ & 51.72 & 24.97 & 22.20 & 1.11 \\
C. ecornis $(\mathrm{n}=126)$ & 27.78 & 57.14 & 12.70 & 2.38 \\
\hline
\end{tabular}


Tabela XII. Caracterização biométrica das espécies de Lesquereusia estudadas no presente trabalho. Caracteres como designados nas Figs 76, 86, 99. Medidas em $\mu \mathrm{m}$. $\mathrm{x}$ - média aritimética; $M$ - mediana; SD - desvio padrão; SE - erro padrão da média; CV - coeficiente de variação em \%; Min - mínimo; Max - máximo; $n$ - número de espécimes investigados.

\begin{tabular}{lcccccccc}
\hline Espécie & $\mathrm{X}$ & $\mathrm{M}$ & $\mathrm{Min}$ & $\mathrm{Max}$ & $\mathrm{SD}$ & $\mathrm{SE}$ & $\mathrm{CV}$ & $\mathrm{n}$ \\
\hline N. wailesi & & & & & & & & \\
largura da teca & 180.41 & 180.0 & 100.0 & 320.0 & 35.40 & 1.65 & 19.62 & 463 \\
altura da teca & 183.33 & 180.0 & 100.0 & 340.0 & 35.28 & 1.64 & 19.25 & 463 \\
diâmetro da abertura & 58.23 & 60.0 & 40.0 & 100.0 & 11.13 & 0.52 & 19.12 & 463 \\
& & & & & & & & \\
L. modesta & & & & & & & & \\
largura da teca & 86.80 & 80.0 & 60.0 & 160.0 & 21.99 & 3.11 & 25.33 & 50 \\
altura da teca & 111.20 & 100.0 & 80.0 & 200.0 & 27.15 & 3.84 & 24.42 & 50 \\
diâmetro da abertura & 31.10 & 30.0 & 20.0 & 60.0 & 8.99 & 1.27 & 28.92 & 50 \\
\hline
\end{tabular}


Tabela XIII. Razões morfométricas para as populações estudadas de Lesquereusia no Rio Tietê. Caracteres como designados nas Figs 76, 86. SD desvio padrão; $\mathrm{n}$ - número de espécimes estudados.

\begin{tabular}{llll}
\hline Espécie $(n)$ & It/at (SD) & da/lt (SD) & da/at (SD) \\
\hline L. modesta $(n=50)$ & $0.79(0.11)$ & $0.38(0.14)$ & $0.29(0.1)$ \\
N. wailesi $(n=463)$ & $0.99(0.15)$ & $0.33(0.07)$ & $0.32(0.06)$ \\
\hline
\end{tabular}


Table XIV. Coeficiente de correlação entre as espécies de Lesquereusia estudadas no Rio Tietê. Caracteres como designados nas Figs 76, 86. $n$ - número de espécimes; NS - não significativo.

\begin{tabular}{lccc}
\hline Espécie $(\mathrm{n})$ & It-at & It-da & at-da \\
\hline N. wailesi $(\mathrm{n}=463)$ & 0.76 & 0.42 & 0.48 \\
L. modesta $(\mathrm{n}=50)$ & 0.81 & $0.06 \mathrm{NS}$ & $0.10 \mathrm{NS}$ \\
\hline $\mathrm{p}<0.001$ & & &
\end{tabular}


Tabela XV. Exploração de habitat das espécies de Lesquereusia estudadas no Rio Tietê. Números em \%. n - número de espécimes

\begin{tabular}{lcccc}
\hline Espécie $(\mathrm{n})$ & \multicolumn{2}{c}{ Lago } & \multicolumn{2}{c}{ Rio } \\
& Sedimento & Raízes & Sedimento & Raízes \\
\hline & & & & \\
N. wailesi $(\mathrm{n}=463)$ & 10.28 & 58.42 & 15.98 & 15.32 \\
L. modesta $(\mathrm{n}=50)$ & 0.00 & 98.00 & 0.00 & 2.00 \\
\hline
\end{tabular}


Tabela XM: Comparações morfométricas entre diferentes populações dos táxons nominais de entidades relacionadas a Arcella hemisphaerica investigados. Caracteres como designados na Fig 108. Medidas em $\mu \mathrm{m}$. ? - não informado.

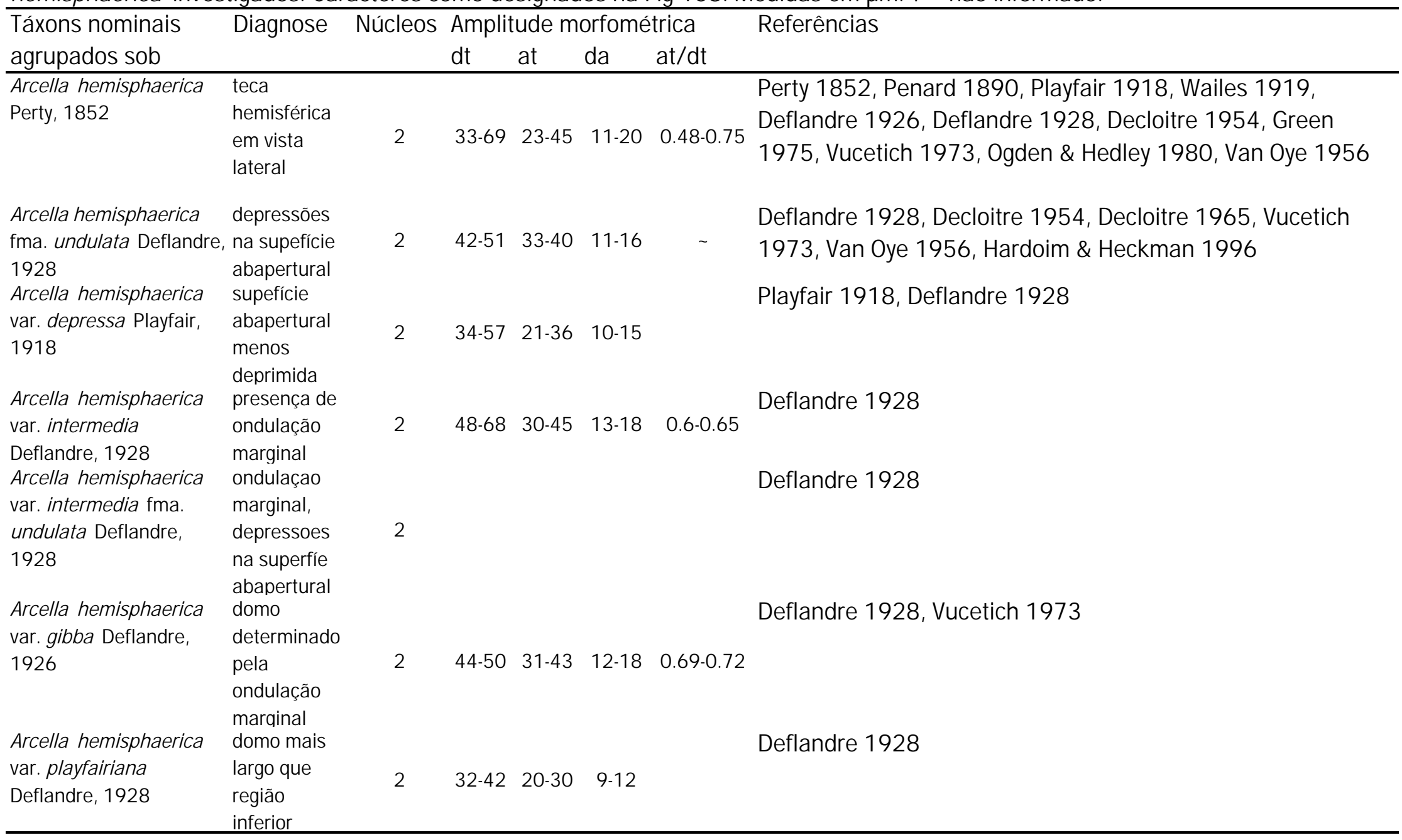




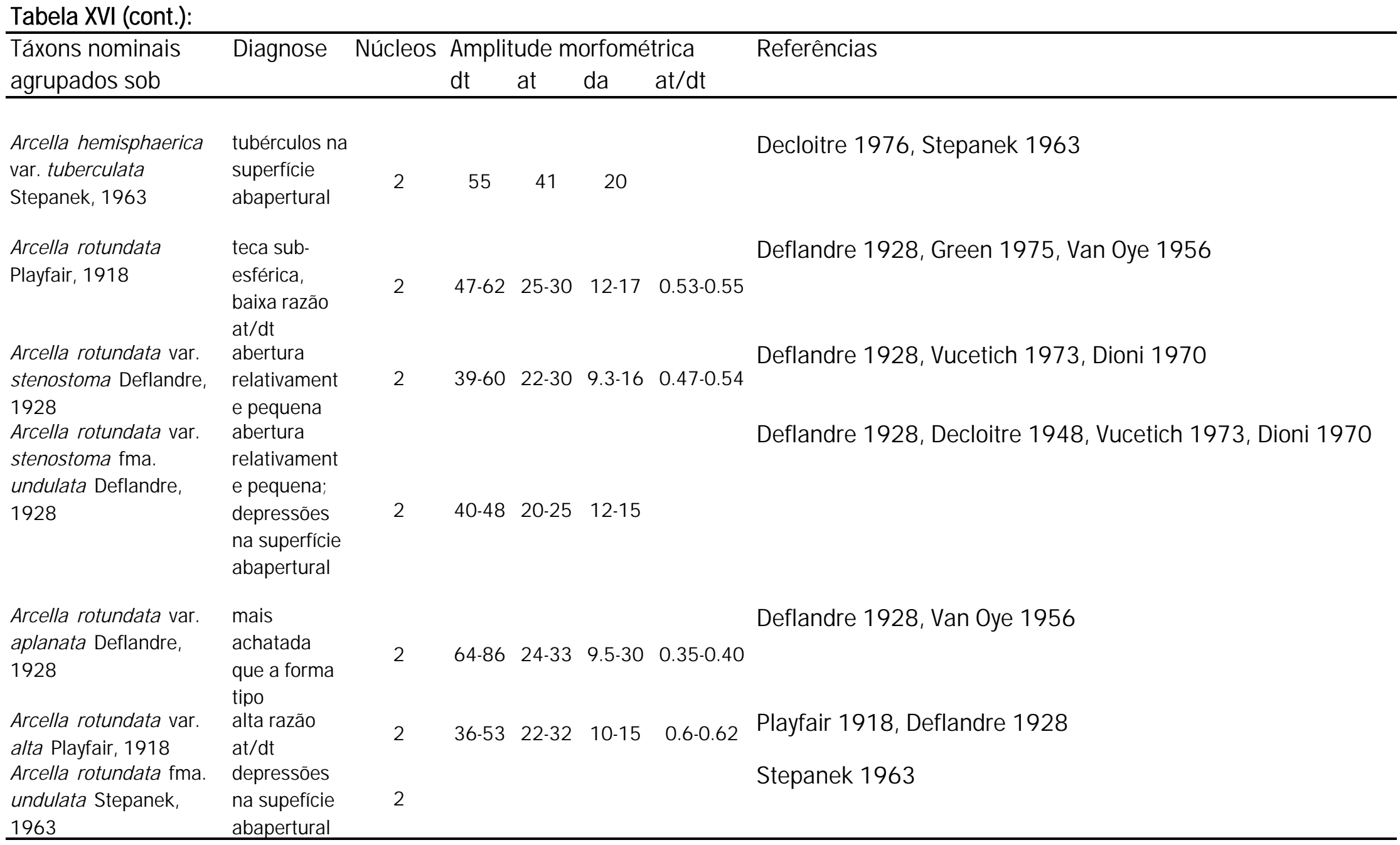


Tabela XMI: Comparações morfométricas entre diferentes populações dos táxons nominais de entidades relacionadas a Arcella gibbosa investigados. Caracteres como designados na Fig 119. Medidas em um. ? - não informado.

\begin{tabular}{|c|c|c|c|c|c|c|c|}
\hline \multirow[t]{2}{*}{ Táxons nominais } & \multirow[t]{2}{*}{ Diagnose } & \multirow[t]{2}{*}{ Núcleos } & \multicolumn{4}{|c|}{ Amplitude morfométrica } & \multirow[t]{2}{*}{ Referências } \\
\hline & & & $\mathrm{dt}$ & at & da & at/dt & \\
\hline $\begin{array}{l}\text { Arcella gibbosa Penard, } \\
1890\end{array}$ & $\begin{array}{l}\text { teca com domo circular; } \\
\text { hemisférica em vista } \\
\text { lateral; depressões } \\
\text { regulares na superfície } \\
\text { abapertural }\end{array}$ & 2 & $70-140$ & $45-80$ & $18-32$ & $0.53-0.69$ & $\begin{array}{l}\text { Deflandre 1928, Decloitre } \\
\text { 1948, Decloitre 1954, } \\
\text { Green 1975, Vucetich } \\
\text { 1973, Velho } 1996\end{array}$ \\
\hline $\begin{array}{l}\text { Arcella gibbosa var. levis } \\
\text { Deflandre, } 1928\end{array}$ & superfície abapertural lisa & & $90-95$ & 60 & 30 & & $\begin{array}{l}\text { Deflandre 1928, Dioni } \\
1970\end{array}$ \\
\hline $\begin{array}{l}\text { Arcella gibbosa var. } \\
\text { mitriformis Deflandre, } \\
1928\end{array}$ & $\begin{array}{l}\text { domo abapertural + alto; } \\
\text { alto at/ dt }\end{array}$ & & $55-95$ & $46-90$ & $14-28$ & $0.63-0.94$ & $\begin{array}{l}\text { Deflandre 1928, Decloitre } \\
\text { 1948, Decloitre 1954, } \\
\text { Vucetich } 1973\end{array}$ \\
\hline $\begin{array}{l}\text { Arcella gibbosa var. } \\
\text { aplanata Van Oye, } 1956\end{array}$ & $\begin{array}{l}\text { domo abapertural + baixo; } \\
\text { baixa at/ dt }\end{array}$ & & 55 & & 15 & 0.27 & $\begin{array}{l}\text { Van Oye 1956, Decloitre } \\
1976\end{array}$ \\
\hline
\end{tabular}


Tabela XMII: Comparações morfométricas entre diferentes populações dos táxons nominais de entidades relacionadas a Arcella discoides investigados. Caracteres como designados na Fig 130. Medidas em $\mu m$. ? - não informado.

\begin{tabular}{|c|c|c|c|c|c|c|c|}
\hline \multirow[t]{2}{*}{ Táxons nominais } & \multirow[t]{2}{*}{ Diagnose } & \multirow[t]{2}{*}{ Núc. } & \multicolumn{4}{|c|}{ Amplitude morfométrica } & \multirow[t]{2}{*}{ Referências } \\
\hline & & & $\mathrm{dt}$ & at & da & at/ dt & \\
\hline $\begin{array}{l}\text { Arcella discoides } \\
\text { Ehrenberg, } 1871\end{array}$ & $\begin{array}{l}\text { baixa at/ dt; circular } \\
\text { em vista apertural }\end{array}$ & 2 & $90-157$ & $25-57.3$ & $21-52$ & $0.2-0.25$ & $\begin{array}{l}\text { Deflandre 1928, Decloitre 1948, } \\
\text { Green 1975, Vucetich 1973, } \\
\text { Dioni 1970, Hardoim and } \\
\text { Heckman 1996, Velho } 1996\end{array}$ \\
\hline $\begin{array}{l}\text { Arcella discoides var. } \\
\text { difficilis Deflandre, } 1928\end{array}$ & ondulação marginal & & $108-128$ & $25-36$ & $37-48$ & 0.25 & Deflandre 1928 \\
\hline $\begin{array}{l}\text { Arcella discoides var. } \\
\text { scutelliformis Playfair, } 1918\end{array}$ & $\begin{array}{l}\text { mais alta que o tipo; } \\
\text { alto at/ dt }\end{array}$ & & 44-95 & $25-37$ & $14-34$ & $0.29-0.34$ & Deflandre 1928, Van Oye 1956 \\
\hline $\begin{array}{l}\text { Arcella discoides var. } \\
\text { foveosa Playfair, } 1918\end{array}$ & $\begin{array}{l}\text { depressões na } \\
\text { superfície } \\
\text { abapertural }\end{array}$ & & $53-78$ & $25-38$ & $18-28$ & $0.3-0.35$ & Playfair 1918, Deflandre 1928 \\
\hline $\begin{array}{l}\text { Arcella discoides var } \\
\text { pseudovulgaris Deflandre, } \\
1928\end{array}$ & ondulação marginal & & $76-128$ & 25-39 & $20-48$ & $0.27-0.29$ & Deflandre 1928 \\
\hline $\begin{array}{l}\text { Arcella discoides var. } \\
\text { pseudovulgaris forma } \\
\text { undulata Deflandre, } 1928\end{array}$ & $\begin{array}{l}\text { ondulação marginal; } \\
\text { depressões na } \\
\text { superfície } \\
\text { abapertural }\end{array}$ & 2 & $118-122$ & $25-40$ & $42-50$ & & Deflandre 1928 \\
\hline
\end{tabular}


Tabela XMII (cont.):

\begin{tabular}{|c|c|c|c|c|c|c|c|}
\hline \multirow[t]{2}{*}{ Táxons nominais } & \multirow[t]{2}{*}{ Diagnose } & \multirow[t]{2}{*}{ Núc. } & \multicolumn{4}{|c|}{ Amplitude morfométrica } & \multirow[t]{2}{*}{ Referências } \\
\hline & & & $\mathrm{dt}$ & at & da & at/ dt & \\
\hline $\begin{array}{l}\text { Arcella polypora Penard, } \\
1890\end{array}$ & $\begin{array}{l}\text { anel de poros } \\
\text { circunda a abertura }\end{array}$ & $6-20$ & $75-200$ & $25-42$ & $37-43$ & $0.2-0.29$ & Penard 1980, Deflandre 1928 \\
\hline $\begin{array}{l}\text { Arcella polypora var. } \\
\text { curvata Deflandre, } 1928\end{array}$ & $\begin{array}{l}\text { teca arqueada em } \\
\text { vista lateral }\end{array}$ & $4-12$ & $120-135$ & $25-43$ & $48-57$ & & Deflandre 1928 \\
\hline $\begin{array}{l}\text { Arcella megastoma Penard, } \\
1902\end{array}$ & $\begin{array}{l}\text { teca subesférica; } \\
\text { baixo at/ dt; alto } \\
\text { número de núcleos }\end{array}$ & $\begin{array}{l}35- \\
200\end{array}$ & $140-402$ & $25-45$ & $40-216$ & 0.22 & $\begin{array}{l}\text { Deflandre 1928, Green 1975, } \\
\text { Vucetich } 1972 \text { 1973, Hardoim et } \\
\text { Heckman 1996, Velho } 1996\end{array}$ \\
\hline $\begin{array}{l}\text { Arcella megastoma fma } \\
\text { arcuata Deflandre, } 1928\end{array}$ & $\begin{array}{l}\text { teca arqueada em } \\
\text { vista lateral }\end{array}$ & $\sim$ & $198-215$ & $25-45$ & $83-110$ & & Deflandre 1928 \\
\hline
\end{tabular}


Tabela XIX. Caracterização biométrica das espécies de Arcella. Caracteres como designados nas Figs 108, 119, 130 e 149. Medidas em $\mu \mathrm{m}$. X - média aritmética; M mediana; SD - desvio padrão; SE - erro padrão da média; CV - coeficiente de variação em \%; Min - mínimo; Max - máximo; $n$ - número de espécimes investigados.

\begin{tabular}{lcccccccc}
\hline & $\mathrm{X}$ & $\mathrm{M}$ & Min & Max & SE & SD & CV & $\mathrm{n}$ \\
\hline & & & & & & & & \\
Arcella hemisphaerica & & & & & & & & \\
diâmetro da teca & 68.48 & 70.00 & 60.00 & 80.00 & 0.22 & 7.52 & 11.00 & 1126 \\
altura da teca & 34.61 & 35.00 & 20.00 & 60.00 & 0.15 & 5.15 & 14.90 & 1126 \\
diametro da abertura & 20.54 & 20.00 & 10.00 & 50.00 & 0.10 & 3.28 & 16.00 & 1125 \\
& & & & & & & & \\
Arcella gibbosa & & & & & & & & \\
diâmetro da teca & 84.67 & 80.00 & 60.00 & 120.00 & 1.46 & 15.00 & 17.70 & 106 \\
altura da teca & 71.65 & 80.00 & 30.00 & 100.00 & 1.78 & 18.29 & 25.50 & 106 \\
diametro da abertura & 24.43 & 20.00 & 15.00 & 60.00 & 0.65 & 6.74 & 27.60 & 106 \\
& & & & & & & & \\
Arcella discoides & & & & & & & & \\
diâmetro da teca & 144.99 & 140.00 & 60.00 & 360.00 & 1.40 & 48.58 & 33.50 & 1198 \\
altura da teca & 30.22 & 30.00 & 20.00 & 90.00 & 0.26 & 8.82 & 29.20 & 1198 \\
diametro da abertura & 67.58 & 70.00 & 15.00 & 200.00 & 0.80 & 27.52 & 40.70 & 1195 \\
& & & & & & & & \\
Arcella brasiliensis & & & & & & & & \\
diâmetro da teca & 144.00 & 150.00 & 110.00 & 160.00 & 9.27 & 20.74 & 14.40 & 5 \\
altura da teca & 84.00 & 80.00 & 80.00 & 100.00 & 4.00 & 8.94 & 10.60 & 5 \\
diametro da abertura & 32.00 & 30.00 & 20.00 & 40.00 & 3.74 & 8.37 & 26.10 & 5 \\
\hline
\end{tabular}


Tabela XX. Razões morfométricas para as populações estudadas de Arcella no Rio Tietê. Caracteres como designados s Figs 108, 119, 130 e 149. SD - desvio padrão; $\mathrm{n}$ - número de espécimes estudados.

\begin{tabular}{llll}
\hline Espécies (n) & at/ dt (SD) & at/da (SD) & da/dt (SD) \\
\hline & & & \\
Arcella hemisphaerica (1125) & $0.51(0.05)$ & $1.71(0.29)$ & $0.30(0.05)$ \\
Arcella gibbosa (106) & $0.85(0.20)$ & $3.03(0.87)$ & $0.29(0.07)$ \\
Arcella discoides (1195) & $0.23(0.08)$ & $0.52(0.28)$ & $0.46(0.09)$ \\
Arcella brasiliensis (5) & $0.59(0.09)$ & $2.80(0.87)$ & $0.22(0.05)$ \\
\hline
\end{tabular}


Table XXI. Coeficiente de correlação entre as espécies de Arcella estudadas no Rio Tietê. Caracteres como designados s Figs 108, 119, 130 e 149; n - número de espécimes.

\begin{tabular}{lccc}
\hline Espécies $(\mathrm{n}) \mathrm{p}$ & $\mathrm{dt}-\mathrm{at}$ & $\mathrm{dt}-\mathrm{da}$ & at-da \\
\hline & & & \\
Arcella hemisphaerica $(1125) \mathrm{p}=0.0001$ & $0.71 *$ & 0.33 & 0.27 \\
Arcella gibbosa $(106) p=0.0001$ & 0.54 & 0.48 & 0.36 \\
Arcella discoides $(1195) \mathrm{p}=0.001$ & 0.53 & 0.91 & 0.50 \\
\hline * $p=0.001$ & & &
\end{tabular}


Tabela XXII. Exploração de habitat das espécies de Arcella estudadas no Rio Tietê. Números em \%; $\mathrm{n}$ - número de espécimes

\begin{tabular}{lcccc}
\hline \multicolumn{1}{c}{ Espécies(n) } & \multicolumn{2}{c}{ Rio } & \multicolumn{2}{c}{ Lago } \\
& Raízes & Sedimento & Raízes & Sedimento \\
\hline & & & & \\
Arcella hemisphaerica (1125) & 81.4 & 0.0 & 13.3 & 5.3 \\
Arcella gibbosa (106) & 12.8 & 0.0 & 68.1 & 19.1 \\
Arcella discoides (1195) & 57.7 & 4.8 & 33.0 & 4.5 \\
Arcella brasiliensis (5) & 20.0 & 0.0 & 20.0 & 60.0 \\
\hline
\end{tabular}


Figuras 
Prancha I; Figs. 1 - 4: ilustrando Material e Métodos. 1. imagem da região na cidade de São Paulo onde se encontra o Parque Ecológico do Rio Tietê (área verde), obtida no programa Google Earth. 2. fotografia da montagem experimental realizada para peneirar as amostras obtidas no Rio Tietê, com duas peneiras geológicas sobrepostas e abaixo delas uma rede de plâncton. 3. gráfico obtido no software "EstimateS" com curvas de diversos estimadores de abundância de espécies, para 18 amostras iniciais. 4. fotografia da montagem experimental realizada para triar as alíquotas em busca de tecamebas. A pipeta Pasteur é utilizada para retirar os indivíduos de interesse com segurança. 
Prancha I; Figs. 1 - 4
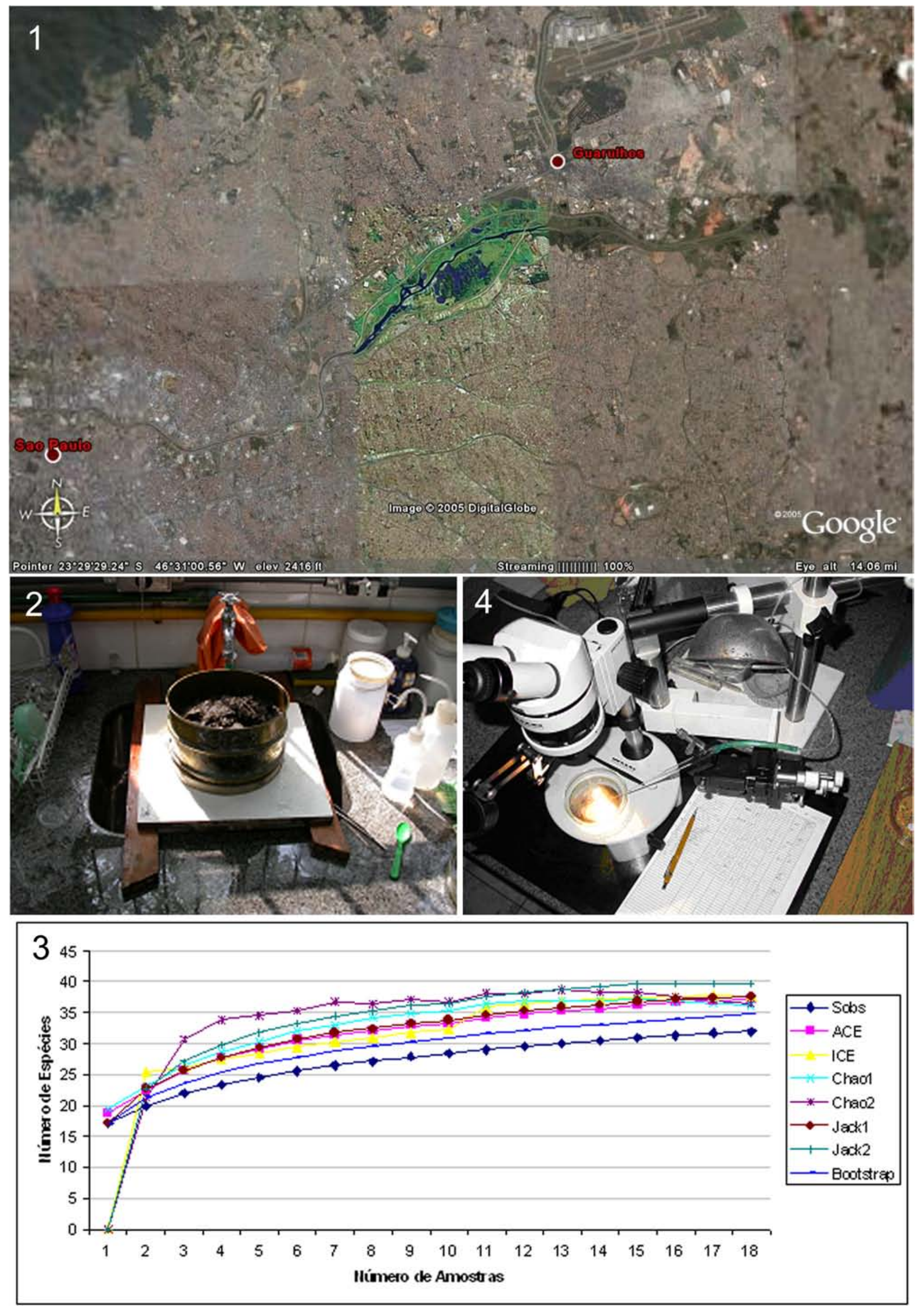
Prancha lla; Fig. 5: desenho esquemático dos eixos medidos em Difflugia corona; $5 a$ - vista lateral, $5 b$ - vista apertural. at - altura da teca; dt - diâmetro da teca; da diâmetro da abertura; ce - comprimento de espinho. Figs. 6 - 14: fotografias retiradas ao Microscópio Eletrônico de Varredura ilustrando D. corona. 6. vista apertural ilustrando o contorno circular da teca. 7. vista apertural oblíqua ilustrando região de inserção dos espinhos e contorno circular. 8. espinho oco posterior. 9. detalhe da composição da teca em um região do corpo. 10. detalhe de uma parede quebrada evidenciando a homogeneidade na construção da parede da teca. 11. detalhe da composição do espinho posterior evidenciando particulas utilizadas e cimento liso. 12. detalhe da região do complexo apertural evidenciando os lobos de ornamentação. 13. detalhe de um lobo de ornamentação do complexo apertural. 14. detalhe interno da arquitetura do complexo apertural, note as protuberâncias aculeiformes na coluna que representa a parte interna de um lobo. 
Prancha lla; Figs. 5 - 14
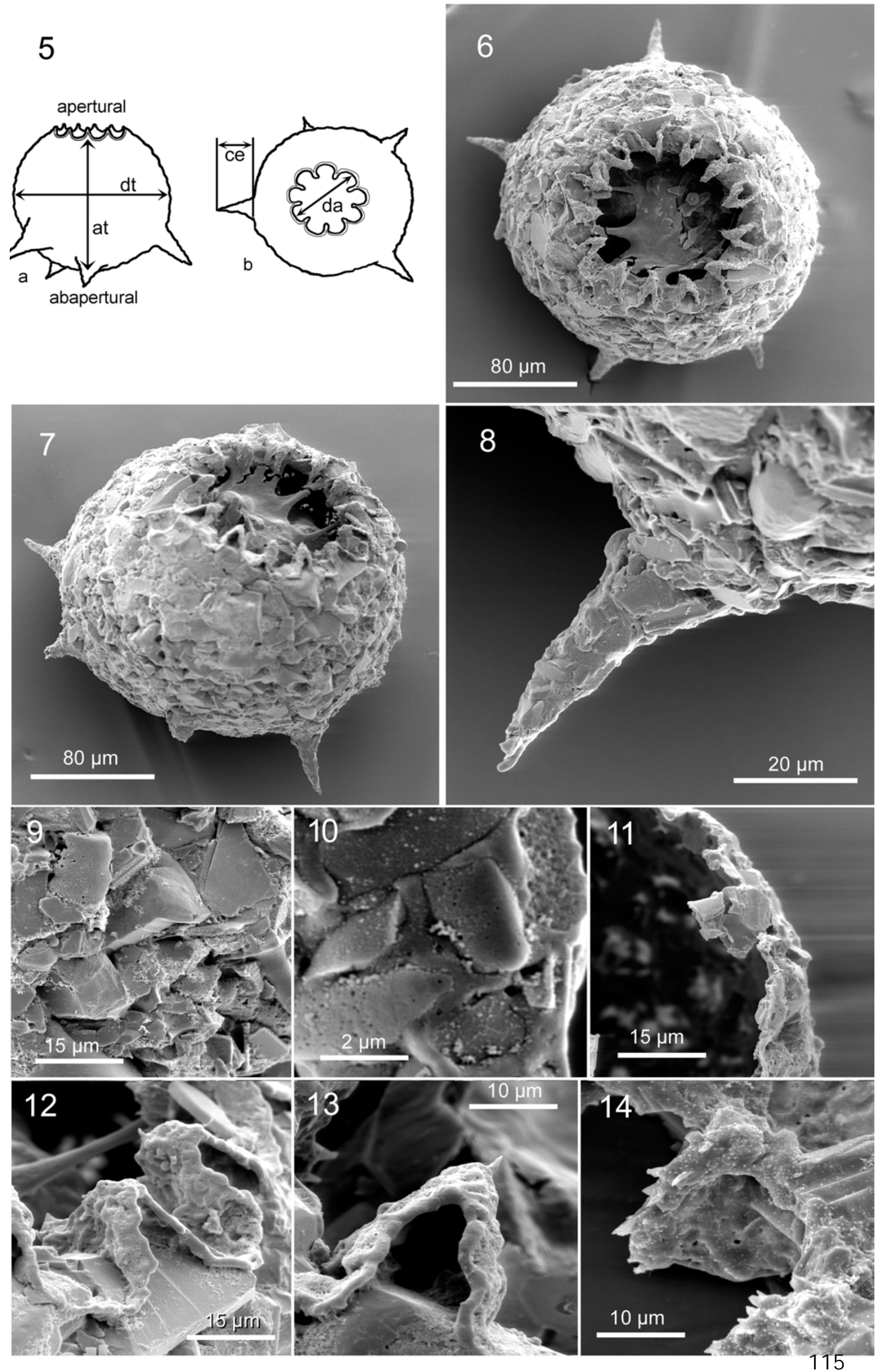
Prancha llb; Figs 15 - 18: fotografias retiradas ao Microscópio Eletrônico de Varredura ilustrando D. corona ecornis. 15. vista apertural evidenciando contorno circular. 16. detalhe de um lobo do complexo apertural. 17. detalhe de uma região da eca mostrando partículas aglutinadas e cimento liso. 18. detalhe da parte interna de um lobo do complexo apertural. 
Prancha llb; Figs. 15 - 18
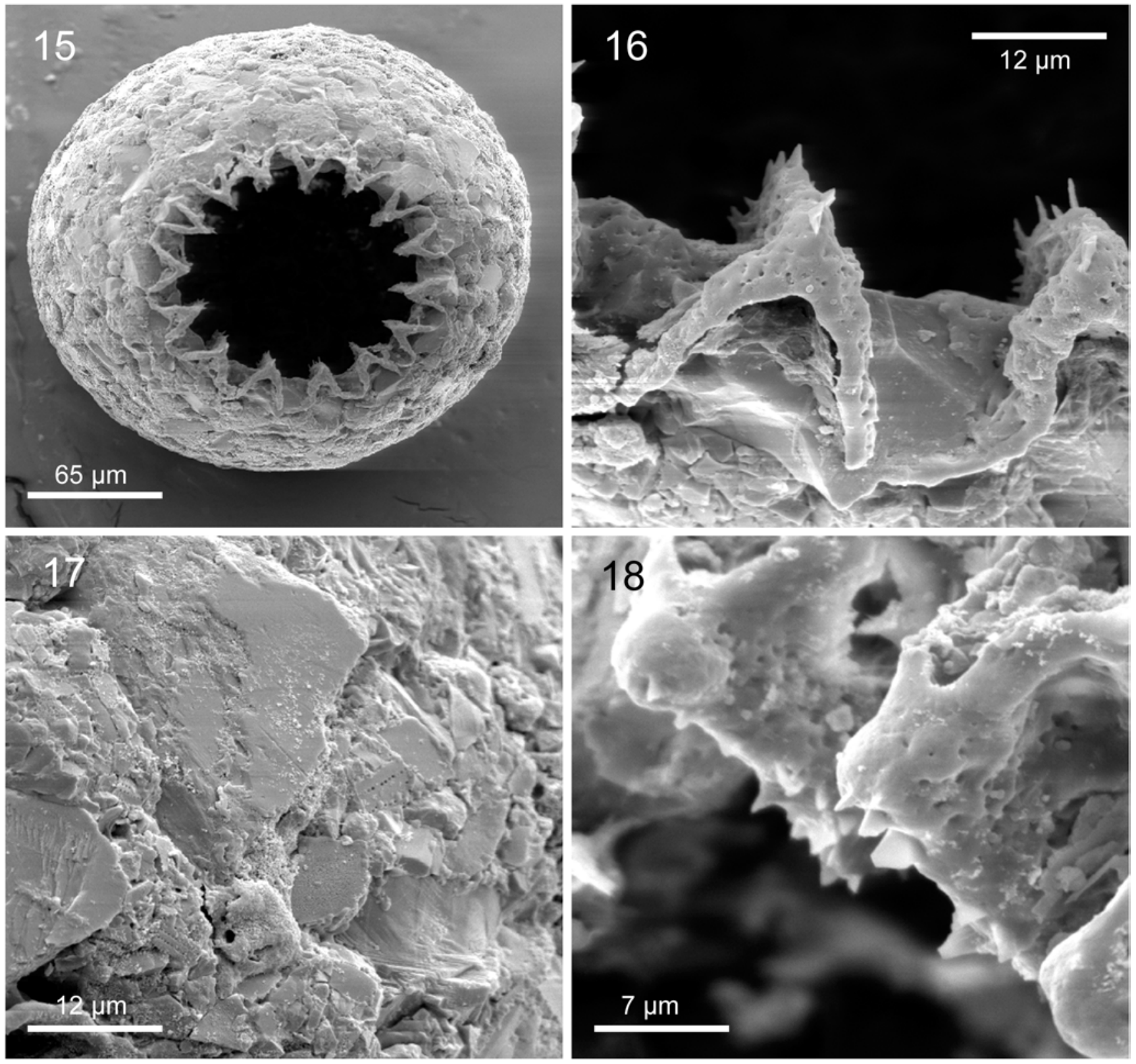
Prancha III; Fig. 19: desenho esquemático dos eixos medidos em Difflugia gramen; 19a - vista lateral, 19b - vista apertural. at - altura da teca; dt - diâmetro da teca; da diâmetro da abertura. Figs. 20 - 24: fotografias retiradas ao Microscópio Eletrônico de Varredura ilustrando D. gramen. 20. vista apertural oblíqua ilustrando o contorno ovóide e aspecto geral da teca. 21 . detalhe de uma região da teca mostrando superfície lisa e partículas componentes da teca. 22. detalhe da composição e cimento liso da teca. 23. complexo apertural com bordo elevado e composto de partículas e cimento, seta mostra um dos poros que rodeiam a abertura. 24 . detalhe do bordo elevado evidenciando a presença de cimento pela projeção em forma de espinho, indicada pela seta. 
Prancha III; Figs. 19 - 24
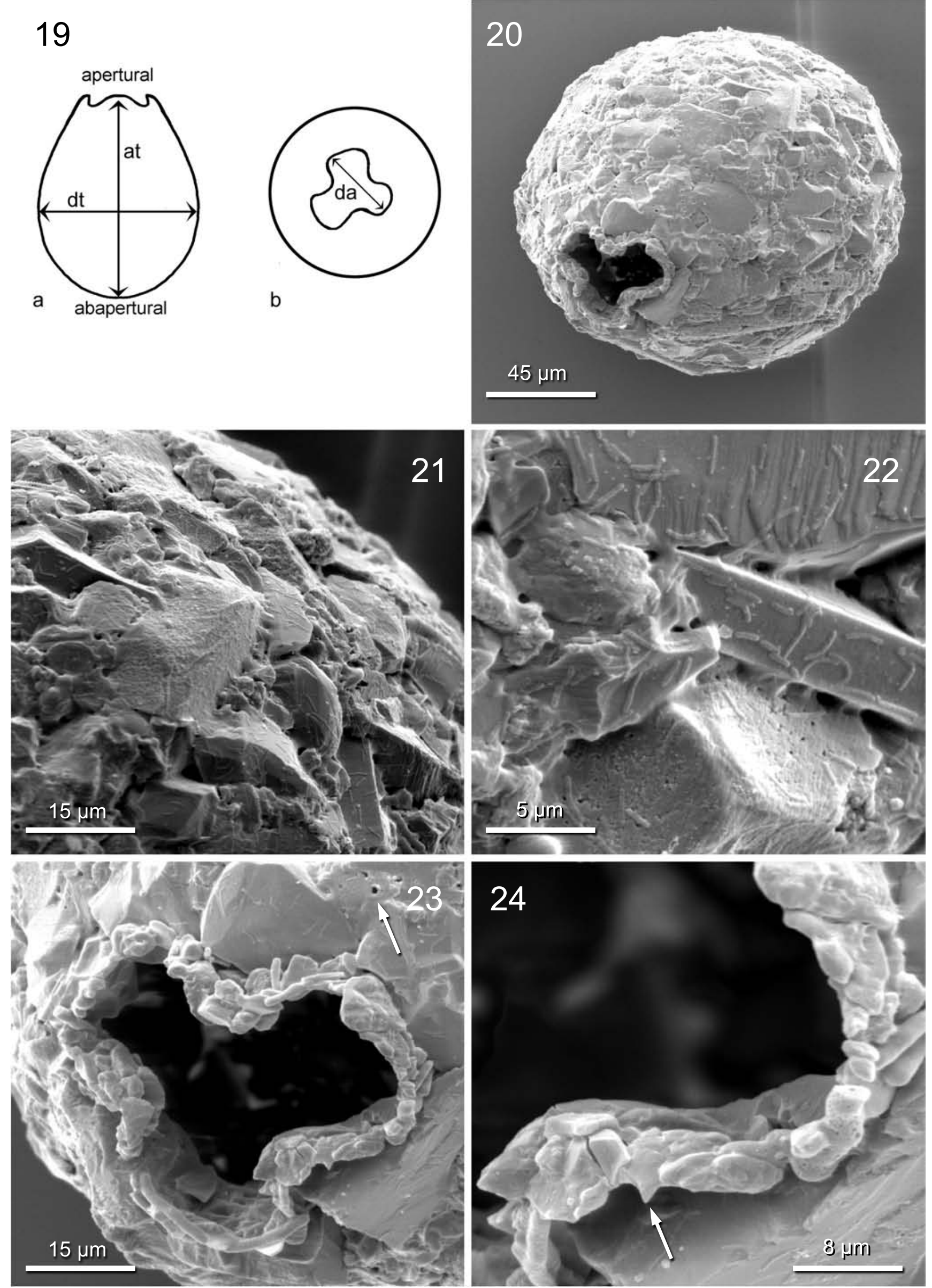
Prancha IV; Fig. 25: desenho esquemático dos eixos medidos em Difflugia lanceolata; 25a - vista apertural, 25b vista lateral - . at - altura da teca; dt - diâmetro da teca; da - diâmetro da abertura. Figs 26 - 34: fotografias retiradas ao Microscópio Eletrônico de Varredura ilustrando D. lanceolata. 26. vista lateral da teca evidenciando contorno e aspecto geral da teca. 27 - 30. diferentes aspectos encontrados para a teca de D. lanceolata, ênfase na variabilidade morfológica do espinho terminal. 31. detalhe de uma região da teca mostrando as partículas componentes achatadas e o cimento em unidades circulares semelhantes a um anel, como que "soldando" as partículas. 32. região do complexo apertural quebrada para evidenciar o padrão de construção homogêneo das paredes da teca. 33. detalhe do complexo apertural. 34. detalhe do bordo do complexo apertural evidenciando a sua composição por material cimentante sobreposto. 
Prancha IV; Figs. 25 - 34
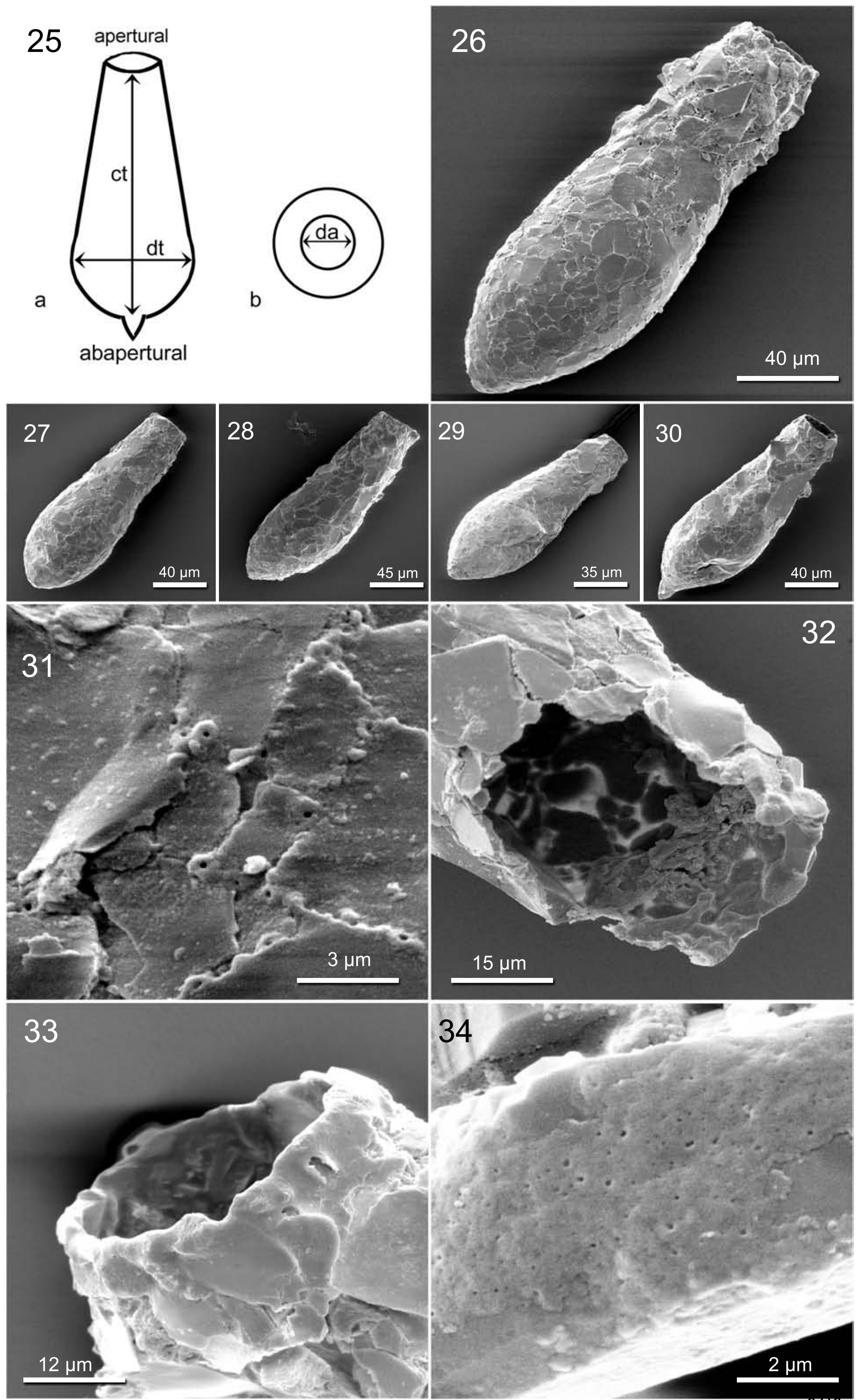

34 
Prancha V; Fig. 35: desenho esquemático dos eixos medidos em Difflugia claviformis; 35a - vista apertural, 35b vista lateral - . at - altura da teca; dt - diâmetro da teca; da - diâmetro da abertura. Figs. 36 - 42: fotografias retiradas ao Microscópio Eletrônico de Varredura ilustrando D. claviformis. 36 - 38: vista lateral da teca, evidenciando contorno e aspecto geral, ênfase na variedade encontrada para o espinho posterior. 39. região da teca, evidenciando partículas componentes e cimento. 40. aumento maior detalhando a composição da teca e estrutura em malha de rede do cimento. 41. detalhe do complexo apertural. 42. detalhe da borda do complexo apertural mostrando camadas de cimento depositadas. 
Prancha V; Figs. 35 - 42
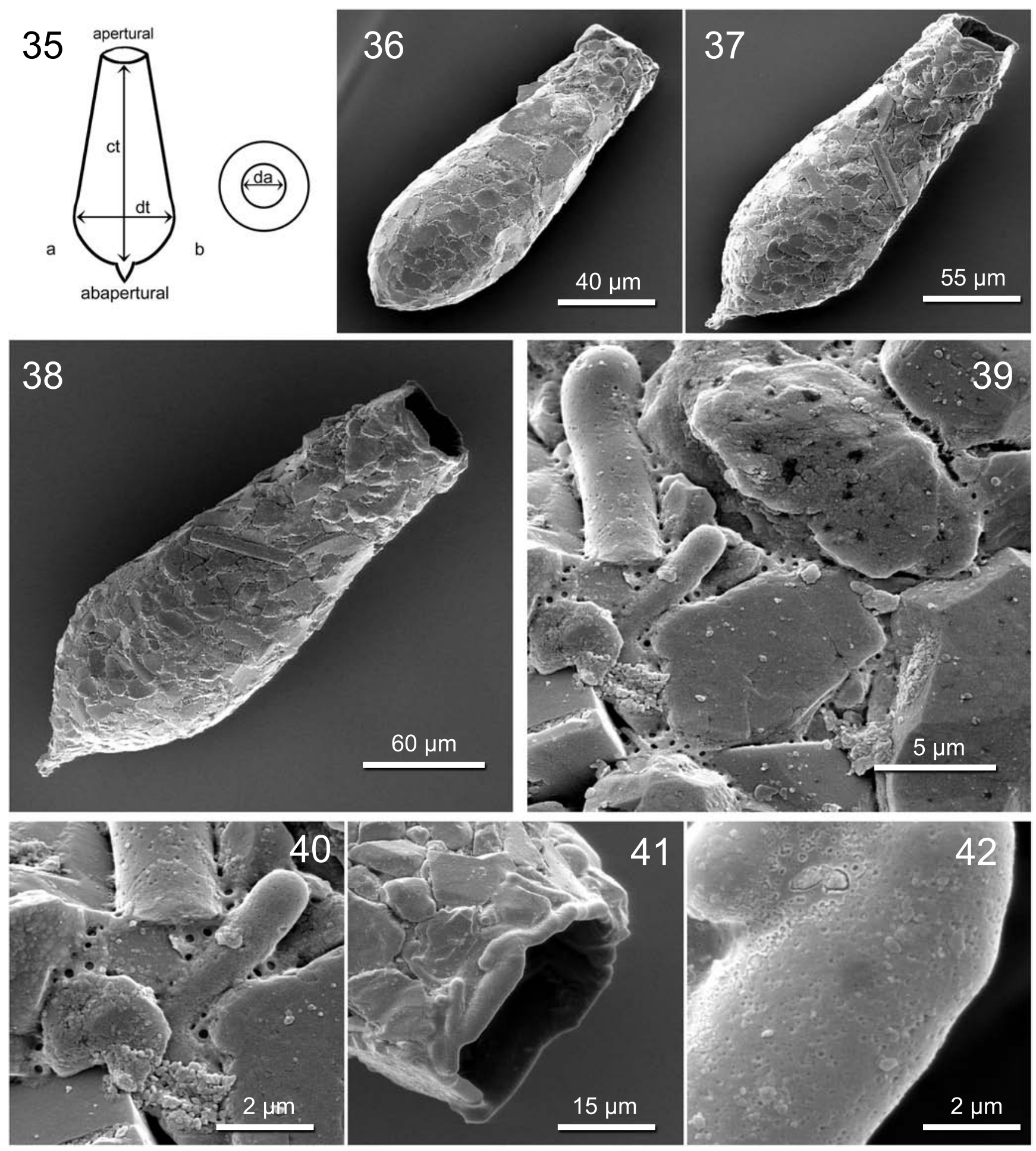
Prancha Vl; Fig. 43: desenho esquemático dos eixos medidos em Difflugia gigantea; 43a - vista apertural, 43b vista lateral - . at - altura da teca; dt - diâmetro da teca; da - diâmetro da abertura. Figs 44 - 51: fotografias retiradas ao Microscópio Eletrônico de Varredura ilustrando D. gigantea. 44 - 46. vista lateral da teca evidenciando contorno e aspecto geral. 47. região da teca, evidenciando partículas componentes e cimento. 48. aumento maior detalhando a composição da teca e estrutura em malha de rede do cimento. 49, 50. detalhe da região do complexo apertural. 51. detalhe da borda do complexo apertural evidenciando camadas de cimento aglutinante depositadas. 
Prancha V; Figs. 43 - 51
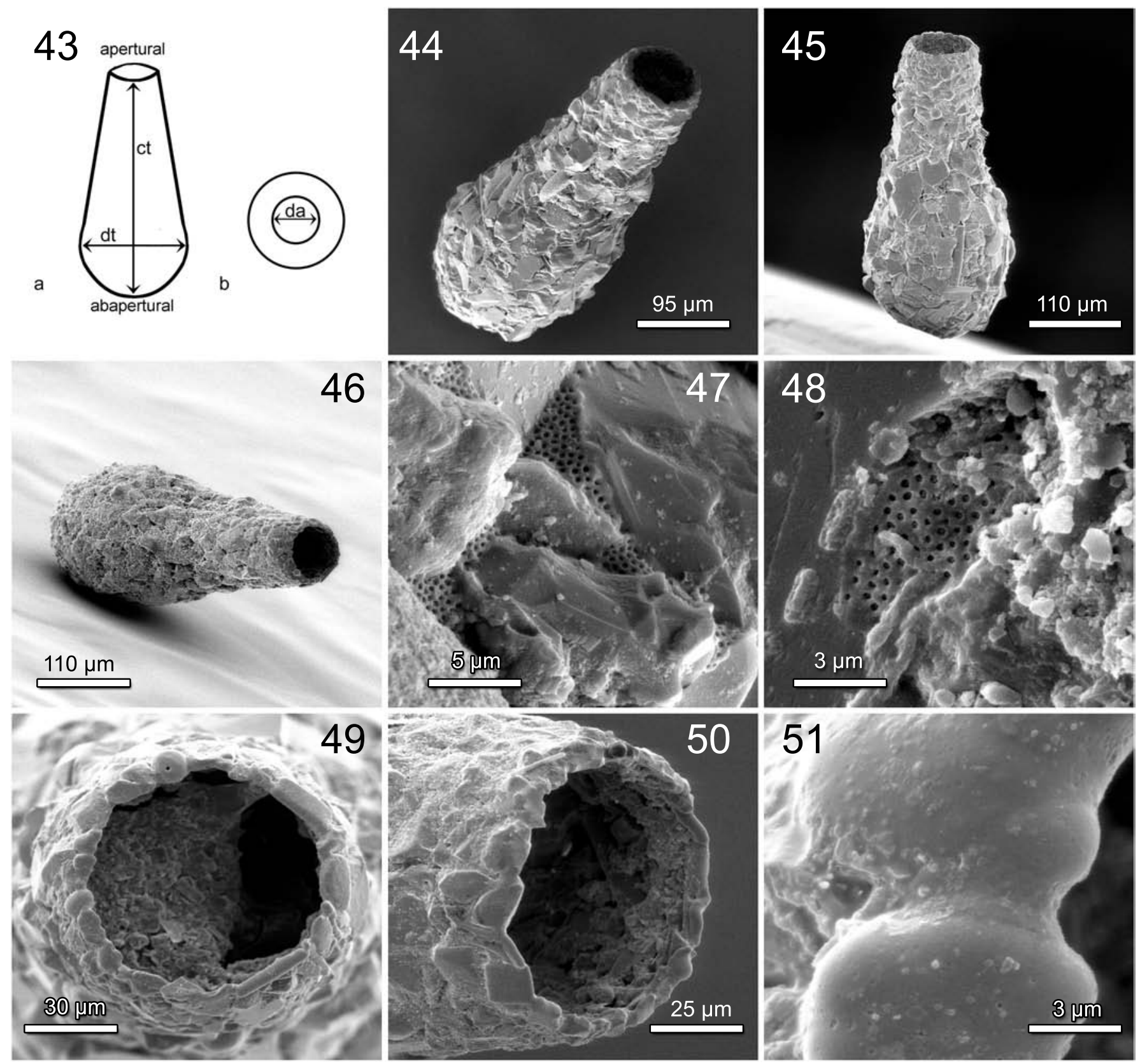
Fig. 52: Histogramas das medidas feitas em Centropyxis aculeata, C. discoides e C. ecornis. $d, h, I, p$, s e x se referem a todas as amostras juntas. Os valores de $d$ são para o teste de Kolgomorov - Smirnov com $p>0,001$. 
C. aculeata

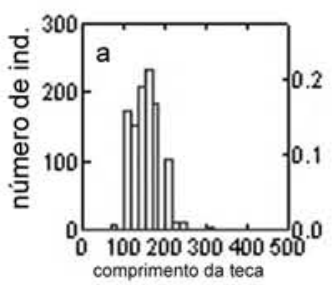

C. discoides
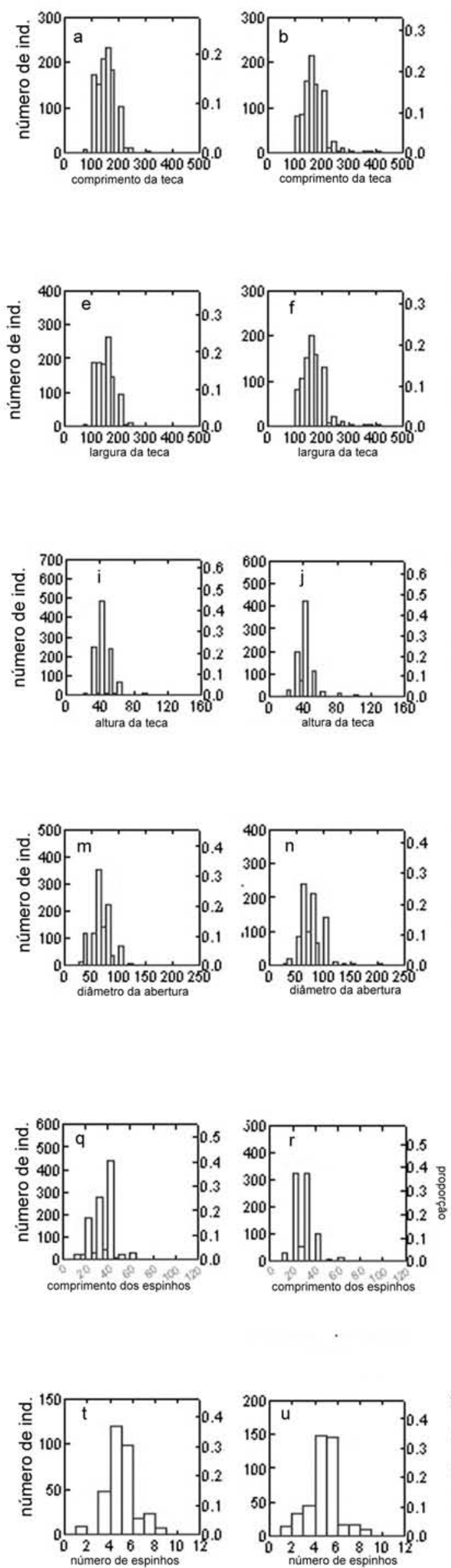
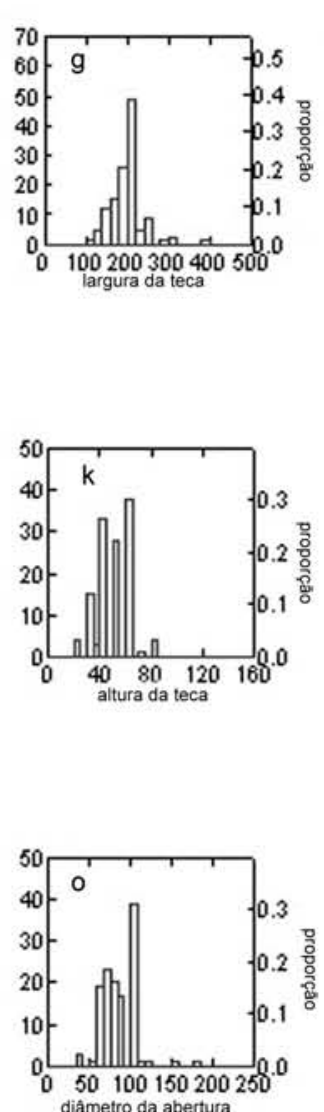

C. ecornis

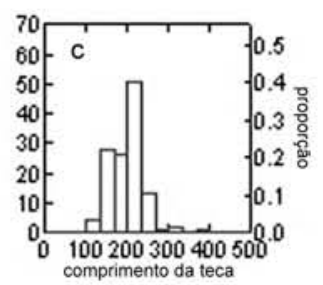

comprimento da teca
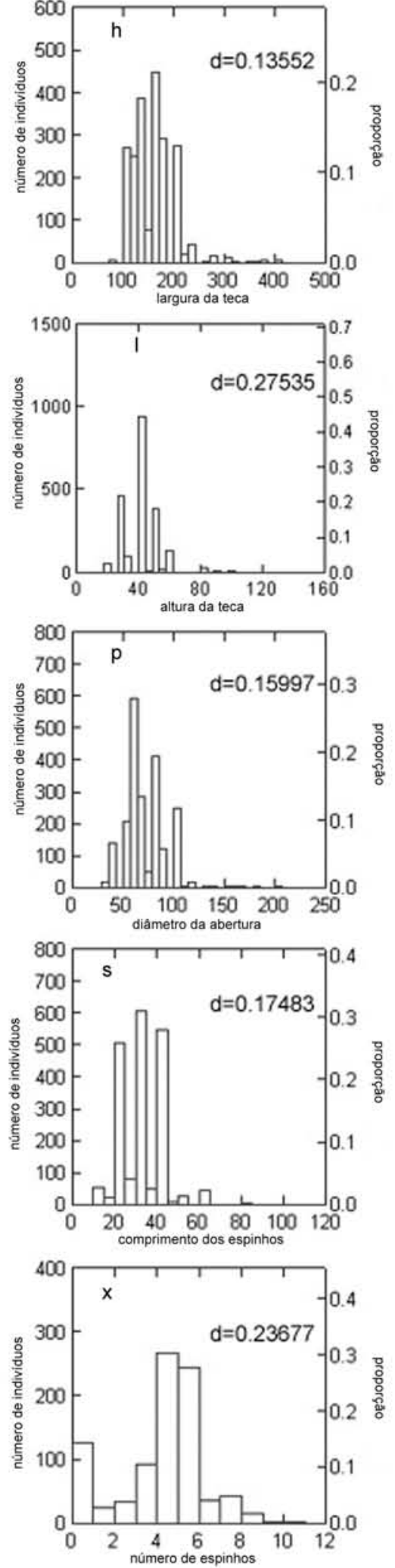
Fig. 53: Gráficos de dispersão comparando todas as medidas duas a duas. 

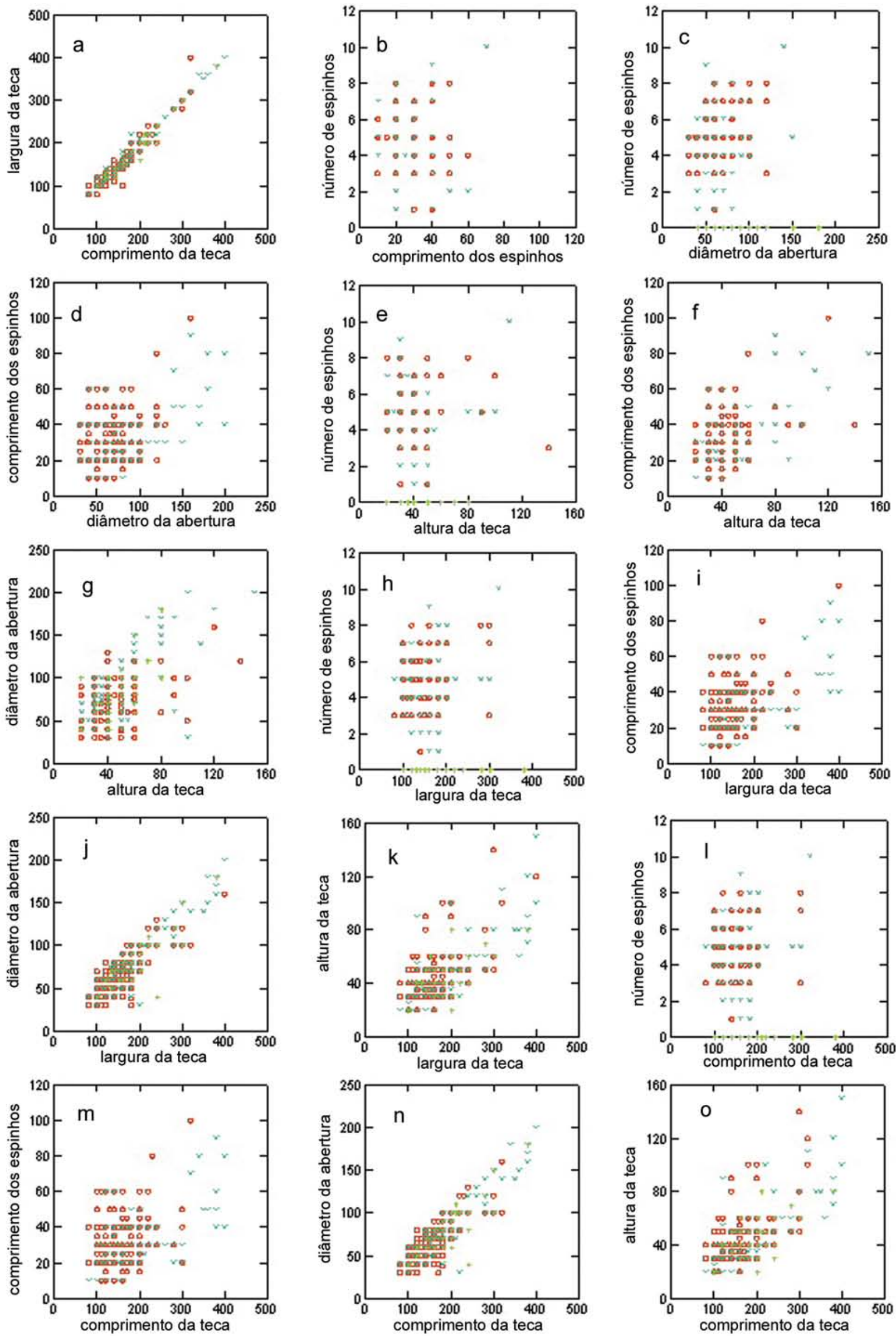

- C. aculeata $\times$ C. discoides + C. ecornis 
Fig. 54: desenho esquemático dos eixos medidos em Centropyxis aculeata; 54a vista apertural, 54b vista lateral - . at - altura da teca; It - largura da teca; da - diâmetro da abertura, ce - comprimento do espinho. 
54
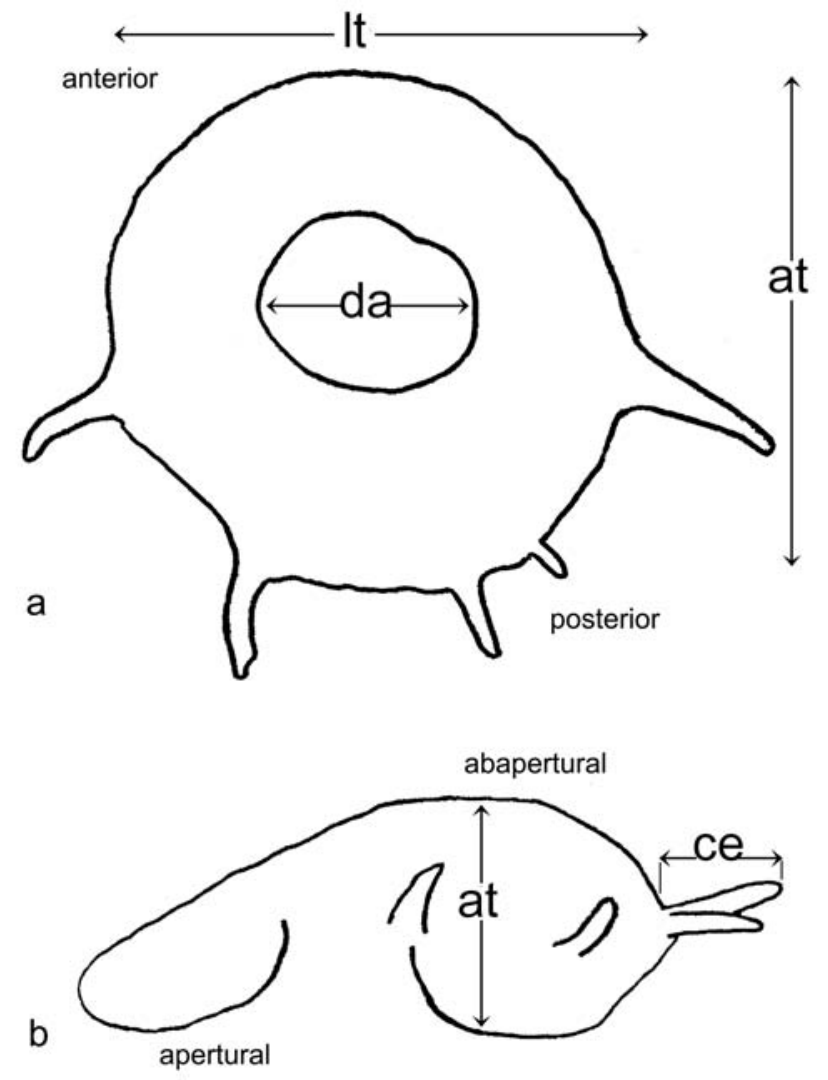
Prancha VIl; Figs. 55 - 75: fotografias retiradas ao Microscópio Eletrônico de Varredura ilustrando Centropyxis aculeata. 55 - 59. vista apertural geral da teca, evidenciando diferentes morfologias possíveis. 60, 61. vista lateral da teca evidenciando diferentes graus de compressão da região anterior. 62 - 67. espinho látero-posteriores, evidenciando diferentes morfologias possíveis. 68. região apertural, detalhe para pilares que sustentam o complexo apertural, mais delgado posterior, mais grosso anterior. 69 . detalhe do pilar posterior, mais delgado. 70. detalhe dos pilares anteriores, mais grossos. 71. vista abapertural, evidenciando as quatro depressões onde se inserem os pilares. 72 . região abapertural de uma teca com grande quantidade de partículas aglutinadas, onde não é possível ver as inserções dos pilares de sustentação. 73. detalhe de uma região aglutinada da teca. 74 . teca quebrada mostrando o padrão do cimento aglutinante na região interior da teca. 75 . detalhe do cimento aglutinante organizado em fios entrelaçados. 
Prancha Vl; Figs. 55 - 75

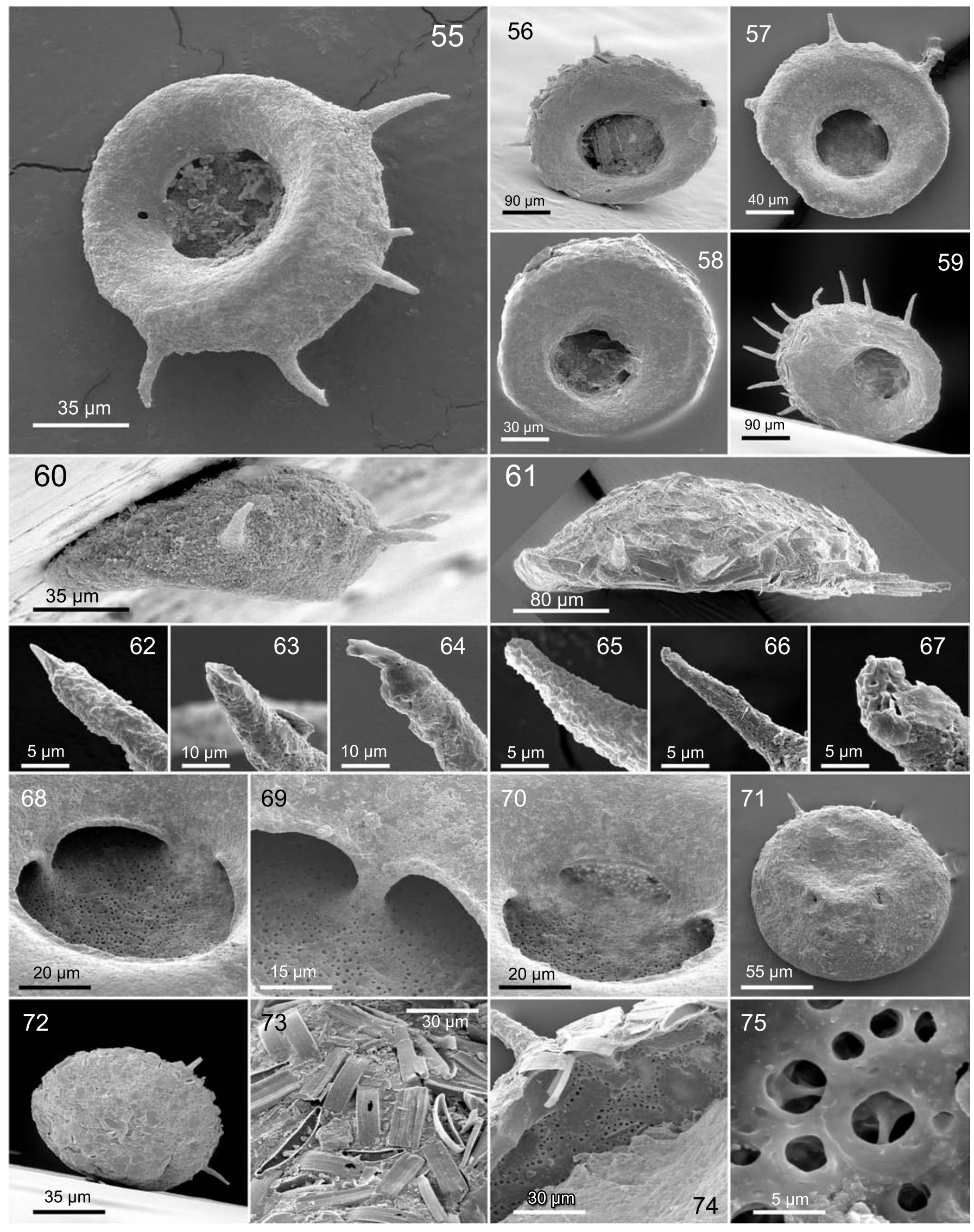


Prancha VIII; Fig. 76: desenho esquemático dos eixos medidos em Netzelia wailesi; 76a - vista lateral, 76b vista apertural - . at - altura da teca; dt - diâmetro da teca; da diâmetro da abertura. Figs. 77 - 85: fotografias retiradas ao Microscópio Eletrônico de Varredura ilustrando N. wailesi. 77. vista apertural oblíqua ilustrando contorno bastante liso e aspecto geral da teca. 78. detalhe de uma região da teca mostrando padrão de aglutinação. 79. detalhe em maior aumento de uma região da teca mostrando cobertura e padrão do cimento aglutinante. 80. detalhe da região interna da teca evidenciando um idiossomo em forma de prego. 81. parede da teca quebrada para mostrar a cobertura interna e externa de cimento. 82. região interna da teca, note os pilares transversais. 83. detalhe de uma região da teca mostrando padrão do cimento. 84. detalhe da complexo apertural, forma geral. 85. complexo apertural evidenciando 0 anel de poros a externos ao bordo livre do complexo. 
Prancha VII; Figs. 76 - 85

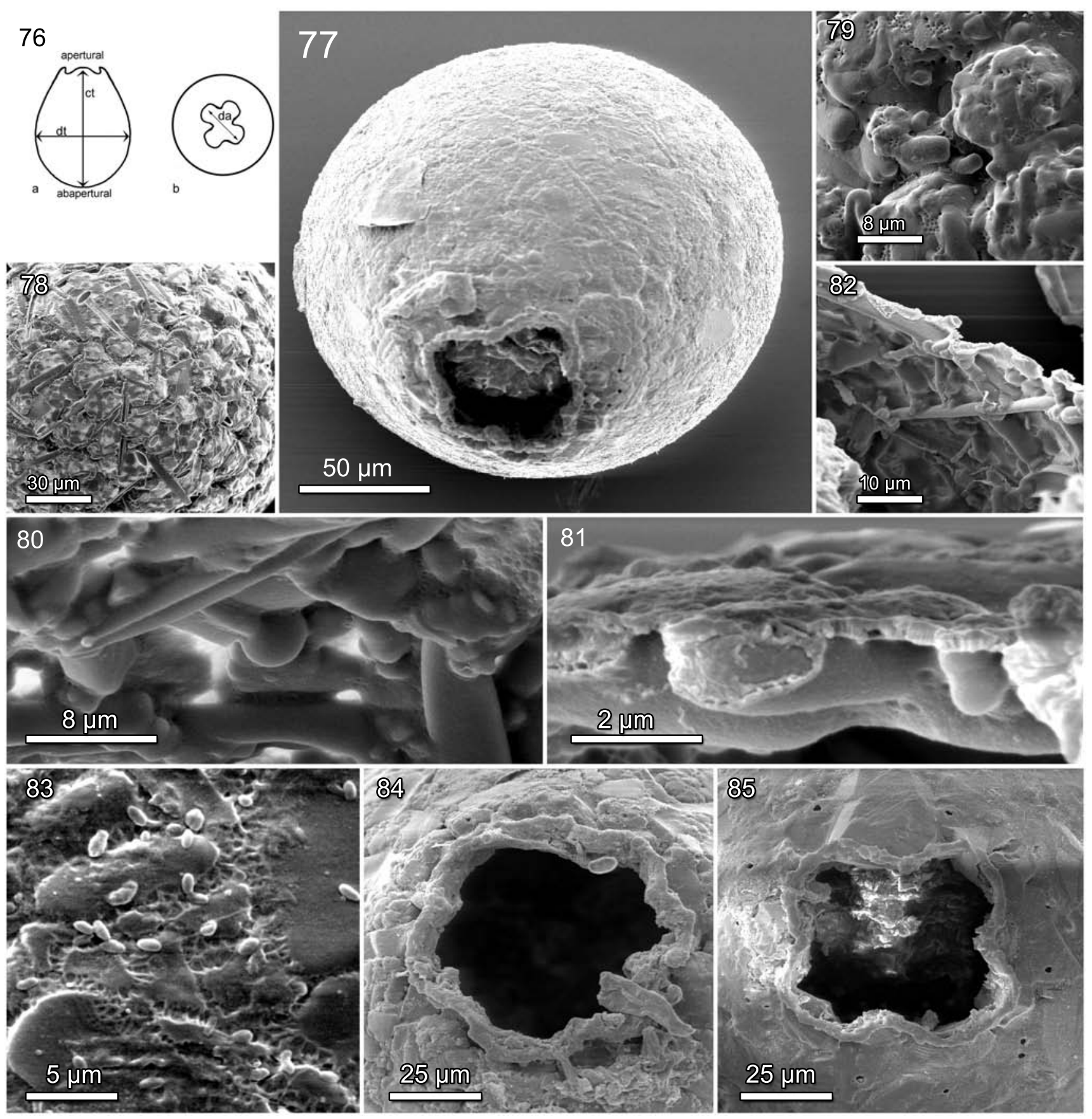


Prancha IXa; Fig. 86: desenho esquemático dos eixos medidos em Lesquereusia modesta; vista lateral. ct - comprimento da teca; It - largura da teca; da - diâmetro da abertura. Figs 87 - 91: fotografias retiradas ao Microscópio Eletrônico de Varredura ilustrando L. modesta. 87 - 89. aspecto geral da teca em vista lateral. 90. aspecto geral da teca em vista apertural. 91. aspecto geral da teca em vista dorsal. 
Prancha IXa; Figs. 86 - 91
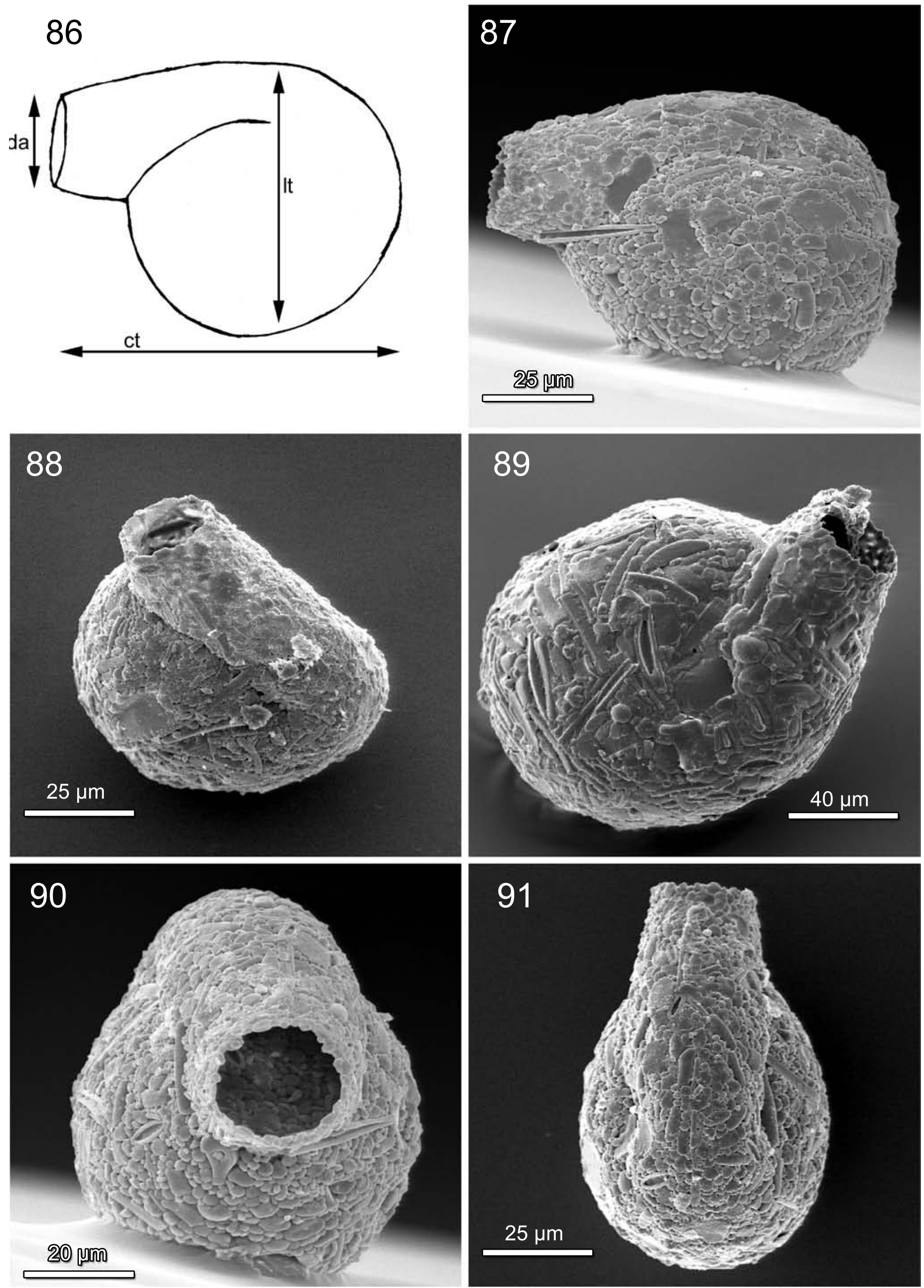
Prancha IXb; Figs. 92 - 98: fotografias retiradas ao Microscópio Eletrônico de Varredura ilustrando L. modesta. 92. detalhe da composição e cimento em uma região da teca. 93. aumento maior evidenciando um idiossomo em forma de " $v$ " e cimento. 94. aumento maior evidenciando um idiossomo cilíndrico e cimento. 95. detalhe da região do complexo apertural evidenciando um idiossomo típico em forma de prego e cobertura de cimento. 96. detalhe da região interna da teca evidenciando componentes aglutinados e cimento. 97, 98. aspecto geral do complexo apertural de indivíduos com diferentes tipos de idiossomos. 
Prancha IXb; Figs. 92 - 98
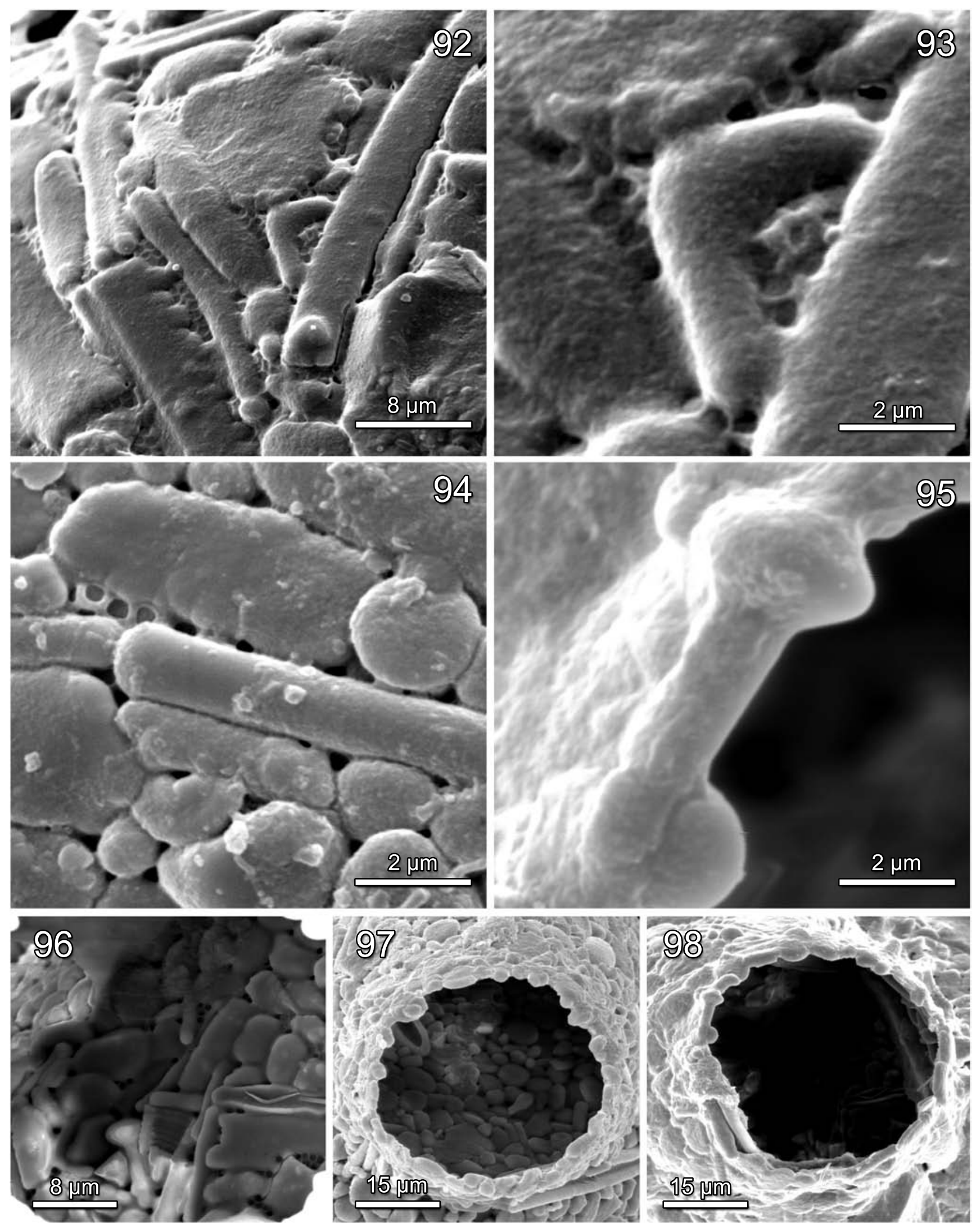
Prancha X; Fig. 99: desenho esquemático dos eixos medidos em Arcella hemisphaerica; 99a - vista lateral, 99b vista apertural -. at - altura da teca; ct comprimento da teca; da - diâmetro da abertura. Figs. 100 - 109: fotografias retiradas ao Microscópio Eletrônico de Varredura ilustrando A. hemisphaerica. 100. aspecto geral de um individuo com nível mediano de ondulações, vista abapertural. 101. aspecto geral de um individuo com um nível baixo de ondulações, vista abapertural. 102. aspecto geral, vista lateral. 103. aspecto geral de um indivíduo com um nível alto de ondulações, vista abapertural. 104. aspecto geral de um indivíduo com um nível alto de ondulações, vista lateral. 105. detalhe padrão de construção alveolar da teca, evidenciando hexágonos ocos de formação. 106. detalhe aspecto geral da construção alveolar. 107. aumento maior, mostrando poros nos vértices de cada hexágono constituinte. 108. aspecto geral, vista apertural. 109. detalhe da abertura com bordo recurvado. 

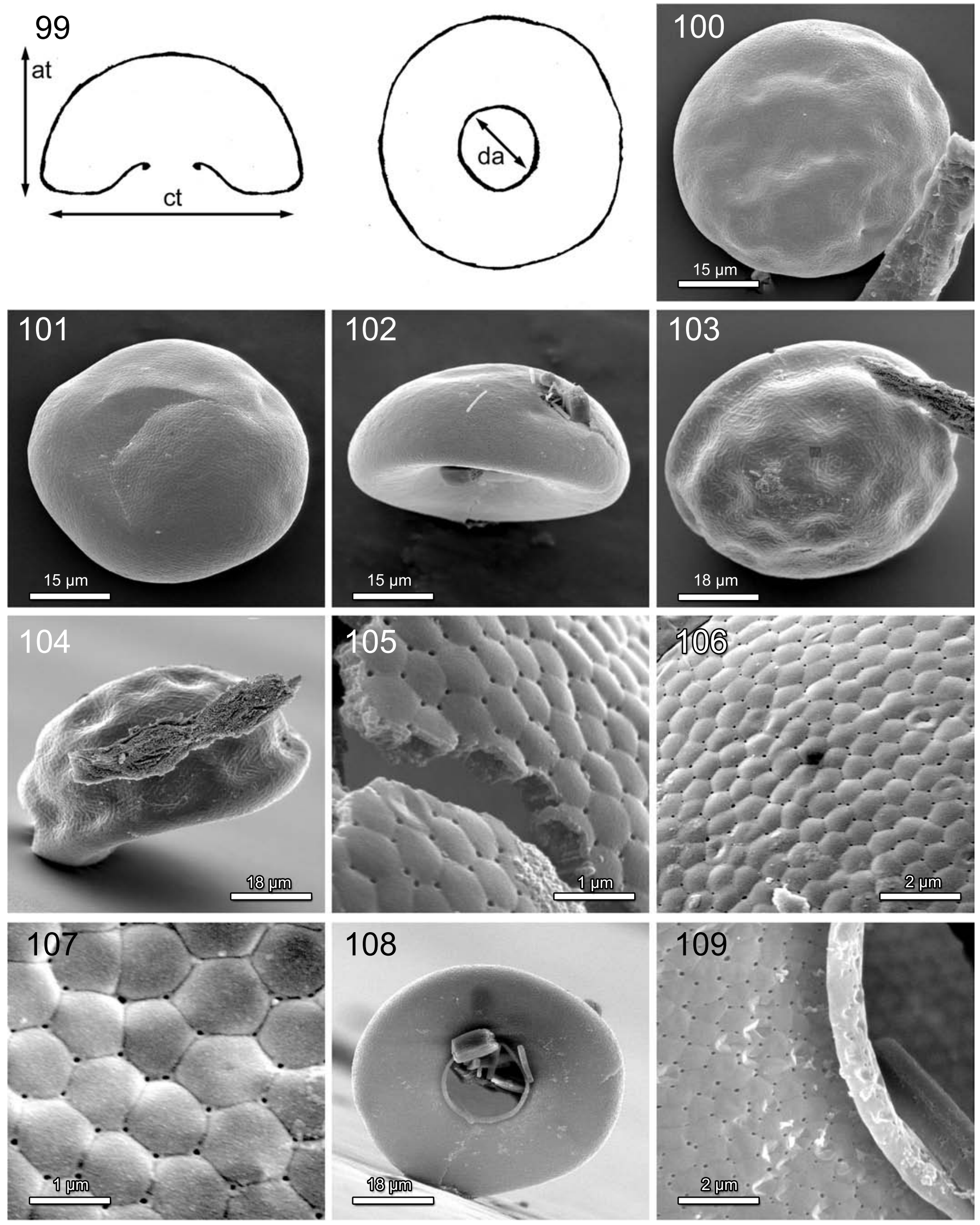
Prancha XI; Fig. 110: desenho esquemático dos eixos medidos em Arcella gibbosa; 110a - vista lateral, 110b vista apertural - . at - altura da teca; ct - comprimento da teca; da - diâmetro da abertura. Figs. 111 - 120: fotografias retiradas ao Microscópio Eletrônico de Varredura ilustrando A. gibbosa. 111. vista apertural oblíqua evidenciando aspectos gerais da teca. 112-114. vista lateral de indivíduos mostrando a variabilidade no padrão de costelas e depressões característico da espécie. 115. detalhe dos hexágonos constituintes e sua conformação oca. 116. aspecto do padrão de construção alveolar. 117. aumento maior evidenciando que na região abapertural, a maioria dos vértices dos hexágonos inflados é provida de dois ou mais poros. 118, 119. detalhe dos hexágonos na região apertural, evidenciando como estão colapsados e a presença de um poro em cada vértice. 120. detalhe do complexo apertural com o bordo recurvado. 


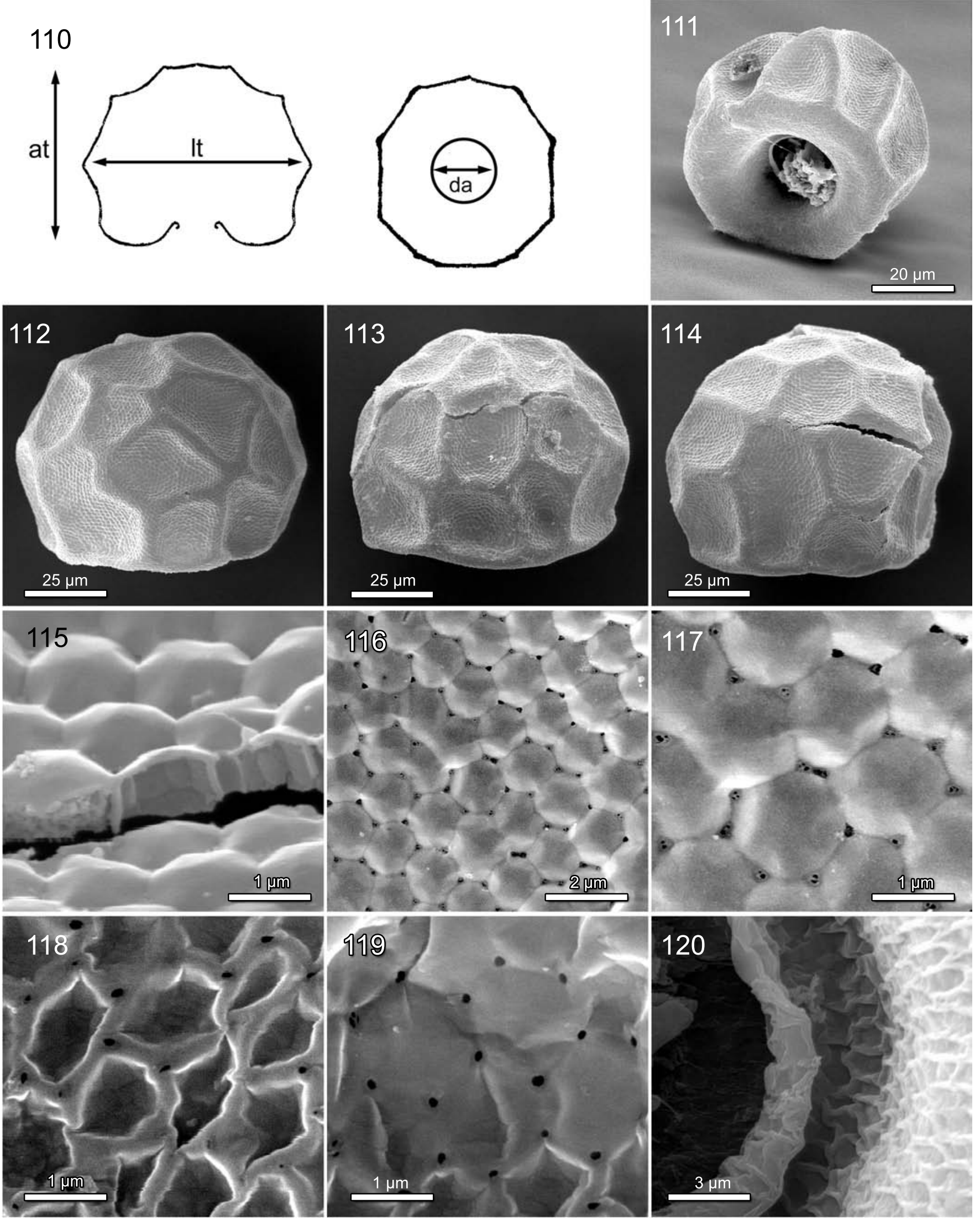


Prancha Xlla; Fig. 121: desenho esquemático dos eixos medidos em Arcella discoides; $121 \mathrm{a}$ - vista lateral, 121b vista apertural - . at - altura da teca; ct comprimento da teca; da - diâmetro da abertura. Figs. 122 - 132: fotografias retiradas ao Microscópio Eletrônico de Varredura ilustrando A. discoides. 122, 123. vista abapertural evidenciando aspecto geral da teca. 124. vista apertural oblíqua evidenciando aspecto geral da teca. 125, 126, 127. vista lateral da teca evidenciando diferentes graus de curvatura da teca. 128. detalhe da construção alveolar mostrando as unidades ocas. 129. detalhe da construção alveolar da teca evidenciando a irregularidade dos alvéolos. 130. aumento menor evidenciando construção alveolar da teca. 131, 132. detalhe da construçao alveolar evidenciando que a região abapertural é coberta por uma camada extra de matriz orgânica. 
Prancha Xlla; Figs. 121 - 132

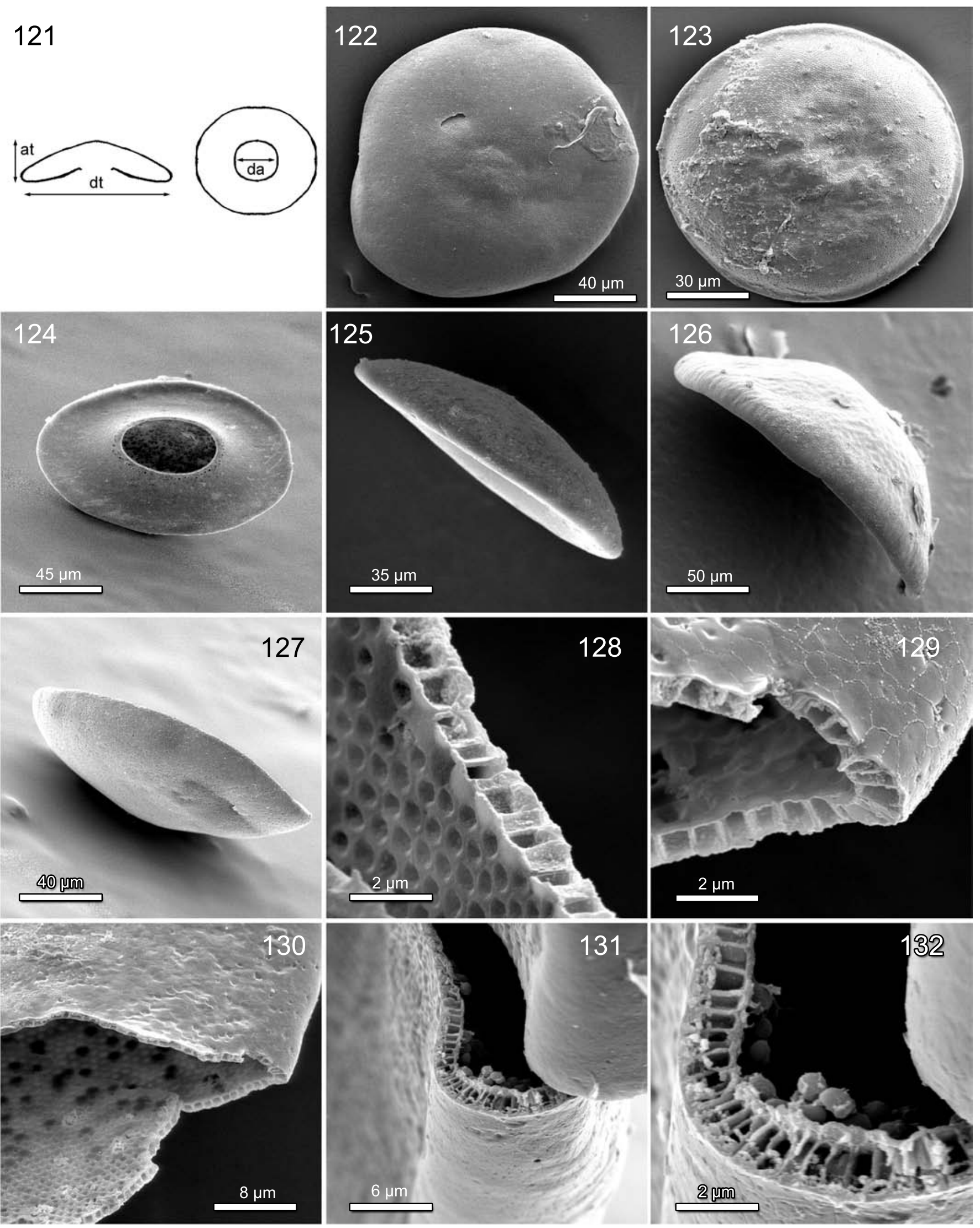


Prancha Xllb; Figs. 133 - 139: fotografias retiradas ao Microscópio Eletrônico de Varredura ilustrando A. discoides. 133. detalhe da construção da teca na região abapertural, com camada de cobertura. 134. detalhe da construção da teca na região apertural, sem camada de cobertura e com unidades colapsadas. 135, 136, 137, 138. vista apertural, evidenciando aspecto geral, diferentes morfologias da abertura e anel de poros ao redor da abertura. 139. detalhe do bordo apertural com anel de poros. 

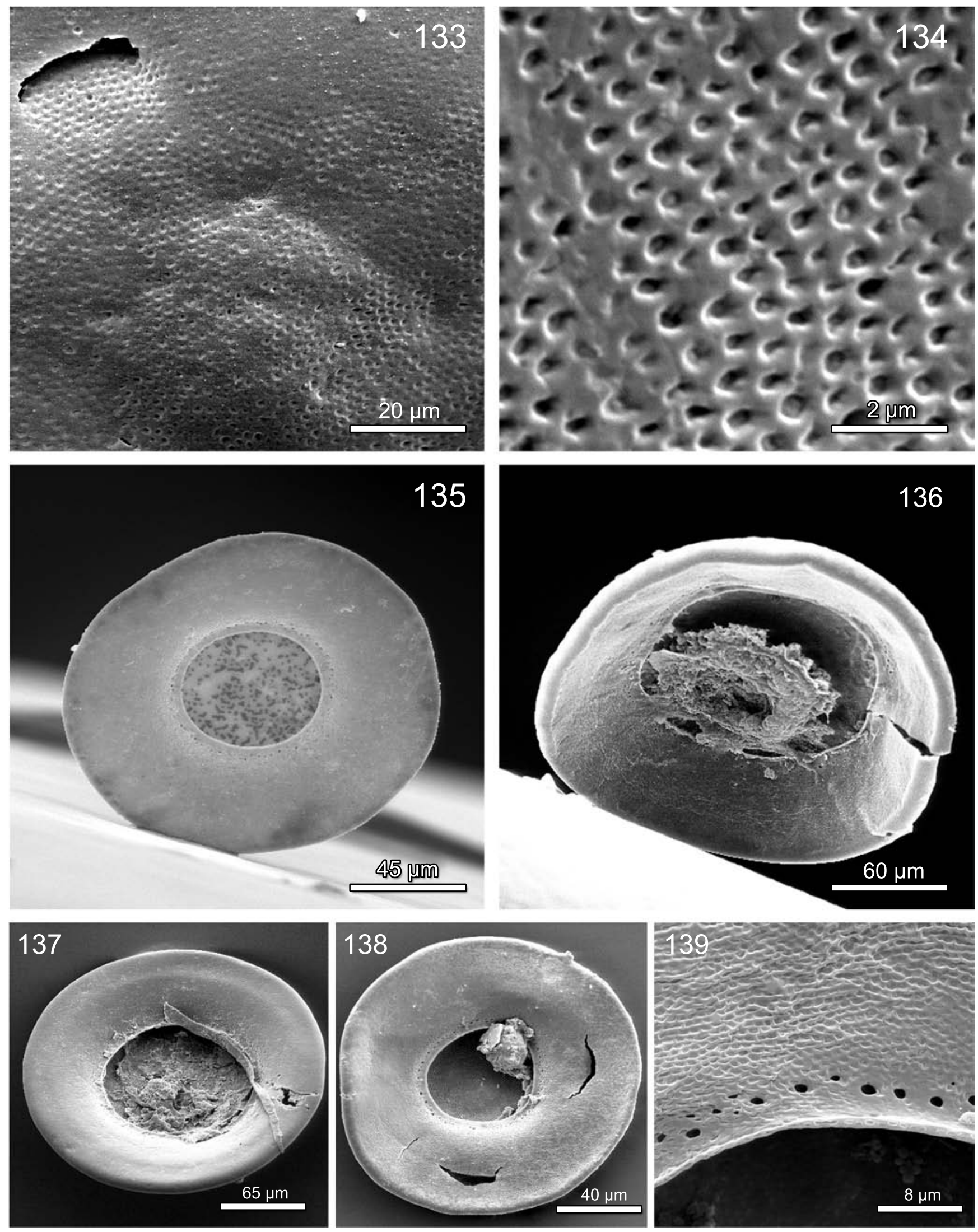
Prancha XIII; Fig. 140: desenho esquemático dos eixos medidos em Arcella brasiliensis; 140a - vista lateral, 140b vista apertural - . at - altura da teca; ct comprimento da teca; da - diâmetro da abertura. Figs. 141- 146: fotografias retiradas ao Microscópio Eletrônico de Varredura ilustrando A. brasiliensis. 141. vista apertural evidenciando aspecto geral. 142. vista lateral evidenciando aspecto geral e ondulações na superfície abapetural. 143, 144. detalhe da construção alveolar da teca. 145. região da abertura mostrando o padrão de construção alveolar. 146. detalhe do bordo levantado do complexo apertural. 
Prancha XII; Figs. 141 - 146

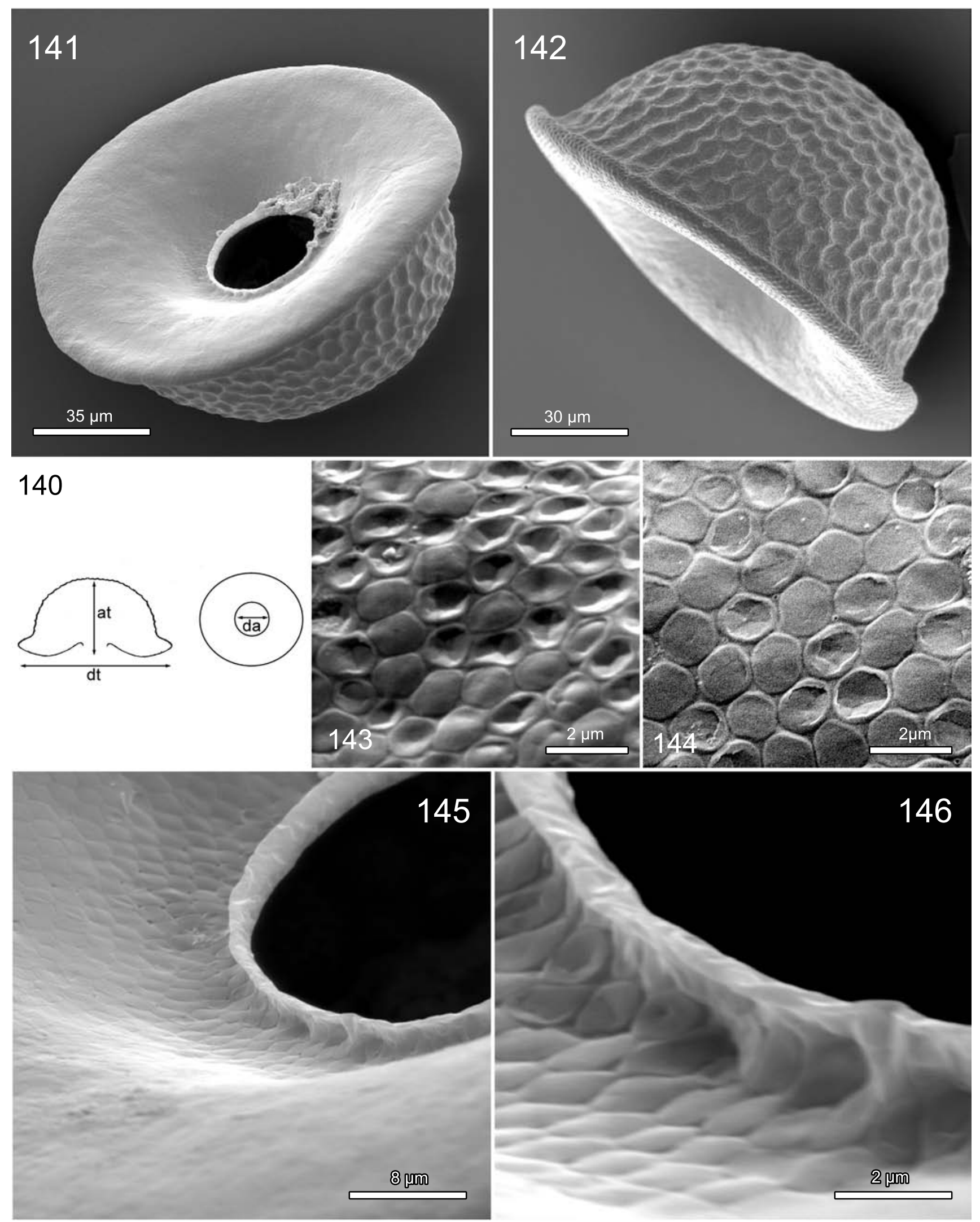


RESUMO

0 presente trabalho explora os aspectos taxonômicos, ecológicos, morfológicos, biométricos e biogeográficos dos Arcellinida Kent, 1880 coletados no Parque Ecológico do Rio Tietê, São Paulo - Brasil. Foram encontrados organismos pertencentes à cerca de 30 táxons nominais, no entanto, a revisão da literatura, novos dados morfológicos obtidos através do Microscópio Eletrônico de Varredura e medidas biométricas realizadas com grande número de indivíduos permitem afirmar que muitos destes táxons estão se referindo a mesma entidade na natureza. Logo, na presente pesquisa são descritas, com detalhes de distribuição geográfica, morfologia ultra-estrutural, morfometria e ecologia, espécies pertencentes a quatro famílias e cinco gêneros: Difflugia corona Wallich, 1864; Difflugia gramen Penard, 1902; Difflugia lanceolata Penard, 1890; Difflugia claviformis Penard, 1899; Difflugia gigantea Chardez, 1967; Centropyxis aculeata (Ehrenberg, 1838); Netzelia wailesi (Ogden, 1980); Lesquereusia modesta Rhumbler, 1895; Lesquereusia mimetica Pènard, 1911; Arcella hemisphaerica Perty, 1852; Arcella gibbosa Penard, 1890; Arcella discoides Ehrenberg, 1871 e Arcella brasiliensis Cunha, 1913. São discutidas inovações taxonômicas para que a comparação de dados obtidos usando técnicas atuais com aqueles reportados na literatura tradicional seja feita da maneira mais explícita possível, de modo a delimitar melhor o conceito taxonômico de cada espécie abordada. 
The present survey explores the taxonomic, ecologic, morphologic, biometric and biogeographic aspects of the Arcellinida Kent, 1880 collected at the Ecological Park of the Tiete River, Sao Paolo - Brazil. Around 30 nominal taxa were identified, however, a review of the literature and new morphologic data obtained via the Scanning Electron Microscope and biometric measures with a large number of individuals allow the inference that many of these taxa are referring to the same natural entity. Therefore, the present work describes species from four families and five genera, along with details about geographic distribution, ultra-structural morphology, morphometry and ecology: Difflugia corona Wallich, 1864; Difflugia gramen Penard, 1902; Difflugia lanceolata Penard, 1890; Difflugia claviformis Penard, 1899; Difflugia gigantea Chardez, 1967; Centropyxis aculeata (Ehrenberg, 1838); Netzelia wailesi (Ogden, 1980); Lesquereusia modesta Rhumbler, 1895; Lesquereusia mimetica Pènard, 1911; Arcella hemisphaerica Perty, 1852; Arcella gibbosa Penard, 1890; Arcella discoides Ehrenberg, 1871 e Arcella brasiliensis Cunha, 1913. Taxonomic innovations are discussed in order to make comparison of recent data with those reported on traditional literature a more explicit practice, allowing a better understanding of each species taxonomic concept. 
Referências Bibliográficas 


\section{REFERÊNCIAS BIBLIOGRÁFICAS}

ANDERSON O. R. (1987) Fine structure of a silica biomineralizing testate amoebae, Netzelia tuberculata. J. Protozool. 34: 302-309

BakKer-GrunWald T., Wöstmann C. (1993) Entamoeba histolytica as a model for the primitive eukaryotic cell. Parasitol. Today 9: 27-31.

BaLDAuF S. L. (2003) The deep roots of eukaryotes. Science 300: 1703-1706

BaLdauf S. L., Roger A. J., Wenk-Siefert I., Doolittle W. F. (2000) A kingdom-level phylogeny of Eukaryotes based on combined protein data. Science 290: 972977

Blanco M. A. (2001) Morphometric characters of Difflugia corona (Testacea, Difflugidae) in lentic environments of Chaco, Argentina. Iheringia, Sér. Zool. 91:79-83.

Bobrov A. A., Charman D. J., Warner B. G. (1999) Ecology of testate amoebae (Protozoa: Testacea) on Peatlands in Western Russia with special attention to niche separation in closely related taxa. Protist 150: 125-136

Bobrov A. A., MAZEl Y. (2004) Morphological variability of testate amoebae (Rhizopoda: Testacealobosea: Testaceafilosea) in natural populations. Acta Protozool. 43: 133-146

Bolivar I., Fahrni J., Smirnov A., PAWLOWSKI J. (2001) SSU rRNA-based phylogenetic position of the genera Amoeba and Chaos (Lobosea, Gymnamoebia): the origin of gymnamoebae revisited. Mol Biol Evol 18: 2306-2314

Boltovskoy E. (1956) Contribución al conocimiento de las tecamebas del Rio de la Plata. Acta Geol. Lilloana 1: 299-314 
Boltovskoy E., LenA H. (1966) Contribución al conocimiento de las tecamebas de Ushuaia (Tierra del Fuego, Argentina). Neotropica 12(38): 55-65

Boltovskoy E., Lena H. (1971) Contribution à l'Etude des Thecamoebiens de la Province de Buenos Aires. Hydrobiol. 38 (3-4): 441-451

BoneCKer C. C., BoneCKer S. L. C., Bozelli R. L., LansaC-TôHa F. A., VelHo L. F. M. (1996) Zooplancton composition under the influence of liquid wastes from a pulp mill in middle Doce River (Belo Horizonte/MG - Brazil) Arq. Biol. Tecnol. 39: 893901

BoneCKer C. C., Bonecker S. L. C., Bozelli R. L., LansaC-TôHA F. A., VelHo L. F. M. (1997) Limnological characterization of Marola lake, a pound in the middle Doce valley river - Belo Oriente, state of Minas Gerais, Brazil. Braz. Arch. Tecnol. 40: $817-828$

BoneCKer C. C., LANSAC-TôHA F. A., BINI L. M. (1998) Composition of zooplancton in different environments of the Mato Grosso do Sul, Brazil. In: Seminário Regional de Ecologia, 3, São Carlos. São Carlos: UFSCar p. 1123-1135.

BoveE, E. C. (1985) Class Lobosea Carpenter, 1861. In Illustrated Guide to the Protozoa (Eds. Lee J. J., Hutner S. H., Bovee E. C.), Society of Protoozoologists, Lawrence, Kansas, U.S.A. 158-209

CASH J., HOPKINSON J. (1905) The British freshwater Rhizopoda and Heliozoa. Vol. I: Rhizopoda. London, Ray Society.

CASH J., HOPKINSON J. (1909) The British freshwater Rhizopoda and Heliozoa. Vol. II: Rhizopoda, part 2. London, Ray Society. 1-116

CAVAlier-Smith T. (1987) Eukaryotes with no mitochondria. Nature 326: 332-333. 
Cavalier-Smith T. (1993) Kingdom Protozoa and its 18 phyla. Microbiol. Rev. 57: 953994.

Cavalier-Smith T. (1998) A revised six-kingdom system of life. Biol. Rev. Camb. Philos. Soc. 73: 203-266.

Cavalier-Smith T. (2000) Flagellate megaevolution: the basis for eukaryote diverification. Pp. 361-390 In: J. R. Green e B. S. C. Leadbeater, eds. The Flagellates: Unity, Diversity and Evolution. Taylor and Francis, London.

Cavalier-Smith T., Chao E. E. (1996) Molecular phylogeny of the free-living archezoan Trepomonas agilis and the nature of the first Eukaryote. J. Mol. Evol. 43: 551562.

Cavalier-Smith T., Chao E. E. Y., Oates B. (2004) Molecular phylogeny of Amoebozoa and the evolutionary significance of the unikont Phalansterium. Europ. J. Protistol. 40: 21-48

ChARDEZ D. (1956) Variations morphologiques et tératologie chez quelques Rhizopodes testacés. Biol. Jaarboek 23: 265-276

ChaRdez D. (1961) Cathalogue des Thecamoebiens de Belgique. Protozoa, Rhizopoda, Testacea. Bull. Inst. Agron. Stns. Rech. Gembloux 29: 269

ChARDEZ D. (1966a) Influence du milieu sur Centropyxis aculeata (Ehrenberg) Stein (Rhizopoda Testacea). Bull. Rech. agron. Gembloux 1(1): 13-19

ChaRDEZ D. (1966b) Note sur quelques Thecamoebiens. Bull. Rech. Agron. Gembloux 1(1): $20-24$

CHARDEZ D. (1967) Difflugia oblonga Ehrenberg et sés variétés (Protozoa, Rhizopoda Testacea). Bull. Rech. Agron. Gembloux 2: 586-595 
Chardez D., Decloitre L. (1973) Nota sistematica sobre la validez de dos especies de tecamebianos: Difflugia oblonga Ehrenberg y D. pyriformis Perty. Physis 32(85): 359-365

Clark C. G., Cross G. A. (1988) Small-subunit ribosomal RNA sequence from Naegleria gruberi supports the polyphyletic origin of amoebas. Mol. Biol. Evol. 5: $512-518$.

Clark C. G., Roger A. (1995) Direct evidence for secondary loss of mitochondria in Entamoeba histolytica. Proc. Natl. Acad. Sci. USA 92: 6518-6521.

Closs D., MADeira M. (1962) Tecamebas e Foraminíferos do Arroio Chuí (Santa Vitória do Palmar, R. Grande do Sul, Brasil). Iheringia, Sér. Zool. 19:1-43

Closs D., MADEIRA M. (1967) Foraminíferos e tecamebas aglutinantes da lagoa de Tramandaí, no Rio Grande do Sul. Iheringia, Sér. Zool. 35:7-31

Closs D., MedeiRos V. M. F. (1967) Thecamoebina and Foraminifera from the Mirim Lagoon, Southern Brazil. Iheringia sér. zool. 35: 75-88

CoLweLL, R. K. (2004) EstimateS: Statistical estimation of species richness and shared species from samples. Versão 7. Guia do usuário e aplicativo disponíveis em: http:// purl.oclc.org/ estimates.

CoRLISS J. O. (1972) Common sense and courtesy in nomenclatural taxonomy. Syst. Zool. 21: 117-122

CORLISS J. O. (1994) An interim utilitarian ('user friendly') hierarchical classification and characterization of the protists. Acta Protozool. 33:1-51.

CunHA A. M. (1913) Contribuição para o conhecimento da fauna de protozoários do Brasil. Mem. Inst. Oswaldo Cruz 5: 101-122 
DABÉs M. B. G. S. (1995) Composição e descrição do zooplâncton de 5 (cinco) lagoas marginais do Rio São Francisco, Pirapora, Três Marias, Minas Gerais - Brasil. Ver. Bras. Biol. 55(4): 831-845

Dabés M. B. G. S., Velho L. F. M. (2001) Testate amoebae (Protozoa, Rhizopoda) associated to littoral aquatic macrophytes in a marginal lake of the São Francisco River, MG, Brazil. Acta Scientiarum 23: 299-304

DADAY E. (1905) Untersuchungen über die Süsswasser-Mikrofauna Paraguays. Protozoa. Bibl. Zool. 18(44):1-342

DeCLoITRE L. (1948) Matériaux pour une faune Rhizopodique d'A. O. F. Bull. Inst. Fr. Afr. Noire. 10: 235-284

DeCloitre L. (1954) Mission A. Villiers au Togo et au Dahomey (1950). Bull. Inst. Fr. Afr. noire 16: 89-125

DeCLoITRE L. (1955) Rhizopodes thecamoebiens du Venezuela. Hydrobiologia 7: 325372

Decloltre L. (1965) Contribution a la faune du Congo (Brazzaville). Mission A. Dexarpentries et A. Villiers. III Rhizopodes Thecamoebiens. Bull. Inst. Fr. Afr. Noire 27: 165-184

DeCLOITRE L. (1976) Le genre Arcella Ehrenberg. Complements a jour au 31.Decembre 1974 de la monographie du genre parue en 1962. Arch Protistenk 118:18-33

DeCLoITRE L. (1978) The Genus Centropyxis Supplement to the Monograph from 1929. Arch. Protistenk. 120: 63-85

DefLANDRE G. (1926) Notes sur quelques Rhizopodes et Heliozoaires du Venezuela. Bull. Soc. Zool. France 51: 515-53 
DeflandRe G. (1928) Le genre Arcella Ehrenberg. Morphologie - Biologie. Essay phylogenetic et systematic. Arch. Protistenk. 64: 152-287

DefLANDRE G. (1929) Le genre Centropyxis Stein. Arch. Protistenk. 67: 322-375

Deflandre G. (1953) Ordres des Testacealobosea (De Saedeleer, 1934), Testaceafilosea (De Saedeleer, 1934), Thalamia (Haeckel, 1862) ou thecamoebiéns (Auct. plur.) (Rhizopoda Testacea). In: Grassé P. P. ed. Traité de Zoologie 1: 97-149

DeKHTYAR M. N. (1993) New species of the family Difflugiidae (Lobosea, Rhizopoda) with remarks on the validity of the genus Protocucurbitella. Zool. Zhurnal 72(6): 5-15 (em Russo)

Dionı W. (1967) Investigación preliminar de la estructura basica de las asociaciones de la micro y meso fauna de las raices de las plantas flotantes. Acta Zool. Lill. 23: $111-13$

DıoNı W. (1970) Taxocenos de tecamebianos en cuencas isleñas del Paraná medio 1. Los tecamebianos de la vegetación flotante en el "madrejón" Don Felipe. Acta Zool. Lill. 27: 200-240

Duleba W., DebenAY J. P. (2003) Hydrodynamic circulation in the estuaries of Estação Ecológica Juréia-Itatins, Brazil, inferred from Foraminifera and Thecamoebian assemblages. J. Foram. Res. 33: 62-93

Durigan J. G., Sipaúba-Tavares L. H., Oliveira D. B. S. (1992) Estudo limnológico em tanques de piscicultura. Parte 1: variação mineral de fatores físicos, químicos e biológicos. Acta Limnol. Bras. 4: 211-223

EHRENBERG C. G. (1838) Die Infusionsthierchen als vollkommene Organismen. Leipzig: L. Voss. 
EHRenBeRg C. G. (1871) Nacht zur Uebersicht der Organischen Atmosphärilien. Abh. Akad. Berlin 233-275

Fahrni J. F., Bolivar I., Berney C., Nassonova E., Smirnov A., Pawlowski J. (2003) Phylogeny of lobose amoebae based on actin and small-subunit RNA genes. Mol. Biol. Evol. 20: 1881-1886

FinlaY B. J. (2002) Global dispersal of free-living microbial eukaryote species. Science 296: 1061-1063

Finlay B. J., Clarke K. J. (1999) Ubiquitous dispersal of microbial species. Nature 400: 828

Finlay B. J., Esteban G. F., Clarke K. J., Olmo J. L. (2001) Biodiversity of Terrestrial Protozoa Appears Homogeneous across Local and Global Spatial Scales. Protist 152: 355-366

Finlay B. J., Esteban G. F., Fenchel T. (2004) Protist diversity is different? Protist 155: $15-22$

Finlay B. J., Esteban G. F., Olmo J. L., Tyler P. A. (1999) Global distribution of freeliving microbial species. Ecography 22: 138-144

Finlay B. J., Fenchel T. (1999) Divergent perspectives on protist species richness. Protist 150: 229-233

FoISSNER W. (1997) Global soil ciliate (Protozoa, Ciliophora) diversity: a probability based approach using large sample collections from Africa, Australia and Antarctica. Biodiv. Conserv. 6: 1627-1638

FoISSNER W. (1998) An updated compilation of world soil ciliates (Protozoa, Ciliophora), with ecological notes, new records, and descriptions of new species. Europ. J. Protistol. 34: 195-235 
FoISSNER W. (1999a) Protist diversity: Estimates of the near-imponderable. Protist 150: $363-368$

FoISSNER W. (1999b) Soil Protozoa as Bioindicators: pros and cons, methods, diversity, representative examples. Agriculture Ecosystems and Environment, 74: $95-112$

Folssner W., Korganova G. (2000) The Centropyxis aerophila complex (Protozoa: Testacea). Acta Protozool. 39: 257-273

Gauthier-LièVre L., Thomas R. (1958) Les Genres Difflugia, Pentagonia, Magrebia et Hoogenraadia (Rhizopodes testacés) en Afrique. Arch. Protistenk. 103: 241370

GreEN J. (1975) Freshwater ecology in the Mato Grosso, Central Brazil, IV: Associations of testate Rhizopoda. J. nat. Hist. 9: 545-560

Grospietsch T. (1975) Beitrag zur Kenntnis der Testaceen-Fauna des Lago Valencia (Venezuela). Verh. Internat. Verein. Limnol. 19: 2778-2784

Hardoim E. L., Heckman C. W. (1996) The seasonal succession of biotic communities in wetlands of the tropical wet-and-dry climatic zone: IV. The free-living Sarcodines and Ciliates of the Pantanal of Mato Grosso, Brazil. Int. Revue ges. Hydrobiol. 81(3): 367-384

Hausmann K., HüLSmann N. (1996) Protozoology. Georg Thieme Verlag, Stuttgart.

Hedley R. H., Ogden C. G., Mordan N. J . (1976) Manganese in the Shell of Centropyxis. Cell Tiss. Res. 171: 543-549

HinkLe G., Leipe D. D., Nerad T. A., Sogin M. L. (1994) The unusually long small subunit ribosomal RNA of Phreatamoeba balamuthi. Nucleic Acids Res. 22: 465-469. 
HINKLE G., SogIn M. L. (1993) The evolution of the Vahlkampfiidae as deduced from 16S-like ribosomal RNA analysis. J. Eukaryot. Microbiol. 40: 599-603.

LAHR D. J. G., Lopes S. G. B. C. (2006) Morphology, biometry, ecology and biogeography of five species of Difflugia Leclerc, 1815 (Protista: Arcellinida: Difflugiidae), from Tiete River, Brazil. Acta Protozool. in press.

LAMINGER H. (1972) Die profundale Testaceenfauna (Protozoa, Rhizopoda) älterer und jüngerer Bodensee-Sedimente. Arch Hydrobiol. 70: 108-129

LansaC-TôHA F. A., Bonecker C. C., Velho L. F. M., Lima A. F. (1997) Composição, distribuição e abundância da comunidade zooplanctônica. In: Vazzoler A. E. M., Agostinho A. A., Hahn N. S. (Eds.) A Planície de Inundação do alto Rio Paraná: aspectos físicos, químicos, biológicos e socioeconômicos. Maringá: Universidade Estadual de Maringá p. 117-155.

LansaC-TôHA F. A., Velho L. F. M., BoneCKer C. C.(1999) Estrutura da comunidade zooplanctônica antes e após a formação do reservatório de Corumbá-GO. In: Henry, R. (ed.) Ecologia de Reservatórios: estrutura, função e aspectos sociais. Botucatu: Universidade Estadual Paulista.

Lansac-Tôha F. A., Velho L. F. M., Bonecker C. C., Aoyagui A. S. M. (2000) Horizontal distribution patterns of testate amoebae (Protozoa: Rhizopoda) in plankton samples of Corumbá Reservoir area, state of Goiás, Brazil. Acta Scientiarum 22(2): $347-353$

Lee J. J., Leedale G. F., Bradbury P. (2000) An Illustrated Guide to the Protozoa (2a edição). Society of Protozoologists, Lawrence, Kansas.

LEIDY J. (1879) Freshwater Rhizopods of North America. U.S. Geological Survey of the Territories. 12 
Levine N. D., Corliss J. O., Cox F. E. et al. (16 co-autores). (1980) A newly revised classification of the Protozoa. J. Protozool. 27: 37-58.

LOPES R. M. (1993) Zooplankton spatial and seasonal distribution in the Tibagi River (Paraná State, Brazil) Semina 14: 95-101

Madeira-Falcetta M. (1974) Ecological distribution of the thecamoebal and foraminiferal associations in the mixohaline environments of the southern Brazilian littoral. An. Acad, Bras. Ciênc. 46 (3-4): 667-687

MARGULIS L. (1974) Five-kingdom classification and the origin and evolution of cells. Evol. Biology 7: 45-78.

Margulis L., Corliss J.O., Melkonian M., Chapman D. (1990) Handbook of Protoctista. Jones and Bartlett, Boston.

MaYR, E. (2001) The biological species concept. In: Species Concepts and Phylogenetic Theory: a Debate (Q. D. Wheeler \& R. Meier, eds), pp. 17-29. Columbia University Press, New York.

Medioli F. S., ScotT D. B. (1983) Holocene Arcellacea (Thecamoebians) from Eastern Canada. Cushman Found. Spec. Publ. 21: 5-63

Mediol F. S., ScotT D. B. (1985) Designation of types, for one genus and nine species of arcellaceans (thecamoebians), with additional original reference material for four other species. J. Foram. Res. 15: 24-37

Meisterfeld R. (1979) Zur Systematik der Testaceen (Rhizopoda, Testacea) in Sphagnum. Eine REM-Untersuchung. Arch. Protistenkd. 121: 246-269

Meisterfeld R. (2000) Order Arcellinida Kent, 1880. In: The Illustrated Guide to the Protozoa. 2 ed. (Eds. J. J. Lee, G. F. Leedale, P. Bradbury). Allen Press, Lawrence, Kansas, USA, 827-860 
Milyutina I. A., Aleshin V. V., Mikrjuov K. A., Kedrova O. S., Petrov N. B. (2001) The unusually long small subunit ribosomal RNA gene found in amitochondriate amoeboflagellate Pelomyxa palustris: its rRNA predicted secondary structure and phylogenetic implication. Gene 272: 131-139.

Mitchell E. A. D., Meisterfeld R. (2005) Taxonomy blurs the debate on cosmopolitanism vs. local endemism of free-living protists. Protist 156: 263267

Netzel H. (1972) Die bildung der Gehäusewand bei der Thekamöbe Centropyxis discoides (Rhizopoda, Testacea). Z. Zellforsch. 135: 45-54

Netzel H. (1975) Morphologie und Ultrastruktur von Centropyxis discoides (Rhizopoda, Testacea) Arch. Protistenkd. 117: 369-392

Nikolaev S. I., Mitchell, E. A. D., Petrov N. B., Fahrni J., Pawlowski J. (2005) The Testate Lobose Amoebae (Order Arcellinida Kent, 1880) Finally Find their Home within Amoebozoa. Protist156: 156-191.

Nunes M. A., Lansac-Tôha F. A., Bonecker C. C., Roberto M. C., Rodrigues L. (1996) Composição e abundância do zooplâncton de duas lagoas do Horto Florestal Dr. Luiz Teixeira Mendes, Maringá Paraná. Acta Limnol. Bras. 8: 207-220

OGden C. G. (1979a) Comparative morphology of some pyriform species of Difflugia (Rhizopoda). Arch. Protistenk. 122: 143-153

OGden C. G. (1979b) Siliceous structures secreted by members of the subclass Lobosia. Bull. Br. Mus. Nat. Hist. (Zool) 36: 203-207

OGDEN C. G. (1980a) Shell structure in some pyriform species of Difflugia (Rhizopodea). Arch. Protistenk. 123: 455-470 
OGden C. G. (1980b) Notes on some Difflugiidae from Norfolk (Rhizopodea, Protozoa). Bull. Br. Mus. nat. Hist. 39(3): 125-138

OGDEN C. G. (1983) Observations on the systematics of the genus Difflugia in Britain (Rhizopoda, Protozoa). Bull. Br. Mus. nat. Hist. (Zool.) 44: 1-73

Ogden C. G. (1988) The role of the organic matrix in the construction of the agglutinate shell of Centropyxis discoides. J. Nat. Hist. 22: 137-148

Ogden C. G. (1990) The structure of the shell wall in testate amoebae and the importance of the organic cement matrix. In: Scanning electron microscopy in taxonomy and functional morphology (Ed. Claugher D.). Syst. Ass. Special Vol., Clarendon Press, Oxford. 41: 235-257

Ogden C. G., FalRman S. (1979) Further observations on Pyriform species of Difflugia (Rhizopodea). Arch. Protistenk. 122: 372-381

Ogden C. G., Hedley R. H. (1980) An Atlas of Freshwater Testate Amoebae. Oxford University Press, Oxford, UK.

Ogden C. G., Meisterfeld R. (1989) The taxonomy and systematics of some species of Cucurbitella, Difflugia and Netzelia (Protozoa: Rhizopoda); with an evaluation of diagnostic characters. Eur. J. Protistol. 25: 109-128

Ogden C. G., ŽIVKović A. (1983) Morphological studies on some Difflugiidae from Yugoslavia (Rhizopoda, Protozoa). Bull. Brit. Mus. nat. Hist. 44(6): 341-375

Oliveira D. B. S., Sipaúba-Tavares L. H., Durigan J. G. (1992) Estudo limnológico em tanques de piscicultura. Parte II: variação semanal de fatores físicos, químicos e biológicos. Acta Limnol. Bras. 4: 123-137

PAGE F. (1987) The classification of 'naked' amoebae (Phylum Rhizopoda). Arch. Protistenk. 133: 199-217. 
Page F., Blanton L. (1985) The Heterolobosea (Sarcodina: Rhizopoda), a new class uniting the Schizopyrenida and the Acrasidae (Acrasida). Protistologica 21: 121-132.

PATterson D. J. (1994) Protozoa: Evolution and Systematics in Progress in Protozoology. Proceedings of the Ninth International Congress of Protozoology (eds. K. Haussman and N. Hülsmann) Fischer, Stuttgart, 1-14

PATTERSON D. J. (1999) The diversity of eukaryotes. Am. Nat. 154: 96-124

PATterson D. J., LARSEN J. (1992) A perspective on protistan nomenclature. J. Protozool. 39(1): 125-131

Patterson D. J., Brugerolle G. (1988) The ultrastructural identity of Stephanopogon apogon and its relatedness to other kinds of protists. Eur. J. Protistol. 23: 279290

Patterson, D.J., LeE, W.J. 2000. Geographic distribution and diversity of free-living heterotrophic flagellates. In: 'The Flagellates" (eds. Green, J. and Leadbeater, B.S.C. Taylor and Francis), 269-287

Penard E. (1890) Études sur les rhizopodes d'eau douce. Mem. Soc. Phys. Hist. Genève 31: 1-230

Penard E. (1899) Rhizopodes de faune profonde dans le lac Léman. Revue suisse Zool. 7: 1-142

Penard E. (1902) Faune Rhizopodique du Bassin du Léman. Kündig, Genève

PenARd E. (1911) On some Rhizopods from Sierra Leone. Journ. of the Queckett Microsc. club 2: 299-306

PERTY J. (1852) Zur Kenntnis Kleinster Lebensformen, mit specialverzeichniss der in der Schwaizbeobachtetenformen, Bern. 
PInTo C. (1925) Protozoários observados no Brasil. Mem Inst Oswaldo Cruz 18: 211327

PLAYFAIR G. I. (1918) Rhizopods of Sydney and Lismore. Proc. of the Linnean Soc. of New South Wales 28: 633-675

Prowazeck S. Von (1910) Contribuição para o conhecimento da fauna de protozoários do Brasil. Mem Inst Oswaldo Cruz 2(2):149-158

RHUMbleR L. (1895) Beiträge zur Kenntnis der Rhizopoden III et IV. Zeit. wiss. Zool. 61: $38-110$

Richards A. T., Cavalier-Smith T. (2005) Myosin domain evolution and the primary divergency of eukaryotes. Nature 436: 1113-1118

Ride W.D.L, Cogger H.G, Dupuis C, Kraus O., Minelli A., Thompson F. C., Tubbs P.K. (1999) International Code of Zoological Nomenclature, 4 ed. International Trust for Zoological Nomenclature. Cromwell, London, UK

Rolla M. E., Dabés M. B. G. S., França R. C., Ferreira E. M. V. M. (1992) Inventário limnológico do Rio Grande a área de influência da futura usina hidrelétrica (UHE) de Igarapava. Acta Limnol. Bras. 4: 139-162

Root F. M. (1918) Inheritance in the assexual reproduction of Centropyxis aculeata. Genetics 3:173-206

Schlegel M., Meisterfeld R. (2003) The species problem in Protozoa revisited. Eur. J. Protistol. 39: 349-355

SCHLUMBERGER P. (1845) Observations sur quelques nouvelles espèces d'Infusoires de la familie des Rhizhopodes. Ann. Sci. nat. Zool. 3(3): 254-256

SCHÖnBoRn W., FOISSNer W., Meisterfeld R. (1983) Licht-und rasterelektronenmikroskopische Untersuchungen zur Schalenmorphologie 
und Rassenbildung bodenbewohnenderTestaceen (Protozoa: Rhizopoda) sowie Vorschläge zurbiometrischen Charakterisierung von Testaceen-Schalen. Protistologica 19: 553-566

Sims G. P., Rogerson A., Aitken R. (1999) Primary and secondary structure of the small-subunit ribosomal RNA of the naked, marine amoeba Vannella anglica: phylogenetic implications. J. Mol. Evol. 48: 740-749.

Sipaúba-Tavares L. H., Ligeiro S. R., Durigan J. G. (1995) Variação de alguns parâmetroslimnológicos em viveiro de piscicultura em função da luz. Acta Limnol. Bras. 7: 138-150

Smirnov A., Nassonova E., Berney C., Fahrni J., Bolivar I., Pawlowski J. (2005) Molecular phylogeny and classification of the Lobose amoebae, Protist 156 (2005), pp. 129-142.

SogIN M. L. 1991. Early evolution and the origin of Eukaryotes. Curr. Opin. Genet. Dev. 1: 457-63.

SoGIN M. L., HINKLE G., LEIPE D. D. (1993) Universal tree of life. Nature 362: 795-795 SONNEBORN T. M. (1957), "Breeding Systems, Reproductive Methods, and Species Problems in Protozoa," In: The Species Problem (Ed. Mayr E.), American Association for the Advancement of Science, Washington, D.C, pp. 155- 324. SPSS, INC. (2000) Systat $® 10$. Chicago, Illinois, USA. STATSOFT, INC. (1995). STATISTICA for Windows [Computer program manual]. Tulsa, OK: StatSoft, Inc., 2300 East 14th Street, Tulsa, OK, 74104-4442, (918) 7491119, fax: (918) 749-2217, e-mail: info@statsoft.com, WEB: http:// www.statsoft.com. 
ŠTĔPÁnEK M. (1952) Testacea of the pond of Hrádek at Kunratice (Prague). Acta Mus. Nat. Prague (Zool.) 8(3): 1-55

ŠTĔPÁNEK M. (1963) Die Rhizopoden aus Katanga. Ann. Musée roy. Afrique centr. Tervuren 8 (117): 1-91

ŠTĔPÁNEK M. (1965) Testacea des Benthos der Talsperre Vranov am Thayafluss. Hydrobiol. 29: 1-66

ŠTĔPÁNEK M., JIŘí J. (1958) Difflugia gramen Penard, Difflugia gramen var. achlora Penard and Difflugia gramen f. globulosa f.n. (Morphometrical and Statistical study). Hydrobiol. 10: S138-S156

THOmAS R.(1957) Centropyxis ecornis et ses varietés. Bull. Soc. Zool de France 82: $259-263$

Thomas R., Gauthier-LIĖVRe L. (1959) Le genre Lesquereusia Schlumberger, 1845. Bull. Soc. d'Hist. Nat. de l'Afrique du Nord. 50: 34-83

TORRES V. S. (1998) Amebas testáceas ocorrentes na região de Porto Alegre, Rio Grande do Sul. II. Novos registros para a região. Rev. Bras. Zool. 15: 545-552

TorReS V. S., Jebram D. H. A. (1994) Amebas testáceas ocorrentes na região de Porto Alegre, RS. Biotemas, 7(1-2):65-78

VAN OYe P. (1949) Rhizopodes de Java. Bijdragen tot de Dierkunde 28: 327-352

VAN Oye P. (1956) Rhizopoda Venezuelas mit Besonderer Berucksichtigung ihrer Biogeographie. Ergebn. d. deutsch. limnol. Venezuela-Expedition 1952 1: $329-360$

VAN Oye P. (1958) Etude sur les Rhizopodes des marais du Sud-ouest d'Uvira (Congobelge). Hydrobiologia 10: 85-137 
VAN OYE P. (1959) Faune rhizopodique du plateau de Kundulungu (Congo Belge) avec considérations concernabt la répartition géographique des Rhizopodes. Hydrobiologia 13 (3): 239-286

VelHo L. F. M., LanSAC-TôHA F. A. (1996) Testate amoebae (Rhizopodes, Sarcodina) from zooplankton of the high Paraná River floodplain, State of Mato Grosso do Sul, Brazil: II. Family Difflugiidae. Stud. Neotrop. Fauna Environ. 31: 179-192

VelHo L. F. M., LANSAC-TôHA F. A., BINI L. M. (1999) Spatial and temporal variation in densities of testate amoebae in the plankton of the Upper Paraná River floodplain, Brazil. Hydrobiologia 411: 103-113.

Velho L. F. M., Lansac-Tôha F. A., Serafim-Junior M. (1996) Testate amoebae (Rhizopodea-Sarcodina) from Zooplankton of the high Paraná River floodplain, State of Mato Grosso do Sul, Brazil: I. Families Arcellidae and Centropyxidae. Stud. Neotrop. Fauna \& Environm 31: 35-50

VUCETICH M. C. (1970) Algunos tecamebianos de la Provincia de Formosa. Neotropica 16(49): $42-48$

VUCETICH M. C. (1972) Tecamebianos del eupleuston de cuerpos de agua de la provincia de Buenos Aires. Acta Zool Lilloana, 29: 271-284

VUCETICH M. C. (1973) Estudio de tecamebianos argentinos en especial los del dominio pampasico. Rev. Mus. la Plata, sér. Zool 11(108): 287-332

VUCETICH M. C. (1978) Nuevos aportes al conocimiento de los tecamebianos del dominio subtropical. Neotropica 24(72): 79-90

Walles G. H. (1913) Freshwater Rhizopoda from North and South America. J. Linn. Soc. Zool. 32: 201-218 
WALLICH G. C. (1864) On the extent and some of the principal causes of structural variation among the Difflugian Rhizopods. Annals and Mag. Of Nat. Hist. 13 (3): $215-245$

WANNER M. (1999) A review on the variability of testate amoebae: methodological approaches, environmental influences and taxonomical implications. Acta Protozool. 38: 15-29

WILKINSON D. M. (2001) What is the upper size limit for cosmopolitan distribution in free-living microorganisms? J. Biogeography 28: 285-291.

Yang J., Beyens L., Shen Y., Feng W. (2004) Redescription of Difflugia tuberspinifera Hu, Shen, Gu et Gong, 1997 (Protozoa: Rhizopoda: Arcellinida: Difflugiidae) from China Acta Protozool. 43: 281-289

YANG J., SHeN Y. (2005) Morphology, Biometry and Distribution of Difflugia biwae Kawamura, 1918 (Protozoa: Rhizopoda). Acta Protozool. 44: 103-111

Zapata J., Alvarez P., Cea C. (2002) Thecamoebians from the Contaco River (40³3'12" S; 7313'00" W), Osorno, Chile. Bol. Soc. Biol. Concépción. 73: $17-35$ 